\title{
National Center for Biotechnology Information
}

- Created by Public Law 100-607 in 1988 as part of National Library of Medicine at NIH to:

- Create automated systems for knowledge about molecular biology, biochemistry, and genetics.

- Perform research into advanced methods of analyzing and interpreting molecular biology data.

- Enable biotechnology researchers and medical care personnel to use the systems and methods developed.

- Builders and providers of GenBank, Entrez, Blast, PubMed. Online systems host more than 2 million users per day, reaching peaks of 5000 web hits per second.

- Center for basic research and training in computational biology. 


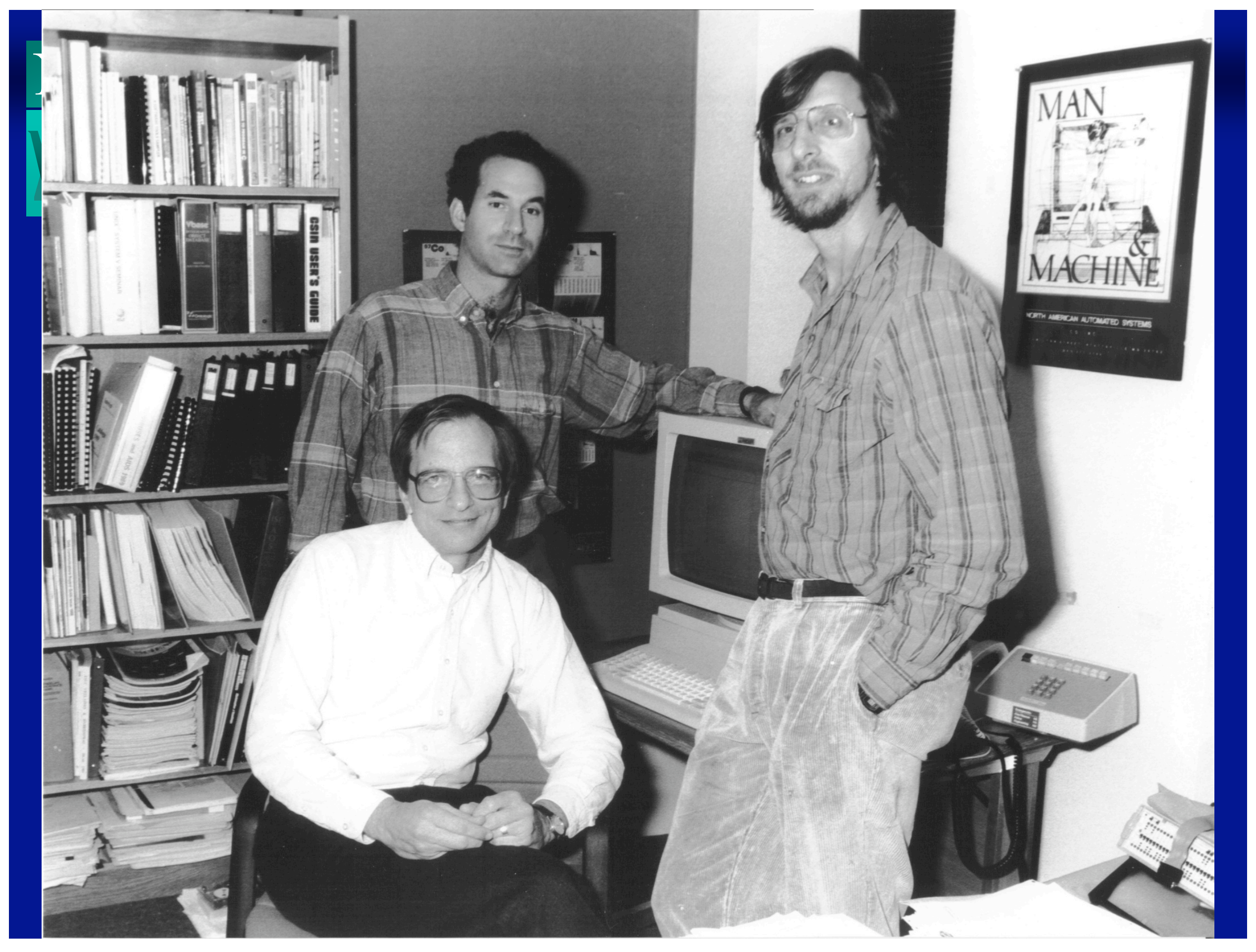




\section{Managing the Genome Data Deluge}

Molecular biologists are turning to computer technology to help them manage the growing flood of sequencing and mapping data their field is producing

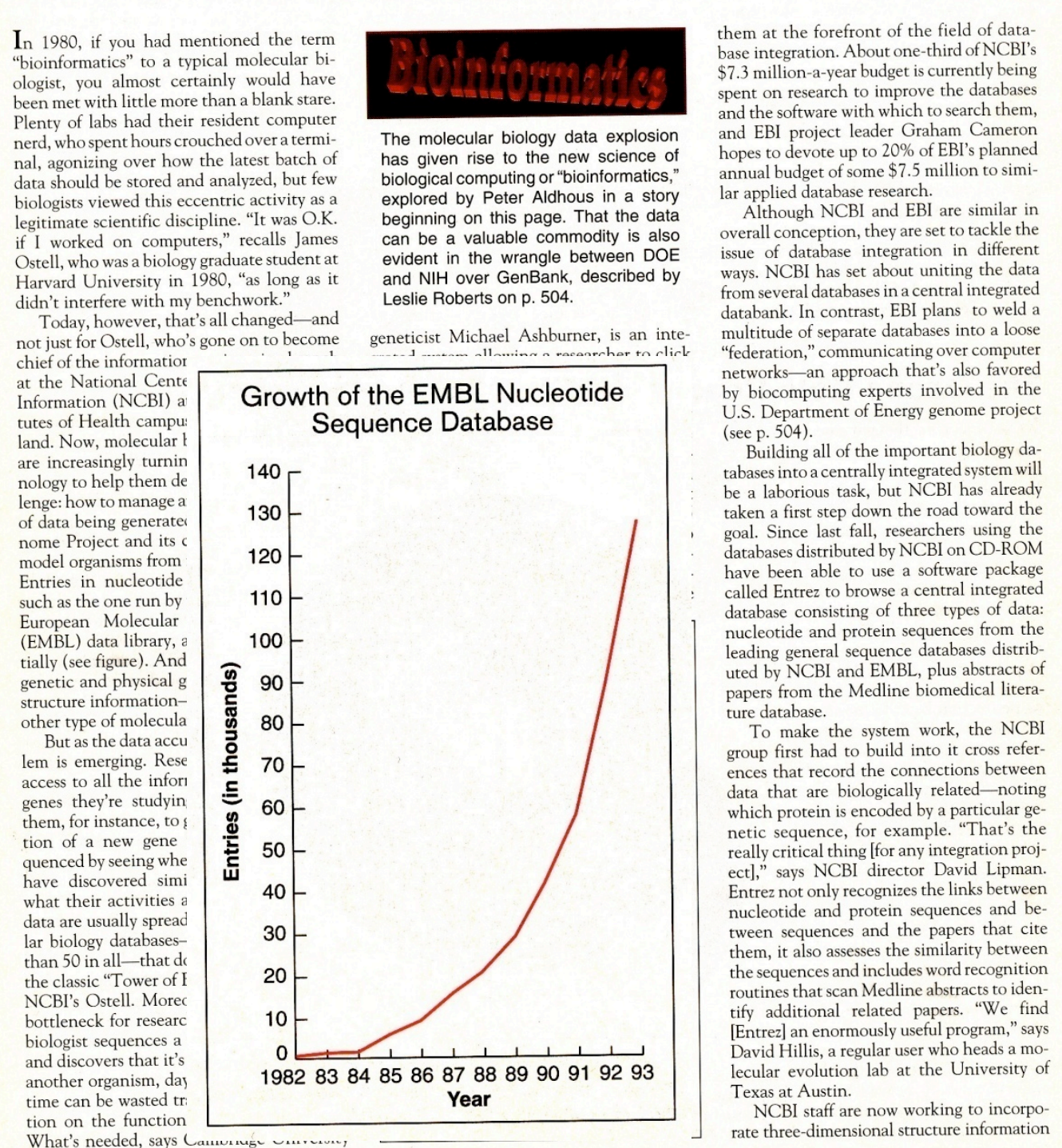




\section{$\mathrm{NCBI}$}

\section{8 - Data Just Keeps Exploding}

Mit10101

Growth of the EMBL Nucleotide

120000000

Sequence Database
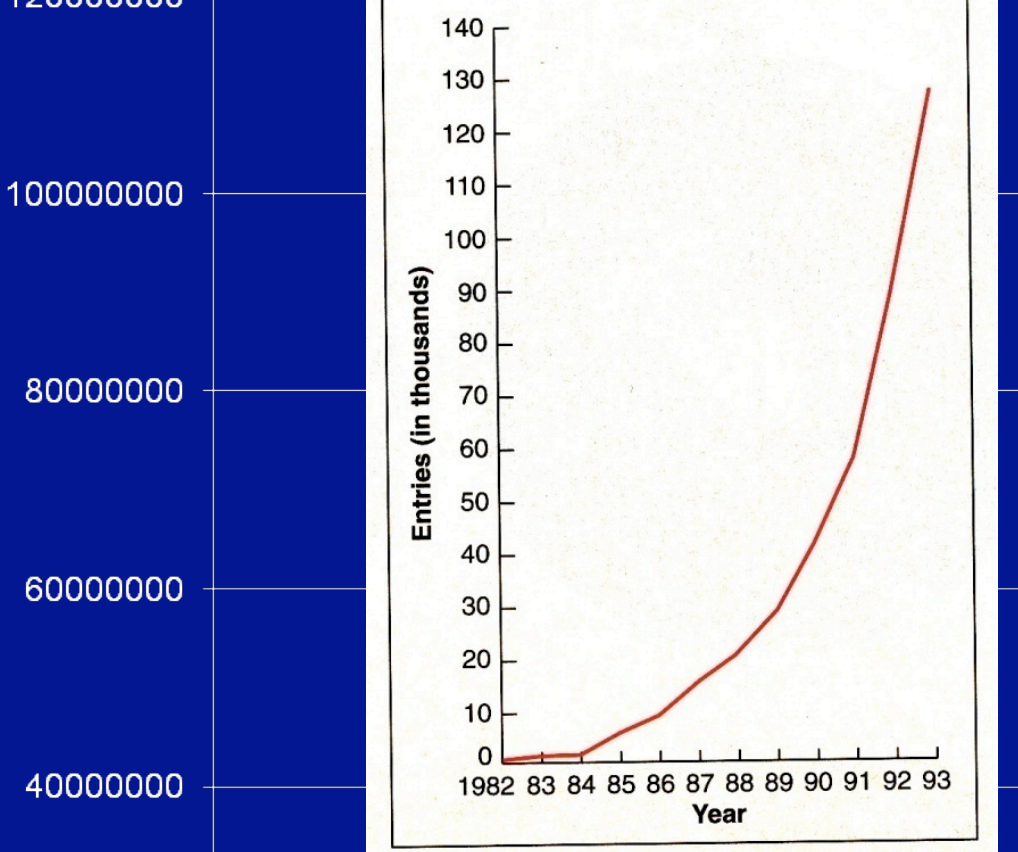

20000000

\section{DANGER!}

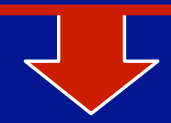

0

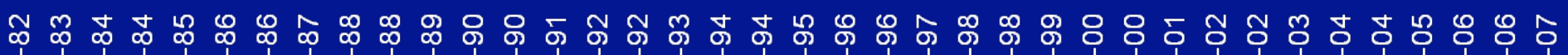

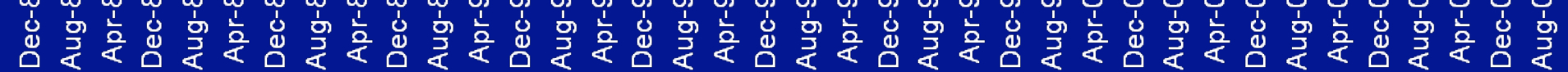




\section{Unique IP's Per Day}

900,000

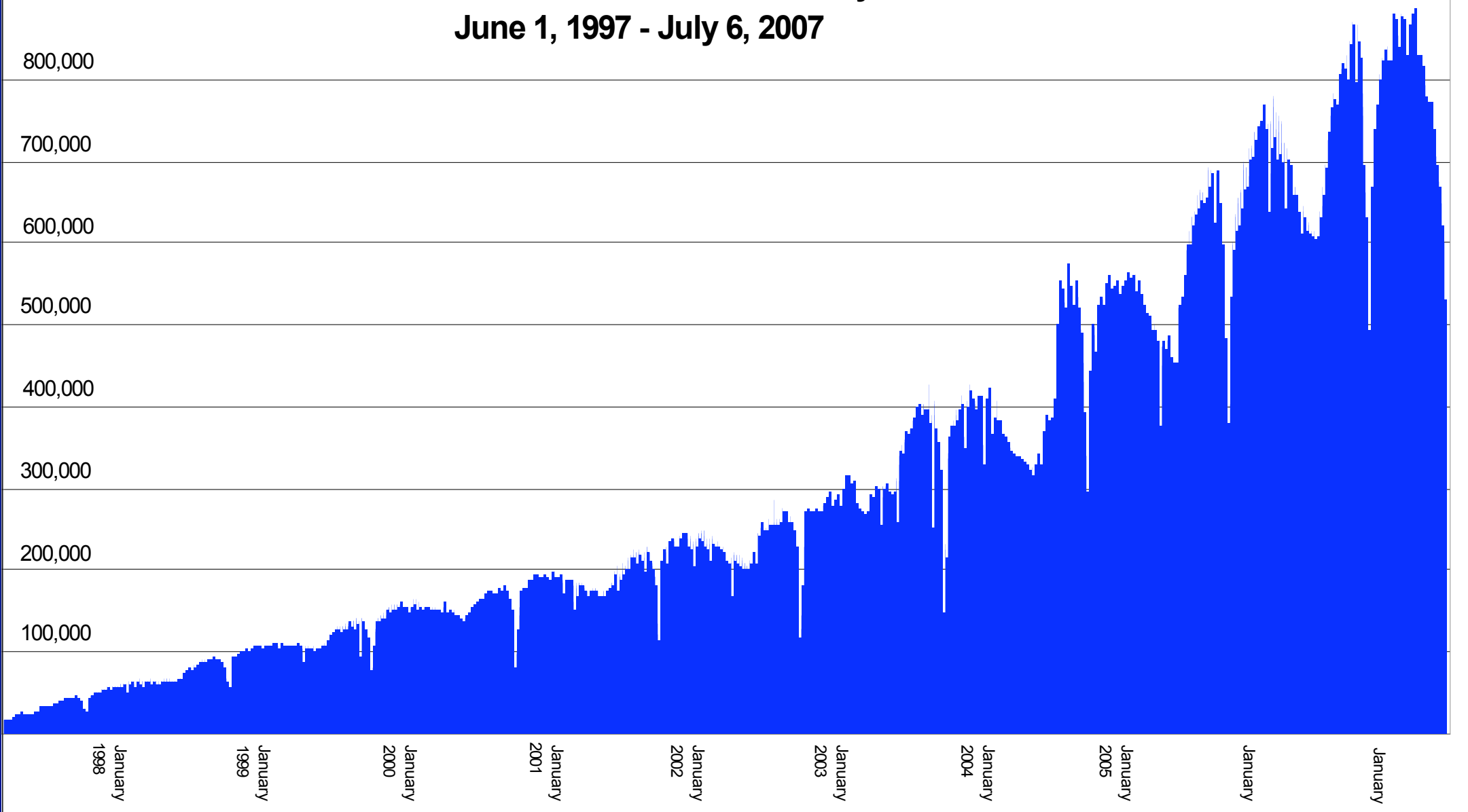




\section{NCBI}

Win

| 110101

\section{Comparative Analysis in Biology}

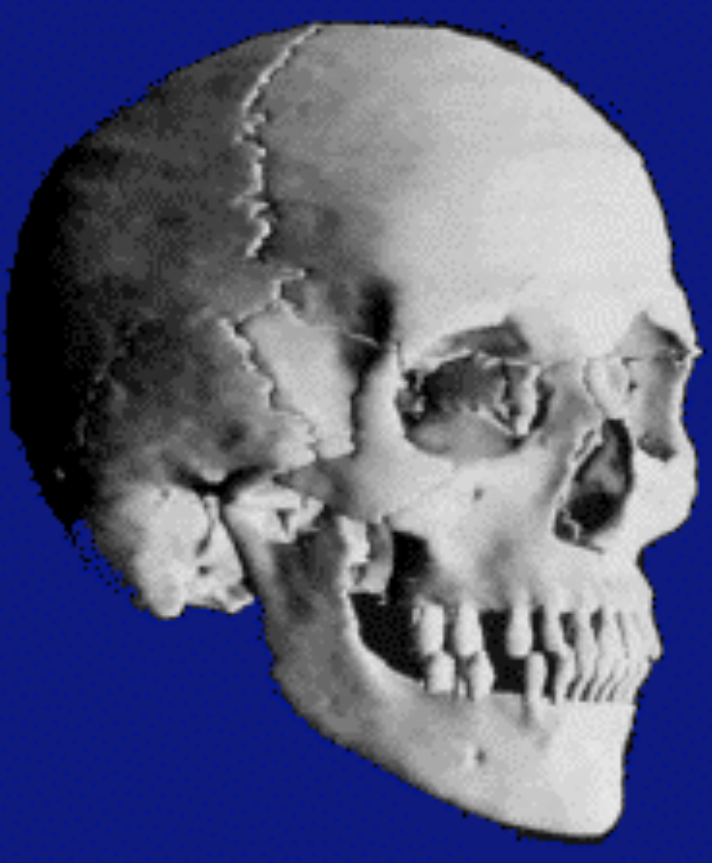

Human

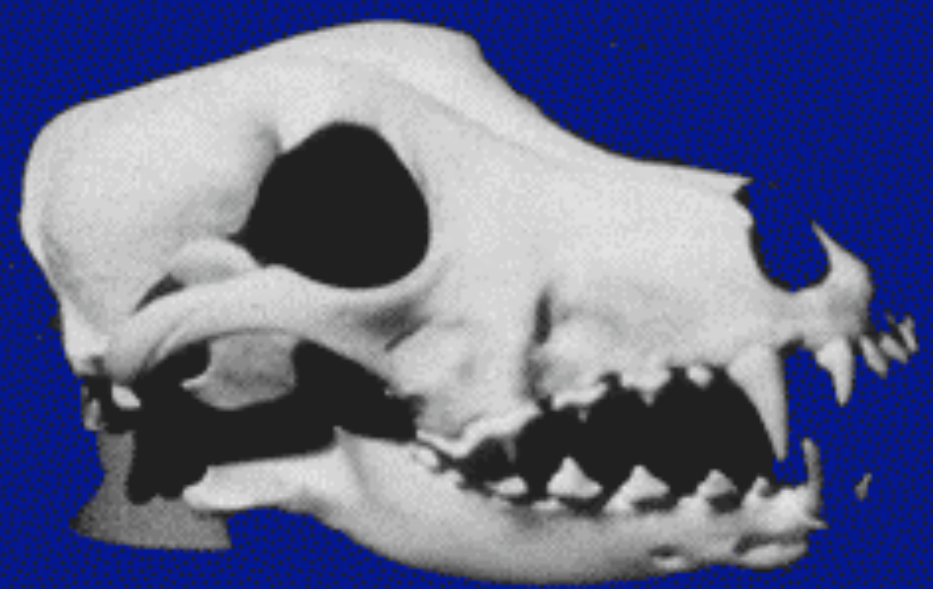

Dog 


\section{NCBI}

\section{Genotype to Phenotype}

Gene

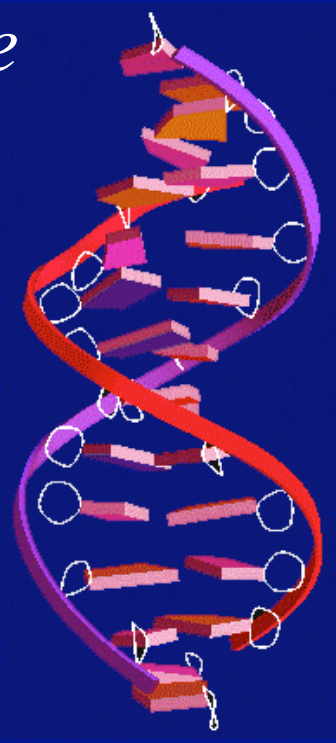

Function

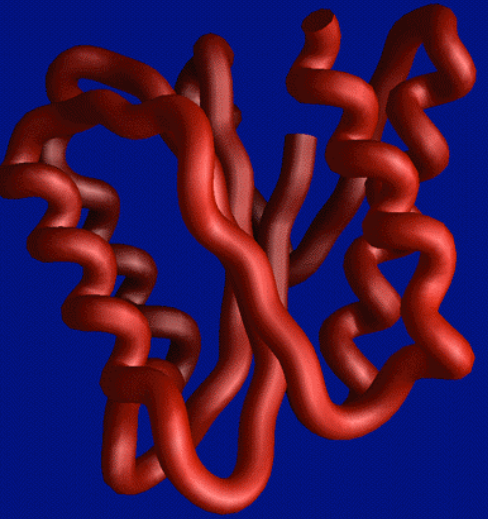

$>$ DNA sequence

AATTCATGAAAATCGTATACTGGTCTGGTACCGGCAACAC TGAGAAAATGGCAGAGCTCATCGCTAAAGGTATCATCGAA TCTGGTAAAGACGTCAACACCATCAACGTGTCTGACGTTA ACATCGATGAACTGCTGAACGAAGATATCCTGATCCTGGG TTGCTCTGCCATGGGCGATGAAGTTCTCGAGGAAAGCGAA TTTGAACCGTTCATCGAAGAGATCTCTACCAAAATCTCTG GTAAGAAGGTTGCGCTGTTCGGTTCTTACGGTTGGGGCGA CGGTAAGTGGATGCGTGACTTCGAAGAACGTATGAACGGC TACGGTTGCGTTGTTGTTGAGACCCCGCTGATCGTTCAGA ACGAGCCGGACGAAGCTGAGCAGGACTGCATCGAATTTGG TAAGAAGATCGCGAACATCTAGTAGA
$>$ Protein sequence

MKIVYWS GTGNTEKMAELIAKG I IESGKDVNT INVSDVNI DELLNEDILILGCSAMGDEVLEESEFEPFIEEISTKISGK KVALFGSYGWGDGKWMRDFEERMNGYGCVVVETPLIVQNE PDEAEQDCIEFGKKIANI 


\section{NCBI}

\section{Comparative Analysis of Genes}

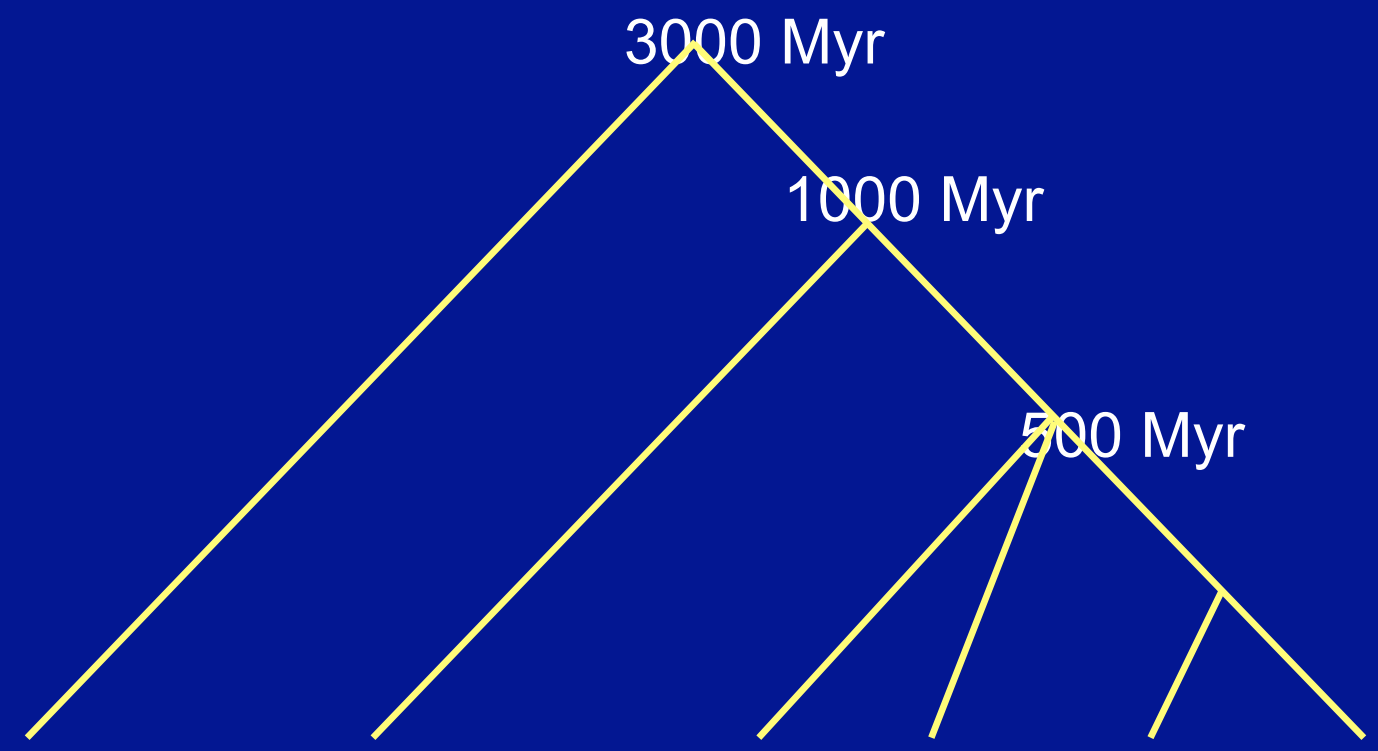

Bacteria

Yeast

Worm

Fly Mouse Human

Human 638 RHACVEVQDEIAFIPNDVYFEKDKQMFHIITGPNMGGKSTYIRQTGVIVLMAQIGCFVPC 697

Yeast 657 RHPVLEMQDDISFISNDVTLESGKGDFLIITGPNMGGKSTYIRQVGVISLMAQIGCFVPC 716

E.COIi 584 RHPVVEQVLNEPFIANPLNLSPQRR-MLIITGPNMGGKSTYMRQTALIALMAYIGSYVPA 642

Colon cancer gene sequence 


\section{NCBI}

\section{Entrez: Pathway to Discovery}

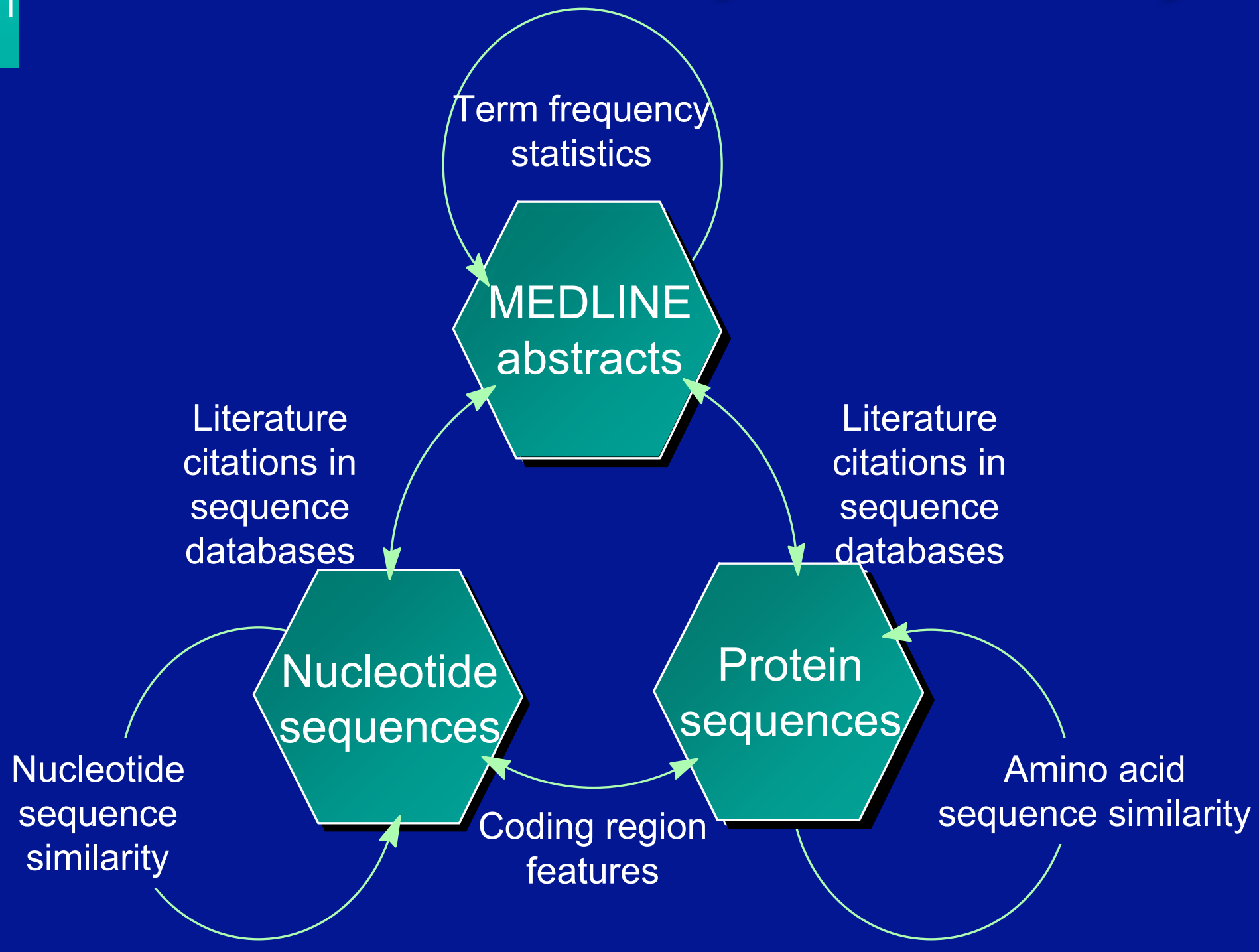




\section{Same Publication?}

JOURNAL Proc. Natl. Acad. Sci. U.S.A. 83 (3), 634-638 (1986)

\#Journal Proc. Nat. Acad. Sci. USA (1986) 83:634-638 


\section{NCBI}

\section{Entrez: Pathway to Discovery}

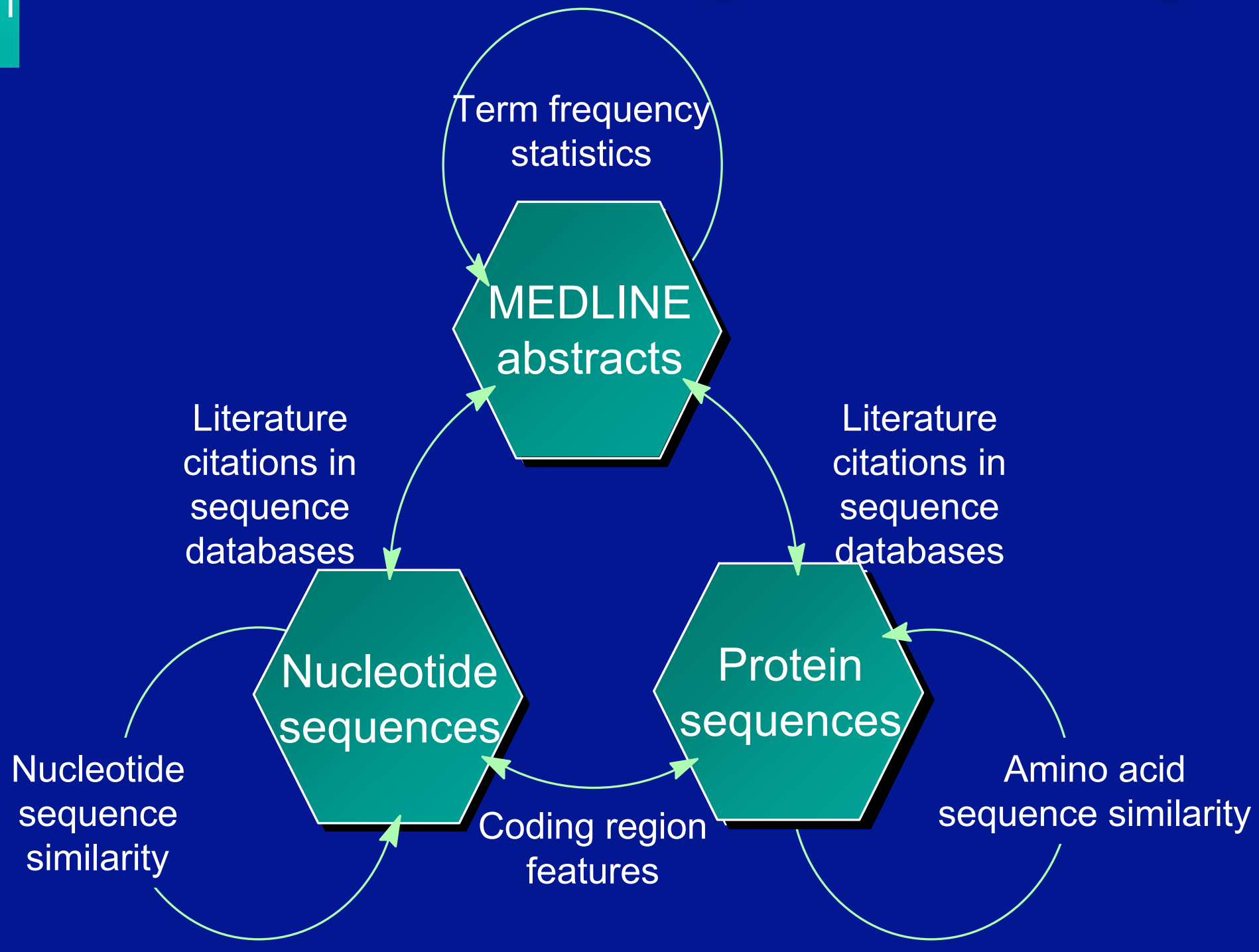




\section{The Basic Model} Intror

Disease

Function

Structure

Mature Peptide

ProPeptide

mRNA

Transcript

Chromosome

Genetics

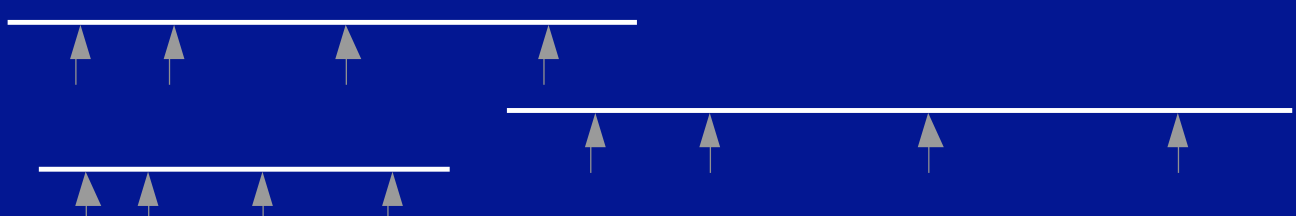

Genomes

Organisms 


\section{NCBI}

\section{Leveraging Resources}
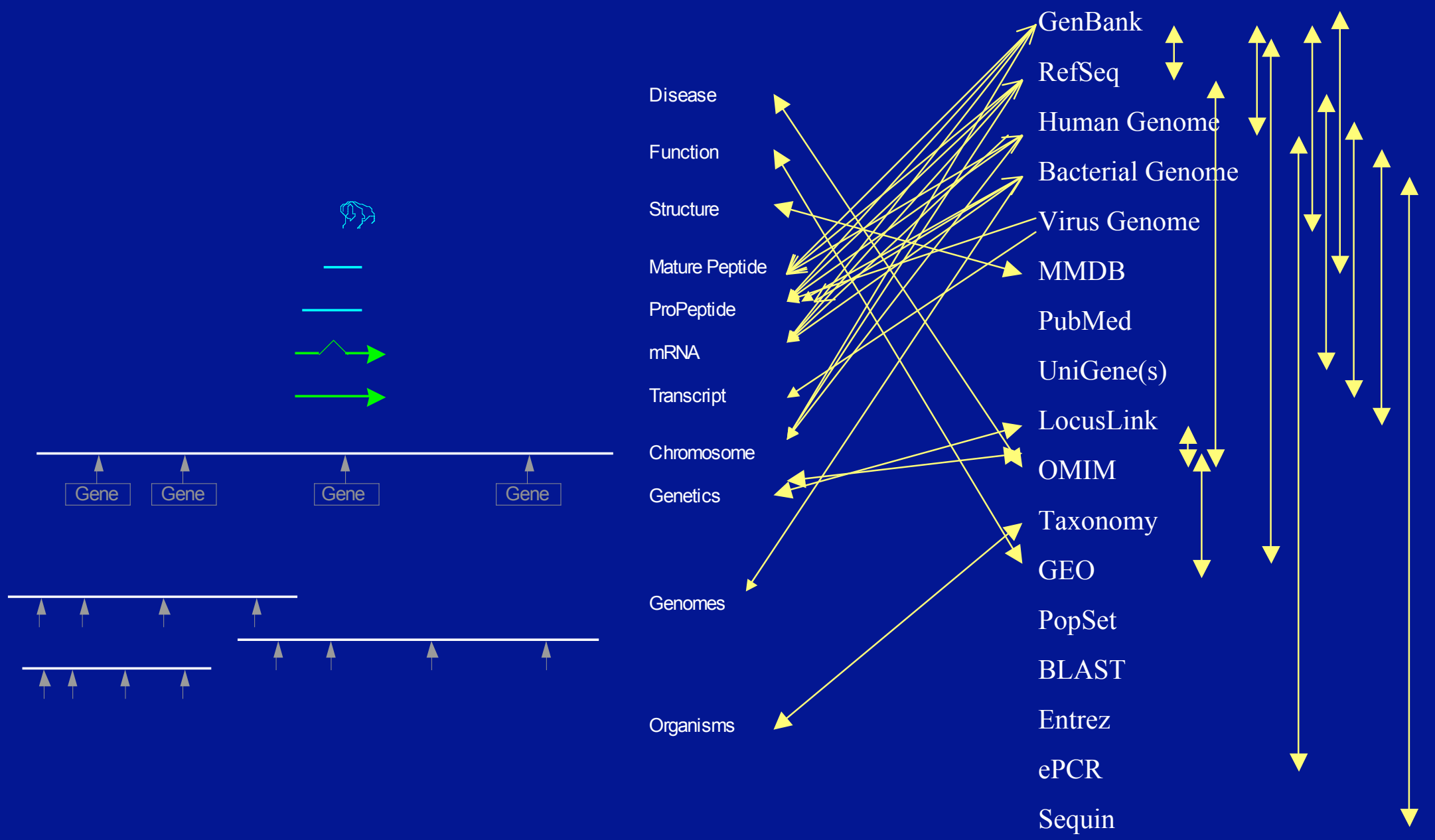

Sequin 


\section{NCBI}

I110101

\section{Entrez Increases Diseovery Space}

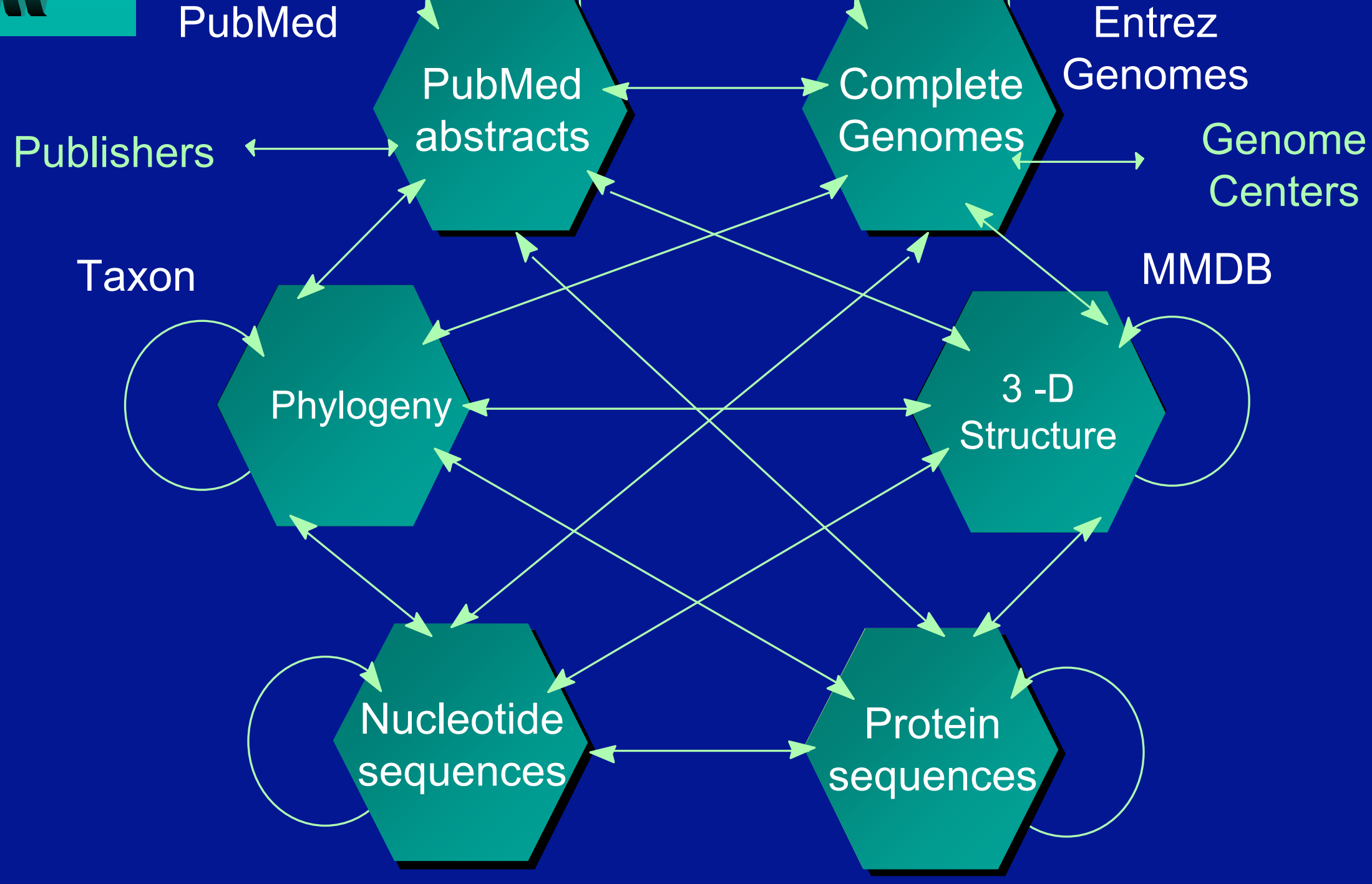




\section{Taxonomy is Curated}

IIII10101

E Taxonomy brows

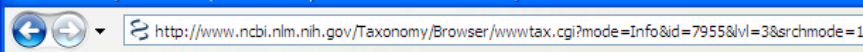

C Common Taxonomy Tree - Windows Internet Explorer

is the ET Taxonomy browser (Danio rerio)

$2 \sqrt{4} x$

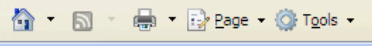

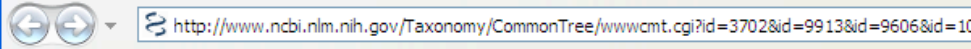

है द E Common Taxonomy Tree

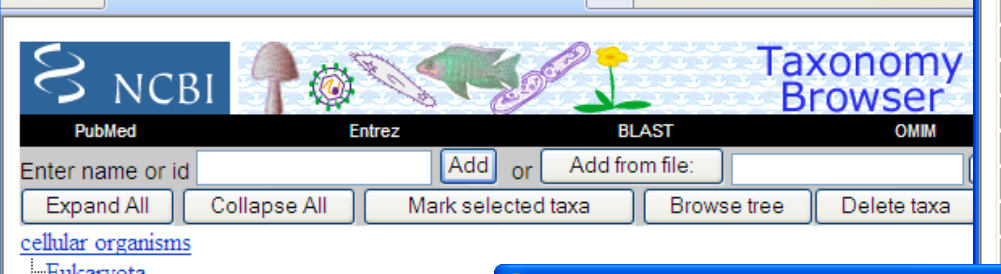

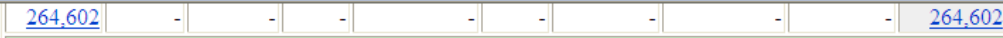

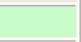

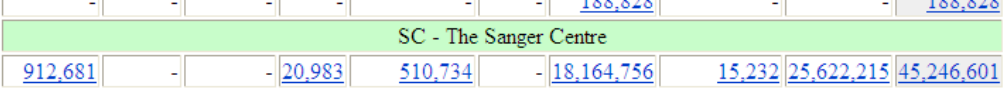

$\underline{188,828}$

UOKNOR - University of Oklahoma Norman Campus, Advanced Center for Genome Technology

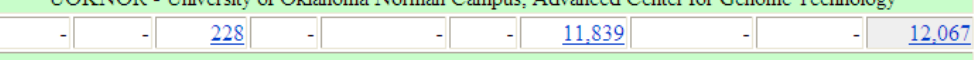
WUGSC - Washington University, Genome Sequencing Center

$\underline{64,518}$

cellular organism

†.Dictyostelium discoideum

PPlasmodium falciparum

Viridiplantae

由. Chlamydomonas reinhardtii

由.Magnoliophyta

Arabidopsis thaliana

$\rightarrow$ Poaceae

†.Zea mays

由. Oryza sativa

FungiMetazoa group

由. Ascomycota

† Sordariomycetes

फ़ Magnaporthe grisea

由. Neurospora crassa

Ф-Saccharomyces cerevisiae

由 Schizosaccharomyces pombe

由. Bilateria

†.Caenorhabditis elegans

Coelomata

由. Euteleostomi

由.Tetrapoda

†.Xenopus laevis

由. Eutheria

由)Bos taurus

Euarchontoglires

फurinae

फंRattus norvegicus

由.Mus musculus

由r. Homo sapiens
口回区 $5,232 \underline{25,622,215} \underline{46,199,857}$

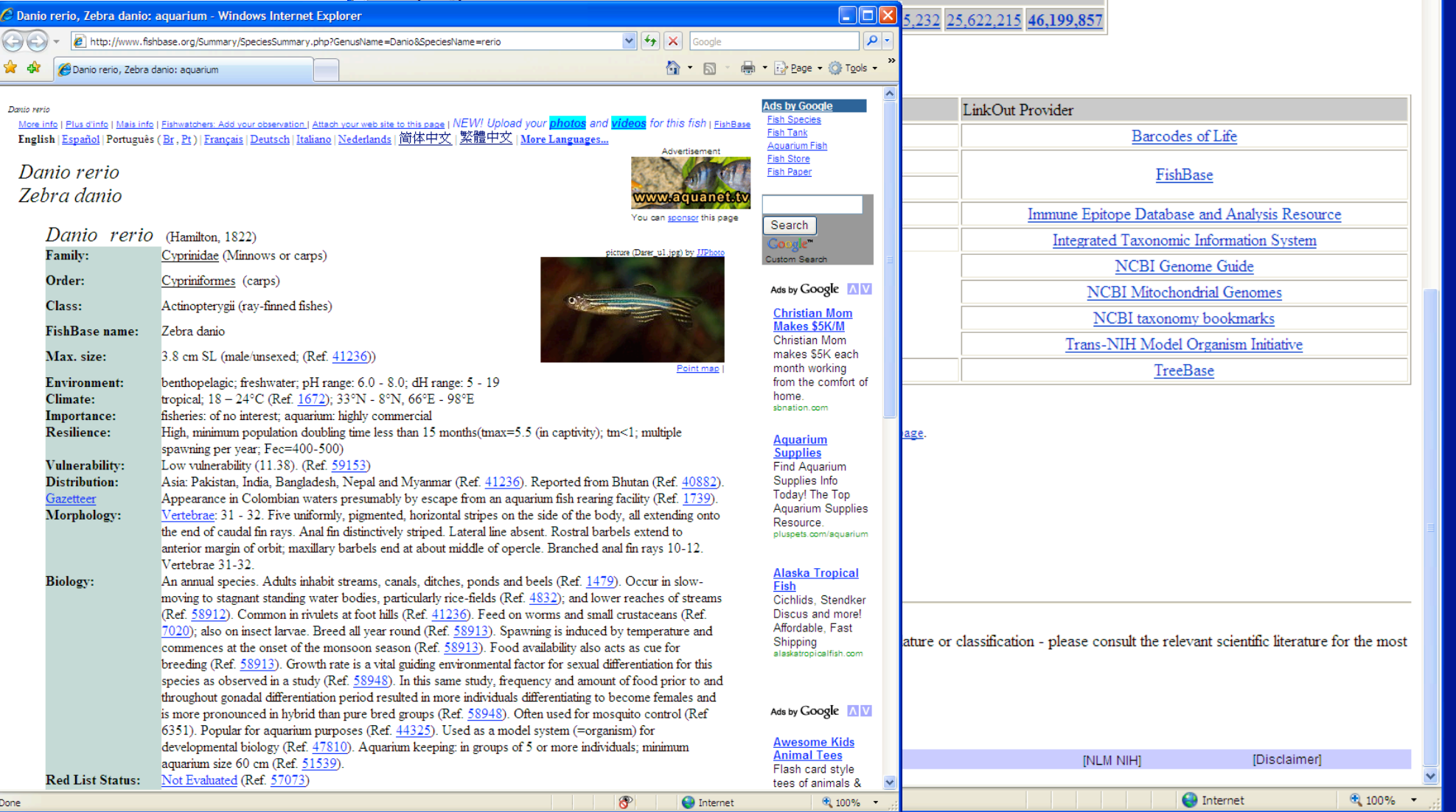




\section{NCBI}

I110101

\section{Entrez Increases Diseovery Space}

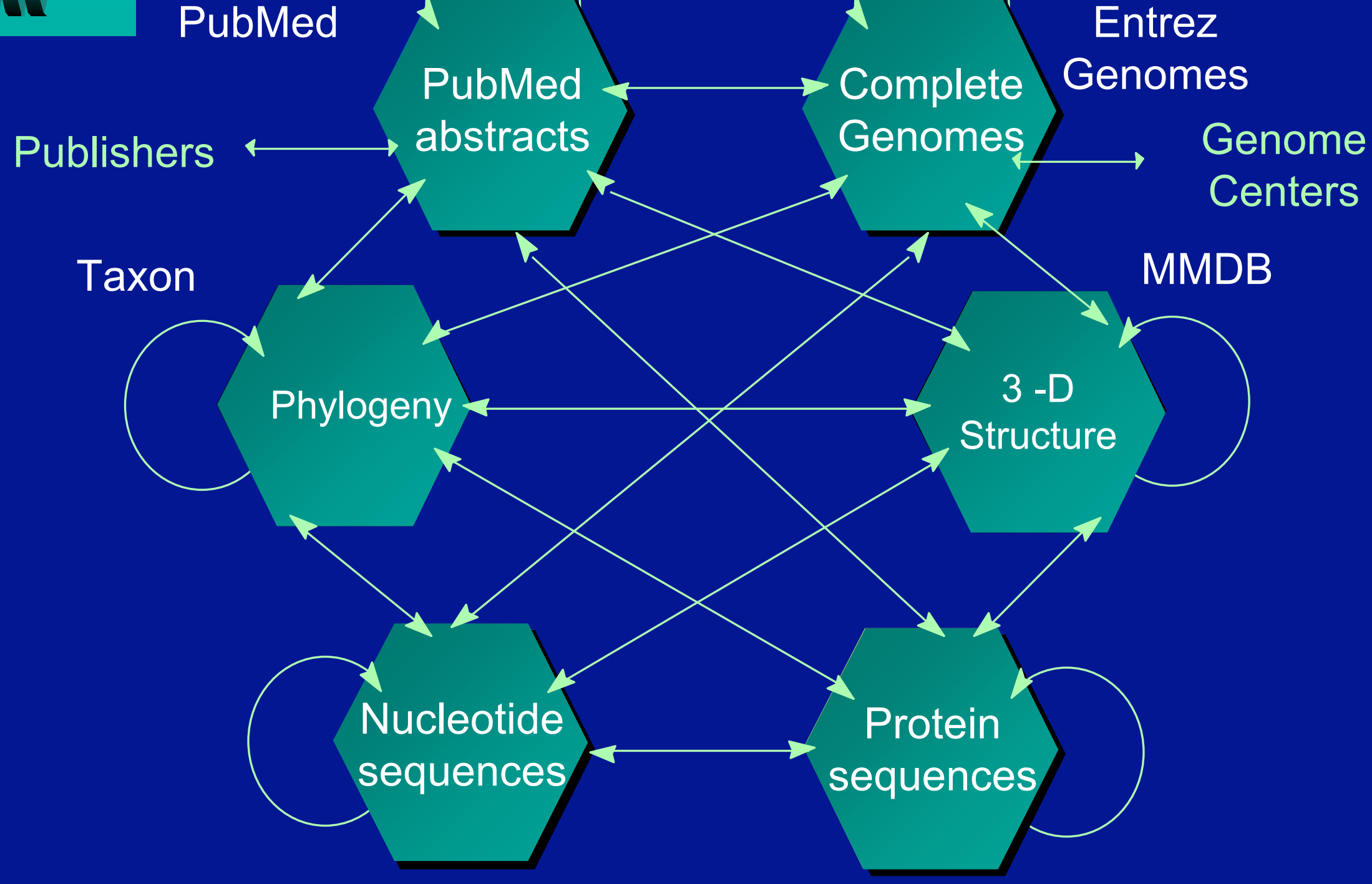




80

gi $1 \overline{1} 68975$

CIDGKAKI IFEnegeEHLTTMEEMyerykhlgefydeeynrwgidvsnvpIYVKSFdpeskRVVKGKVNVIwkyelgkdv 80

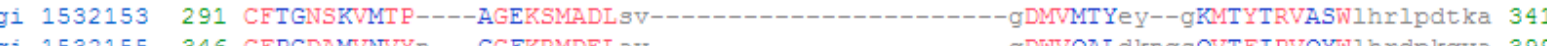

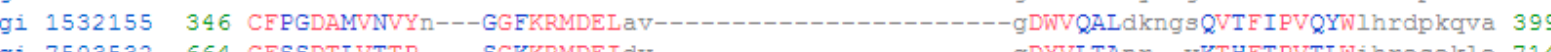
gi 7503532664 CFSSDTLVTTP----SGKKRMDEIdv-----------------------gDYVLTAnr--vKTHFTPVTLWihresekle 714 gi 7510875314 CEPNDAVVNVYe---KAVKRMDELei------------------------gDNVEALdengeDITFLPVKYWlhrdpeqea 367 gi 7521621230 CFIEGTEVLTK----RGFVDFELre-------------------------dDLVAQYdietgEISWTKPYAYverd--yeg 280 gi 7496666421 CFPADAEVNVYe---KGVKRMDELev-------------------------gDWVQALhg--kETTYSPVKYWIhrdpegea 472 gi 7507168961 CFSADSLVTTV----TGQKRMDELqi-------------------------gDYVLVPss-gnVLKYEKVEMFYhrepktrt 1012 gi 7469167443 CFTAGTLIETP----RGPVPVESLra--------------------------gDLVVTRdrgavPVLWSGGRSLeaadlaaep 495

Feature 1

1DQ3 A

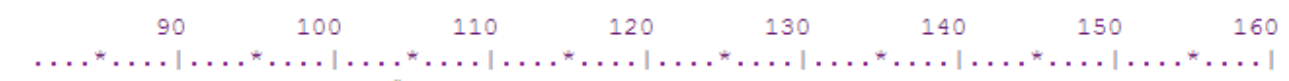

gi 116897

81 TKYEIITNK-----GTKILTSPWHPF $=$

TKILTSPWHPFFVLtpd-

-FKIVEKRADEL

KEGDILIGGmpdged 133

gi 1532153

VDLFVTPNHRYYVNttnnt--

gi 7510875368 EFLEFSLDn-----gETFTLTEKHLVYTTecrqnss-------elkiswESISAGKV---------NAGDCFYLAqsea-- 425

gi 7521621281 SMYRLKHPks----nWEVVATEGHEFIVRn1ktgker-----kepiekvKLHPYSAIpvagrytgEVEEYDLWE1Vsgkg 351

gi 7496666473 EFVEFLIEn-----gESFTLTEKHLVFATdcqqnV--------knlddINPTSTGKI---------NIGECFFMAqpen-- 529

gi 75071681013 NFVVLYTKs-----gRKLSLTGRHLLVAecsqveqYtmnpdgidvamrESKYAEKA---------RKGECVLSIdesg-- 1077

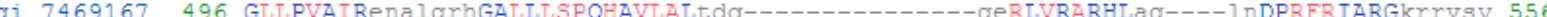

Feature 1

$1 D Q 3$ A

gi $1 \overline{1} 68975$

gi 1532153

gi 1532155

gi 7503532

gi 7510875

gi 7521621

gi 7507168

gi 7469167

Eeature 1

1DQ3_A

gi $1 \overline{1} 68975$

gi 1532153

gi 1532155

gi 7503532

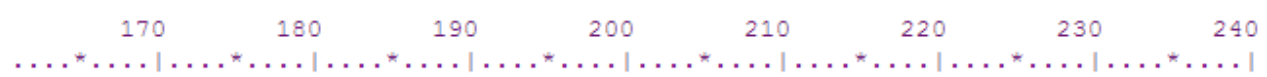

134 ykfifdywlagfiagdgcfdkyhshvkgheyiydrlriydyrietfeiindylektfgrkysigkdrniyyidikarnit 213

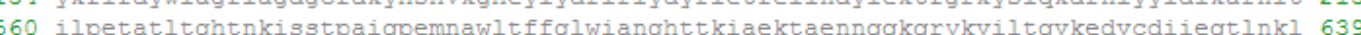

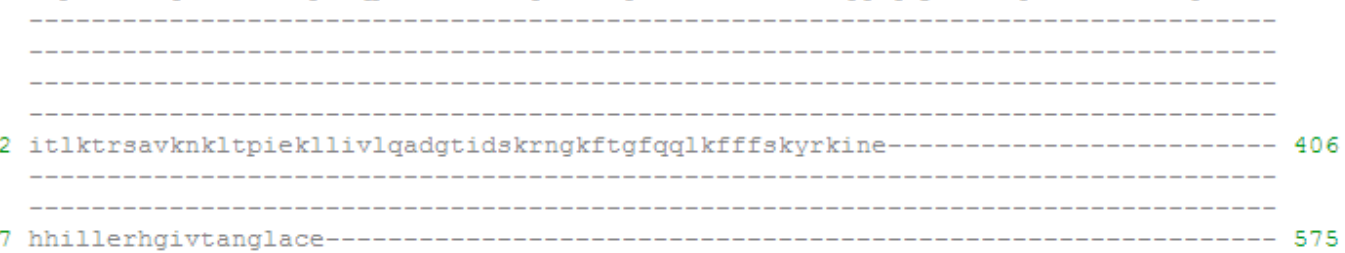

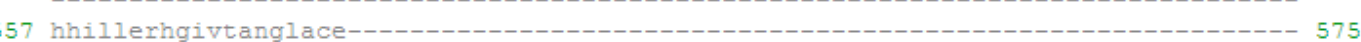

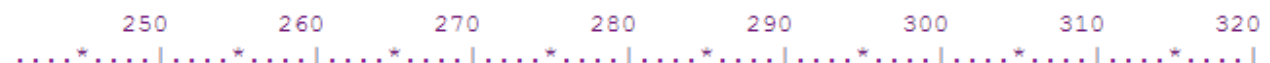

14 shylkllegidngippgilkegknavlsfiaglfdaeghvsnkpgielgmvnkrlied--------------------vth 274 640 gfnfirsgkdytienkqlwsylnpfdngalnkylpdwVwelssqqckillnslclgnclftknddtlhyfstserfandv 719 


\section{NCBI Curation of Alignments Based on Structure}

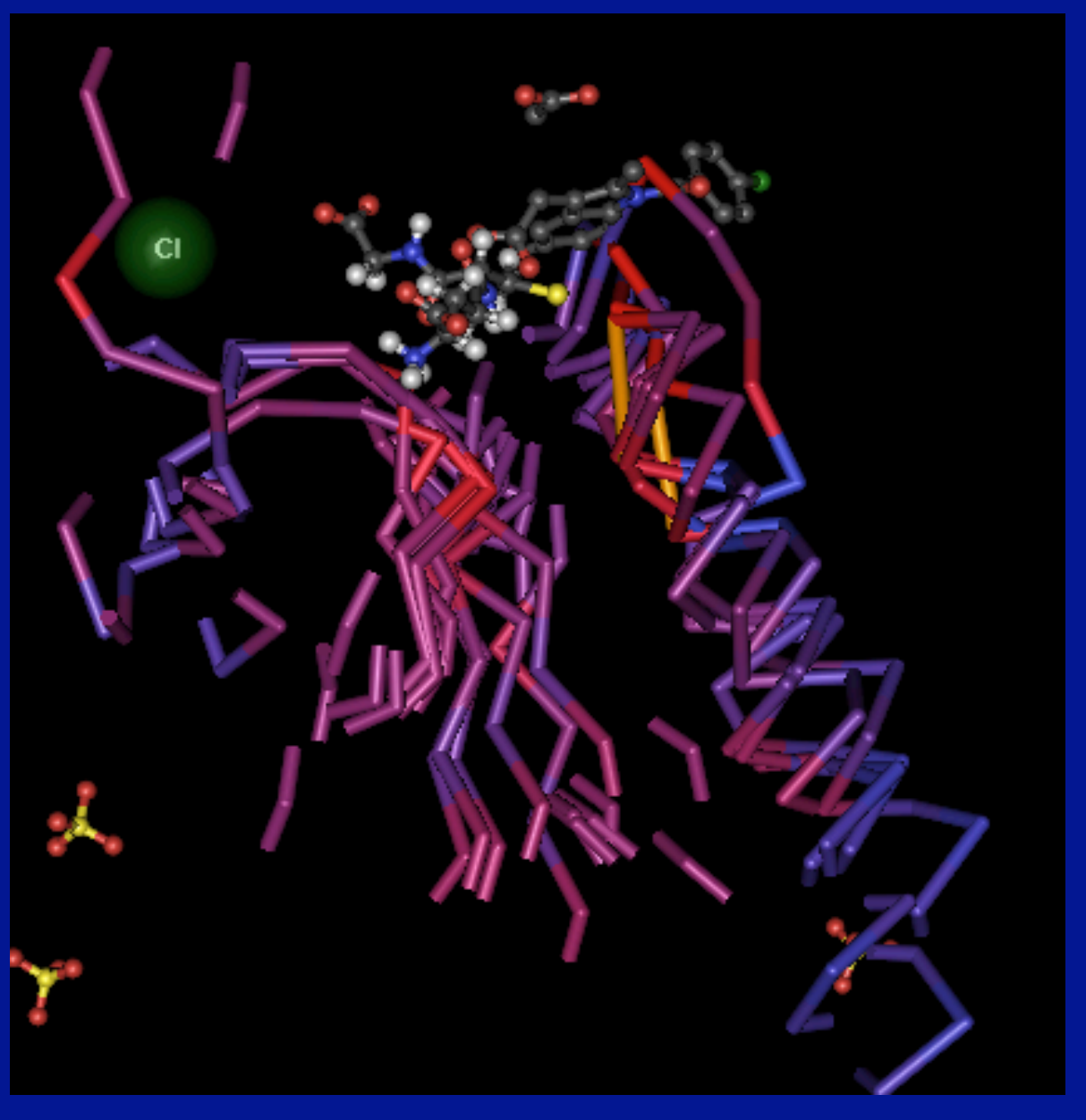

pfam00462

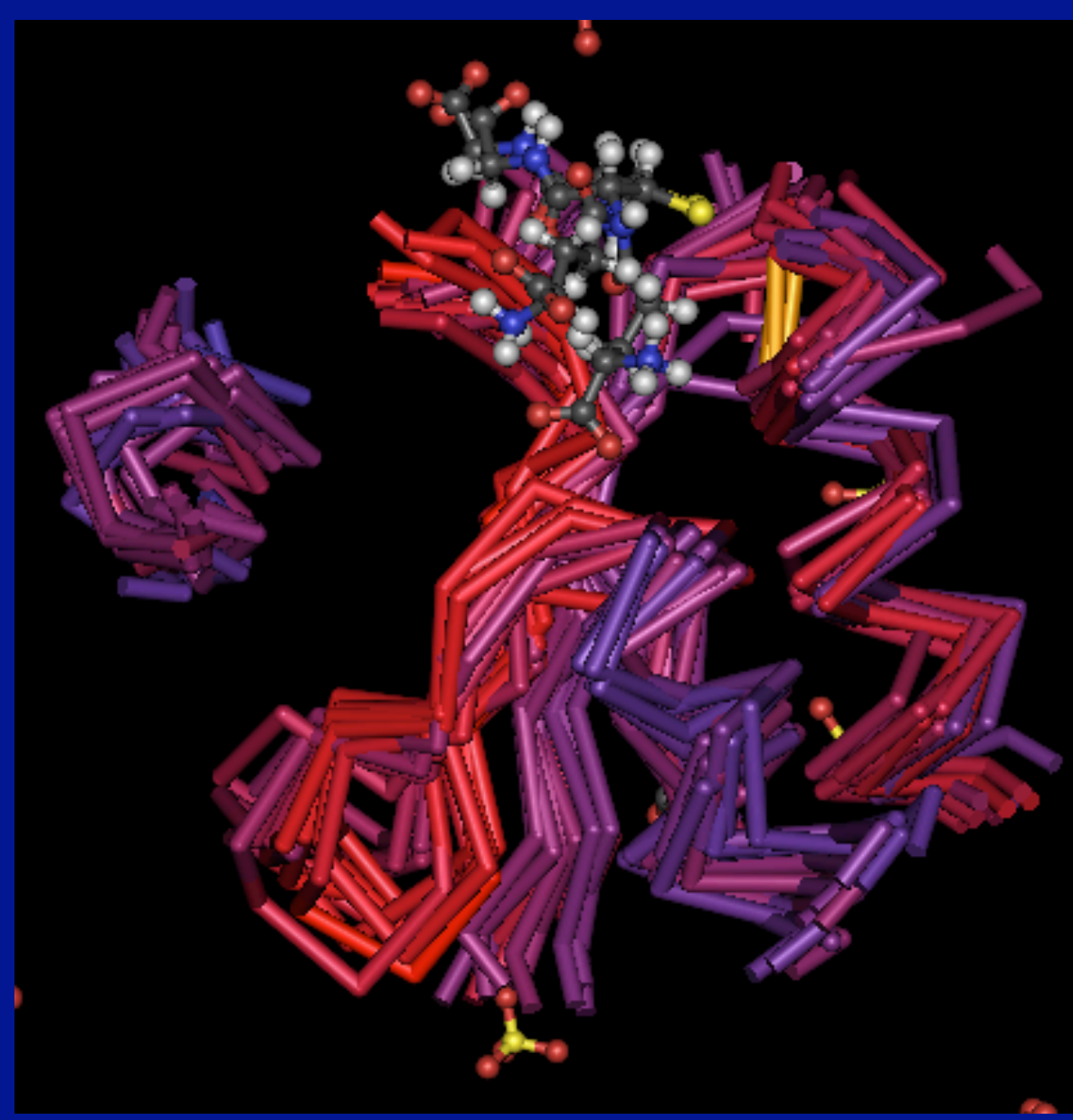

$\operatorname{cd} 02066$ 


\section{NCBI}

\section{ini ....}

LOCUS

DEFINITION

ACCESSION

VERSION

KEYWORDS

SOURCE

ORGANISM

REFERENCE

AUTHORS

TITLE

JOURNAI

REFERENCE

AUTHORS

TITLE

JOURNAL

REFERENCE

AUTHORS

TITLE

JOURNAL

REMARK

COMMENT

FEATURES
AF033819

HIV-1, complete genome.

AF033819

AF033819.3 GI: 4558520

Human immunodeficiency virus 1 (HIV-1)

Human immunodeficiency virus 1

Viruses; Retro-transcribing viruses; Retroviridae;

Orthoretrovirinae; Lentivirus; Primate lentivirus group.

1 (bases 1 to 9181)

Petropoulos, C.J.

Appendix 2: Retroviral taxonomy, protein structure, sequences, and genetic maps

(in) Coffin, J.M. (Ed.);

RETROVIRUSES : 757 ;

Cold Spring Harbor Laboratory Press, Cold Spring Harbor, New York, NY, USA (1997)

2 (bases 1 to 9181 )

Chappey, C.

Direct Submission

Submitted (12-NOV-1997) NIH, NLM, Rockville Pike, Bethesda, MD 20894, USA

3 (bases 1 to 9181 )

Chappey, C.

Direct Submission

Submitted (15-MAR-1999) NIH, NLM, Rockville Pike, Bethesda, MD 20894, USA

Sequence update by submitter

On Apr 2, 1999 this sequence version replaced gi:4416536.

Location/Qualifiers

1.9181

lorganism="Human immunodeficiency virus 1"

/mol_type="genomic RNA"

db xref="taxon: $11676 "$

\section{Retrovirdises}

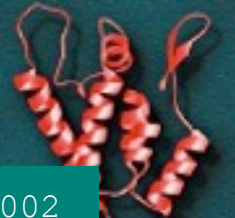

Jobn M. Coffin

Stepben $\boldsymbol{H}$. Iugbes

Earold E. Varmus
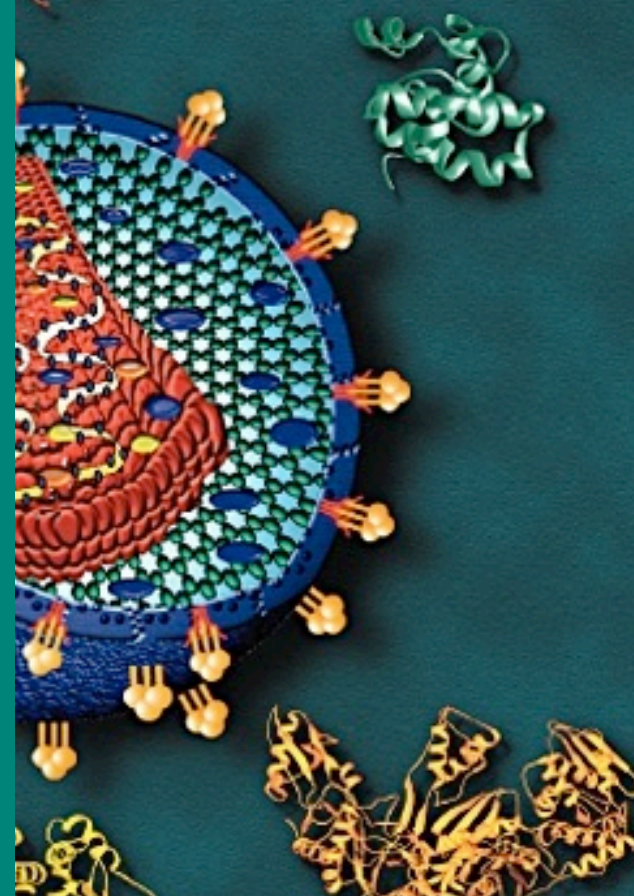

give it

asing

cons

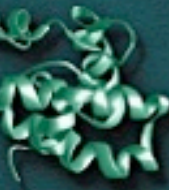

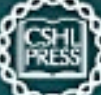




\section{NCBI}

Yeast Genome Completed (1992-1997)

- Chromosomes separately "owned".

- Half the genome transferred to SGD.

- Half is not.

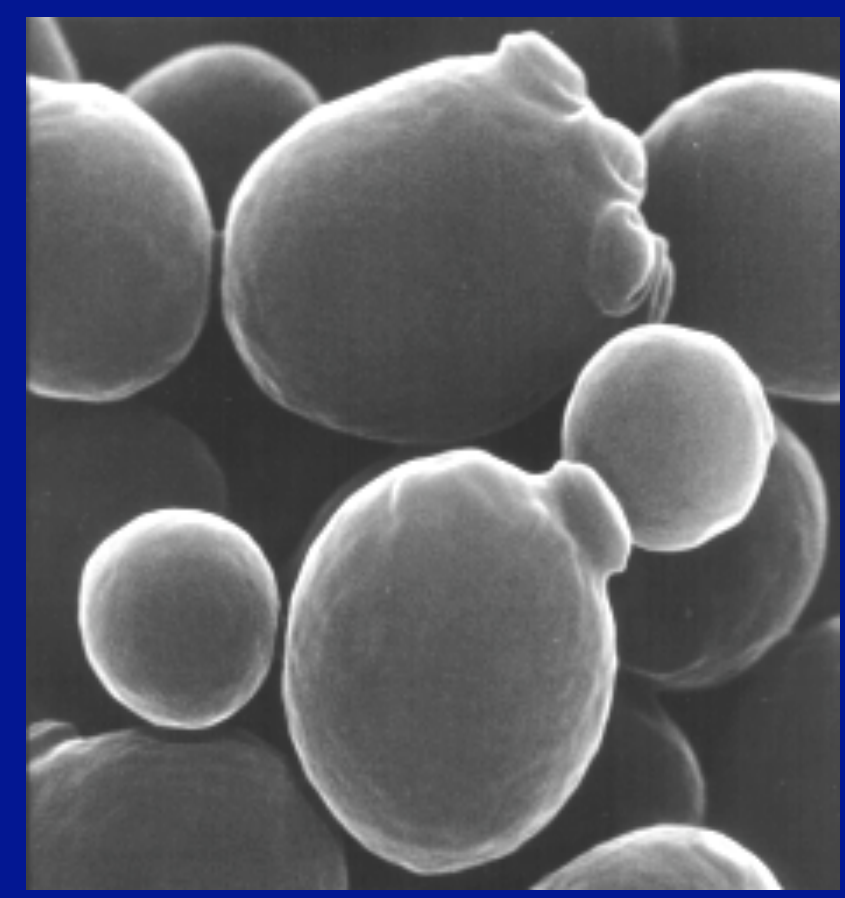




\section{$\mathrm{NCBI}$}

\section{Many Models for RefSeq}

- Yeast - Provided regularly by SGD

- Human - Annotated at NCBI, mRNA and GRC

- CCDS

- Drosophila - Provided by FlyBase, QA, tracking, GenBank update by NCBI

E.coli - Collaboration update EcoGene, ASAP, EcoCyc, others

- Flu - NIAID, NCBI, depts of health 


\section{NCBItack of information in some GenBank sequences}

Г1: CS406467. Reports Sequence 37 from ... [gi:114211870]

Features Sequence

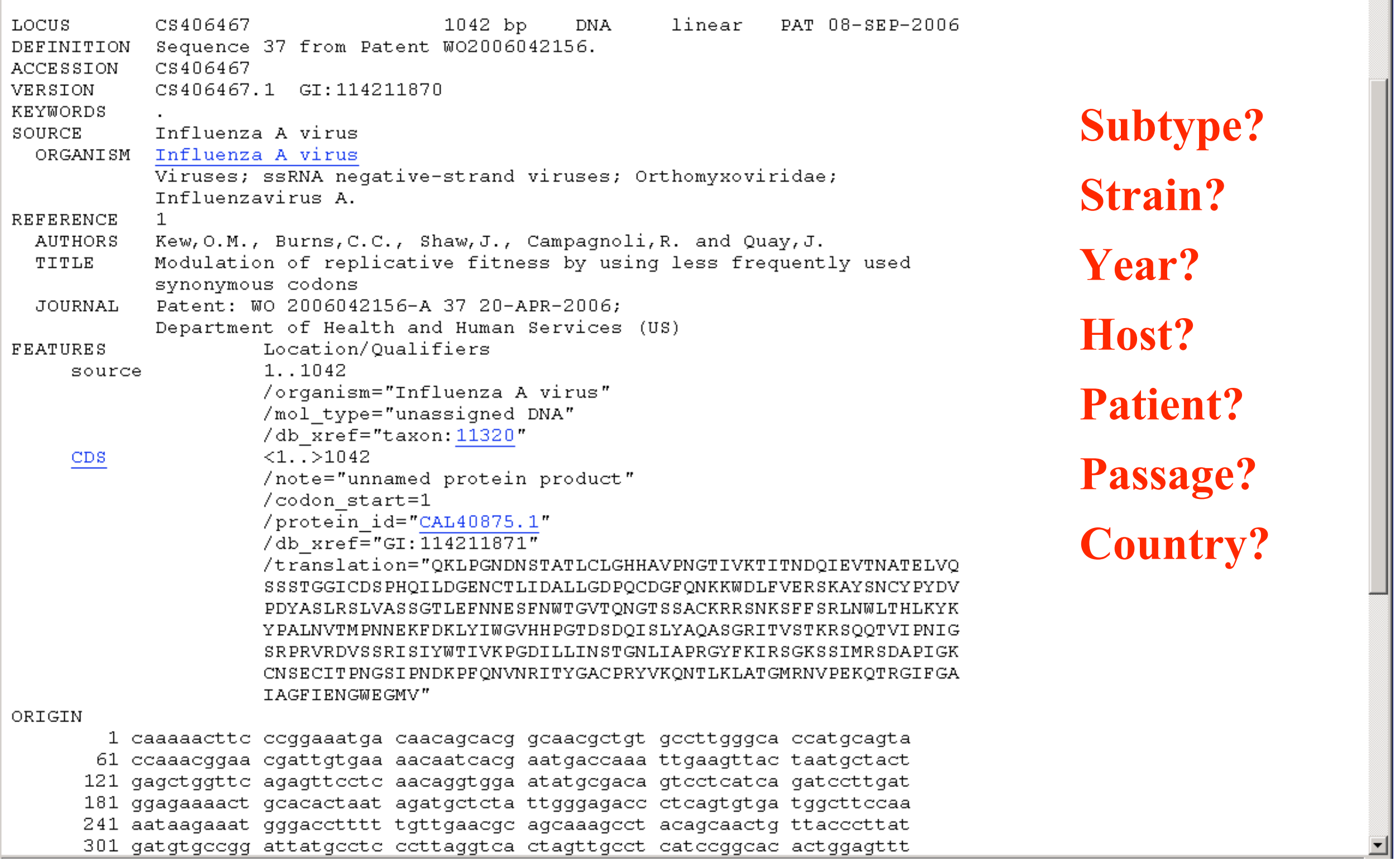




\section{NCBGonflict information in some GenBank sequences}

Г 1: EF597290. Reports Influenza A virus... [gi:148532809]

Features Sequence

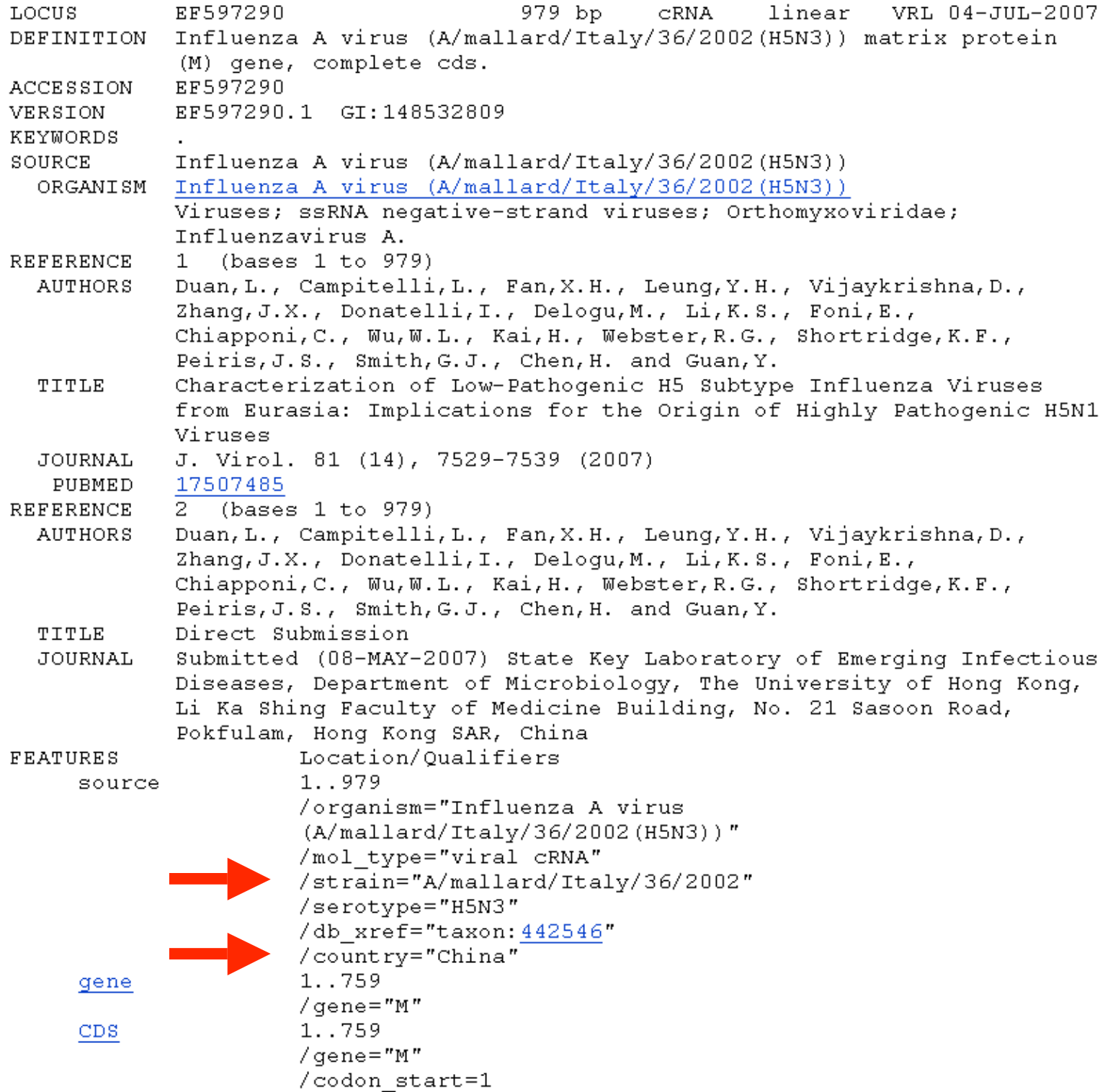




\section{Computer errors?}

1: X66929. Reports Influenza A virus...[gi:505040]

\section{$\underline{\text { Features }} \underline{\text { Sequence }}$}

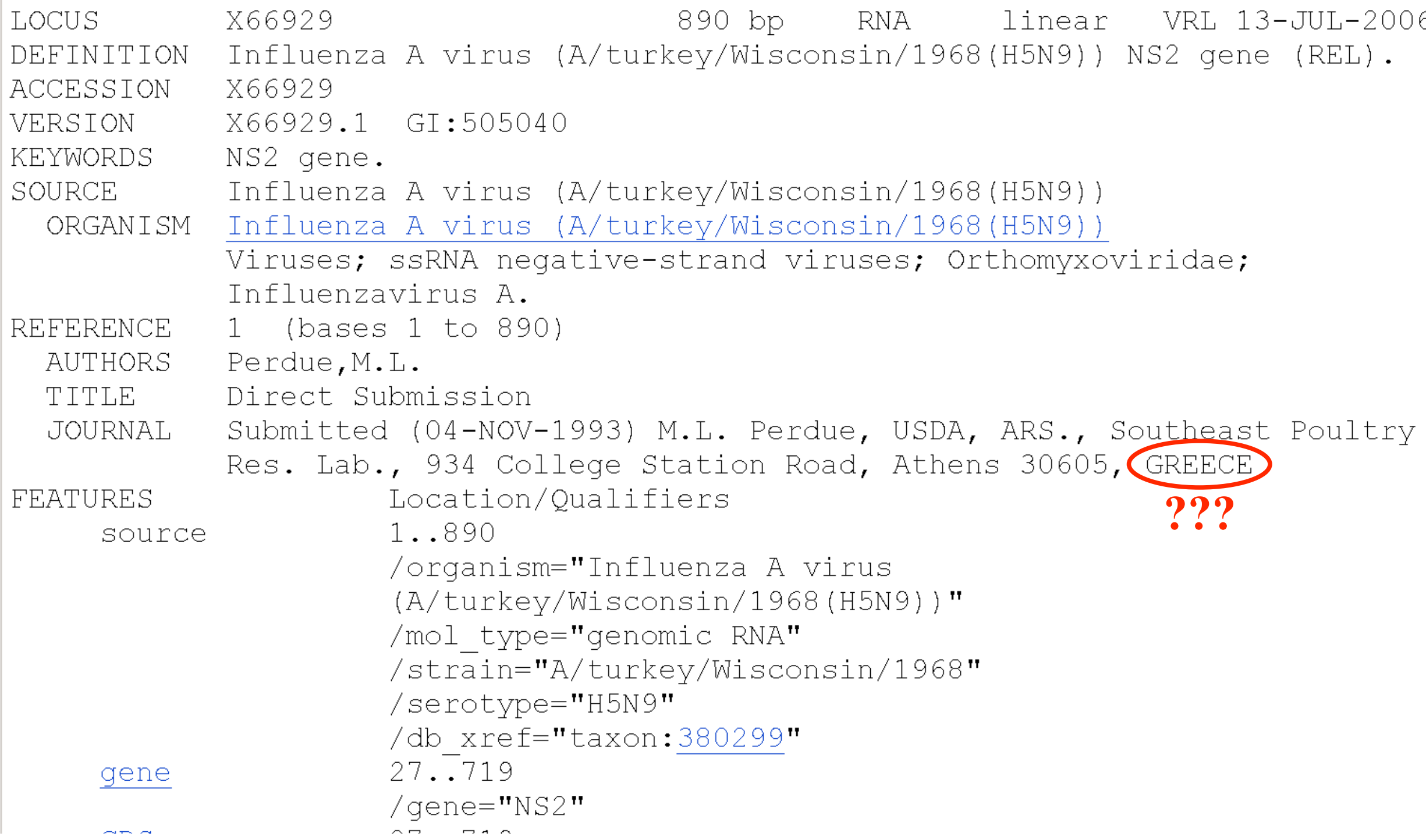




\section{NIGSP}

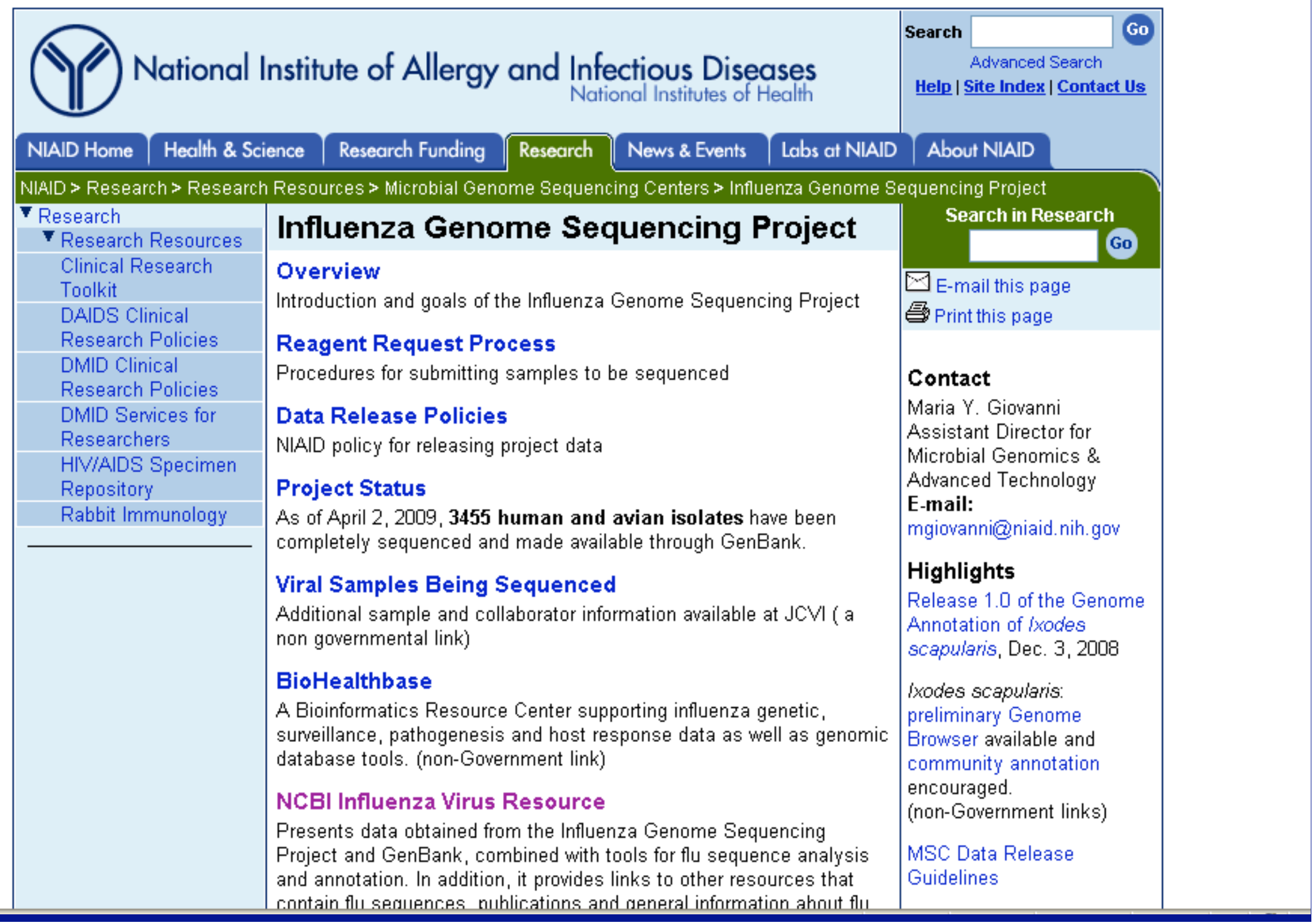




\section{NIAID Flu Project Dataflow}

\section{Mit10101 \\ AS Samplep providers}

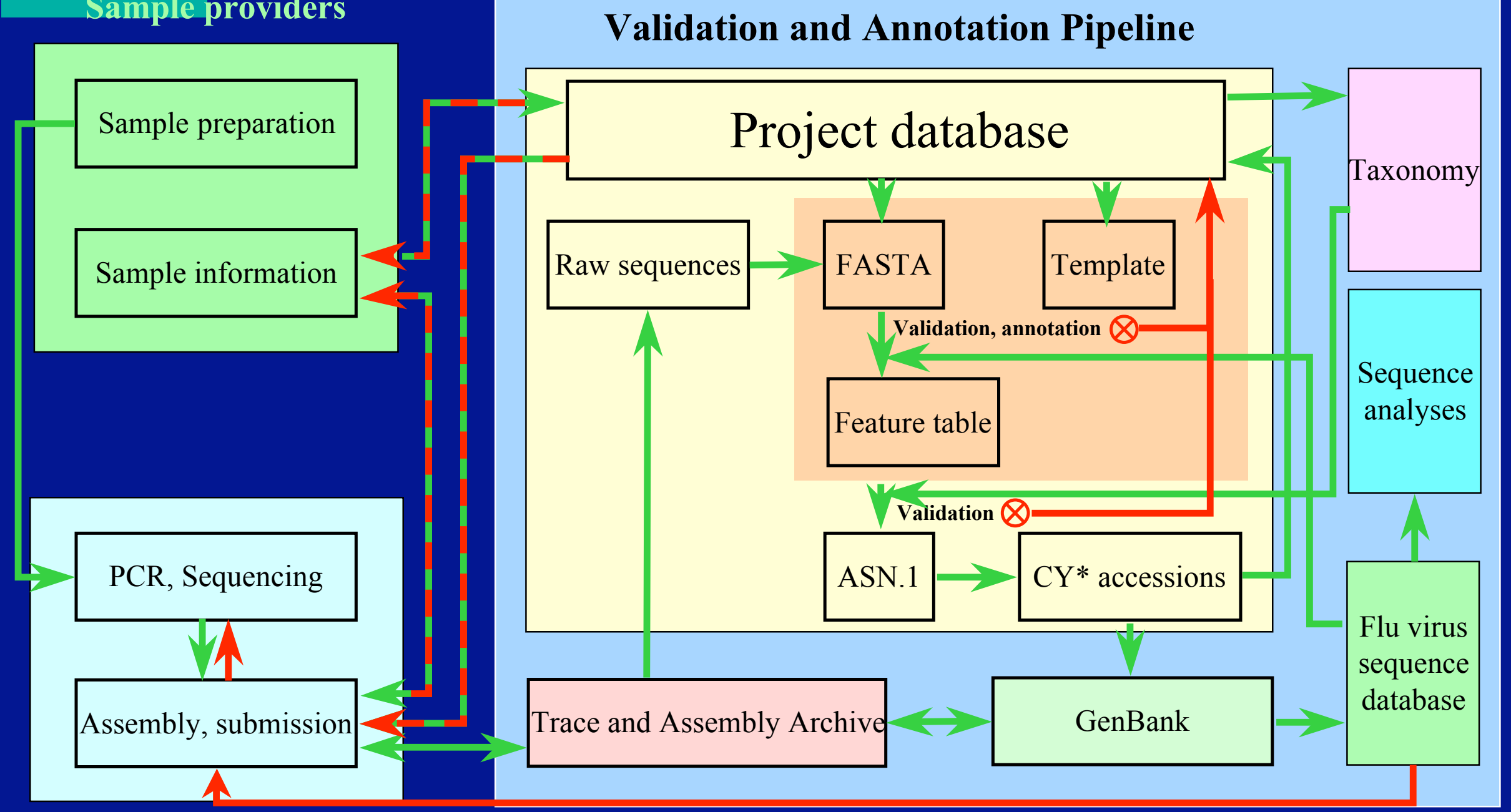

TIGR 


\section{NCBI}

Growth of influenza virus sequences in GenBank 10101

\begin{tabular}{|c|}
\hline$\boxminus \mathrm{NCBI}$ \\
\hline $\begin{array}{l}\text { Growth of flu } \\
\text { sequences }\end{array}$ \\
\hline $\begin{array}{l}\text { GenBank } \\
\text { sequences from } \\
\text { the NIAID } \\
\text { Project }\end{array}$ \\
\hline $\begin{array}{l}\text { Assembly } \\
\text { Archive }\end{array}$ \\
\hline Trace Archive \\
\hline $\begin{array}{l}\text { NIAID data } \\
\text { releasing } \\
\text { status }\end{array}$ \\
\hline \begin{tabular}{|l} 
RefSeq \\
genomes
\end{tabular} \\
\hline RefSeq proteins \\
\hline $\begin{array}{l}\text { Protein } \\
\text { Structures }\end{array}$ \\
\hline 曰Flu resources \\
\hline $\begin{array}{l}\text { NIAID Project } \\
\end{array}$ \\
\hline jCVI Flu \\
\hline CDC Flu \\
\hline $\begin{array}{l}\text { Vaccine } \\
\text { Selection }\end{array}$ \\
\hline WHO Flu \\
\hline 曰NCBI Viruses \\
\hline Viral Genomes \\
\hline Virus Variation \\
\hline Dengue virus \\
\hline Retroviruses \\
\hline SARS-CoV \\
\hline
\end{tabular}

Growth of Influenza Virus Sequences in GenBank

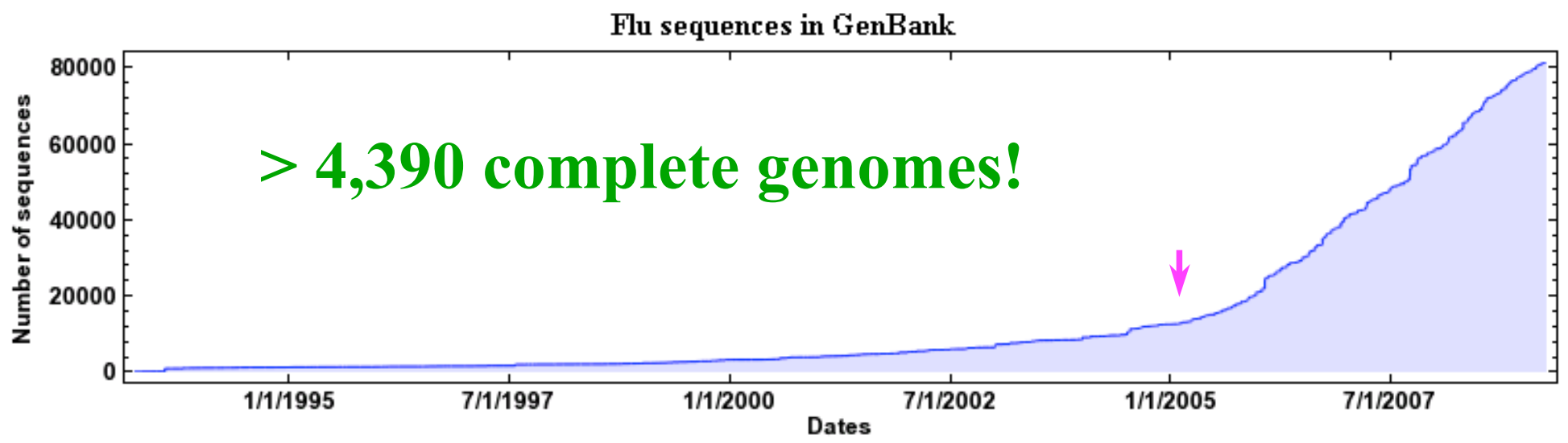

The graph below shows the growth of sequences from large-scale flu genome sequencing projects only. Currently, these include the NIAID Influenza Genome Sequencing Project, the St. Jude Influenza Genome Project, the Centers for Disease Control and Prevention, US Air Force School of Aerospace Medicine, and the University of Hong Kong.

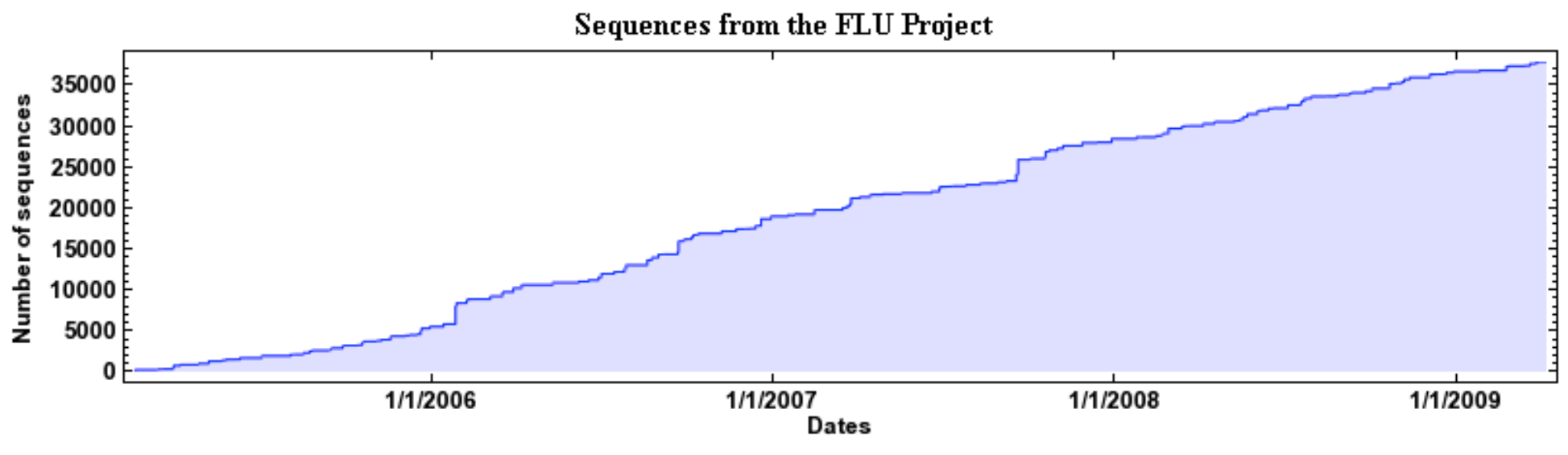




\section{NCBI Same genome from different labs identified}

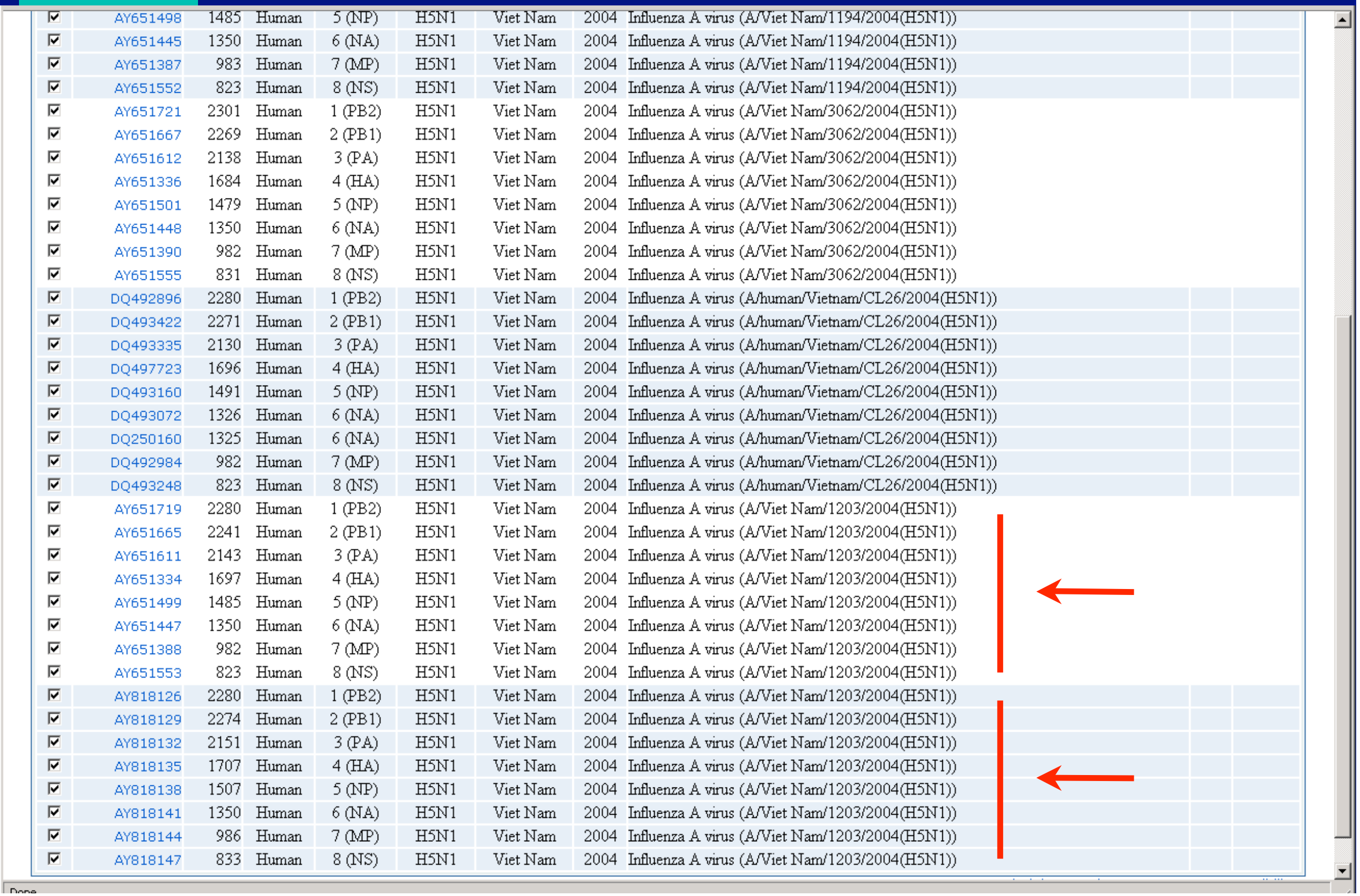




\section{Non-synonymous changes highlighted}

\begin{tabular}{|l|c|c|c|c|c|c|c|c|c|c|c|}
\hline HOME SERRCH SITE Map & Flu home & Database & Alignment & Genome set & Tree & BLAST & FTP & Help & Contact us
\end{tabular} Multiple Alignment for Coding Region Sequences 48 sequences. Alignment length is 1698

Download alignment Print-friendly version

\section{BLAST 2 seq. Clear Build a tree}

Go to position $\sqrt[360 \quad \text { Go }]{ }$

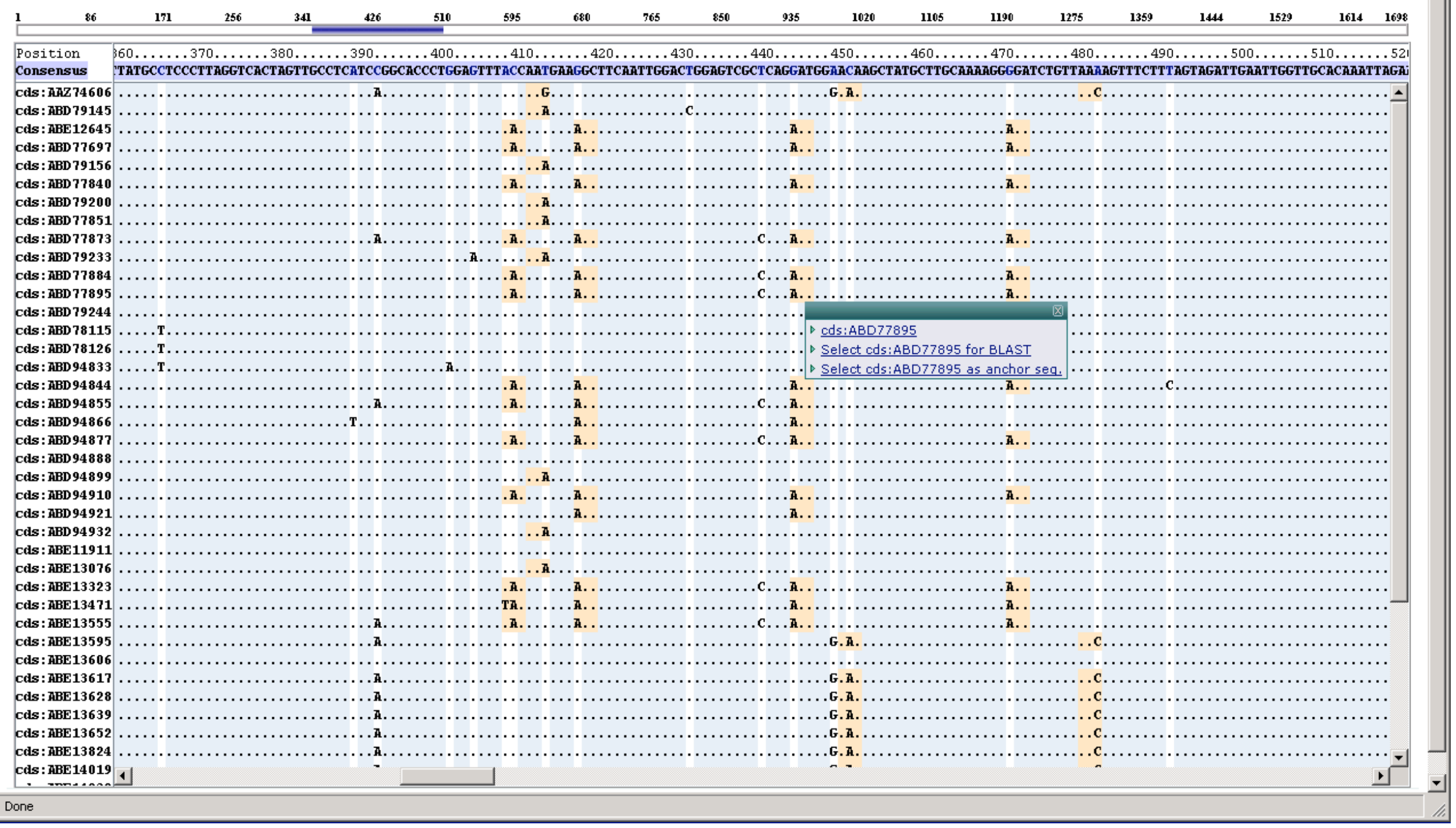




\section{NCBI \\ The tree is interactive}

Whroror

\section{$\sum \mathrm{NCBI}$}

Influenza Virus Resource

Information, Search and Analysis

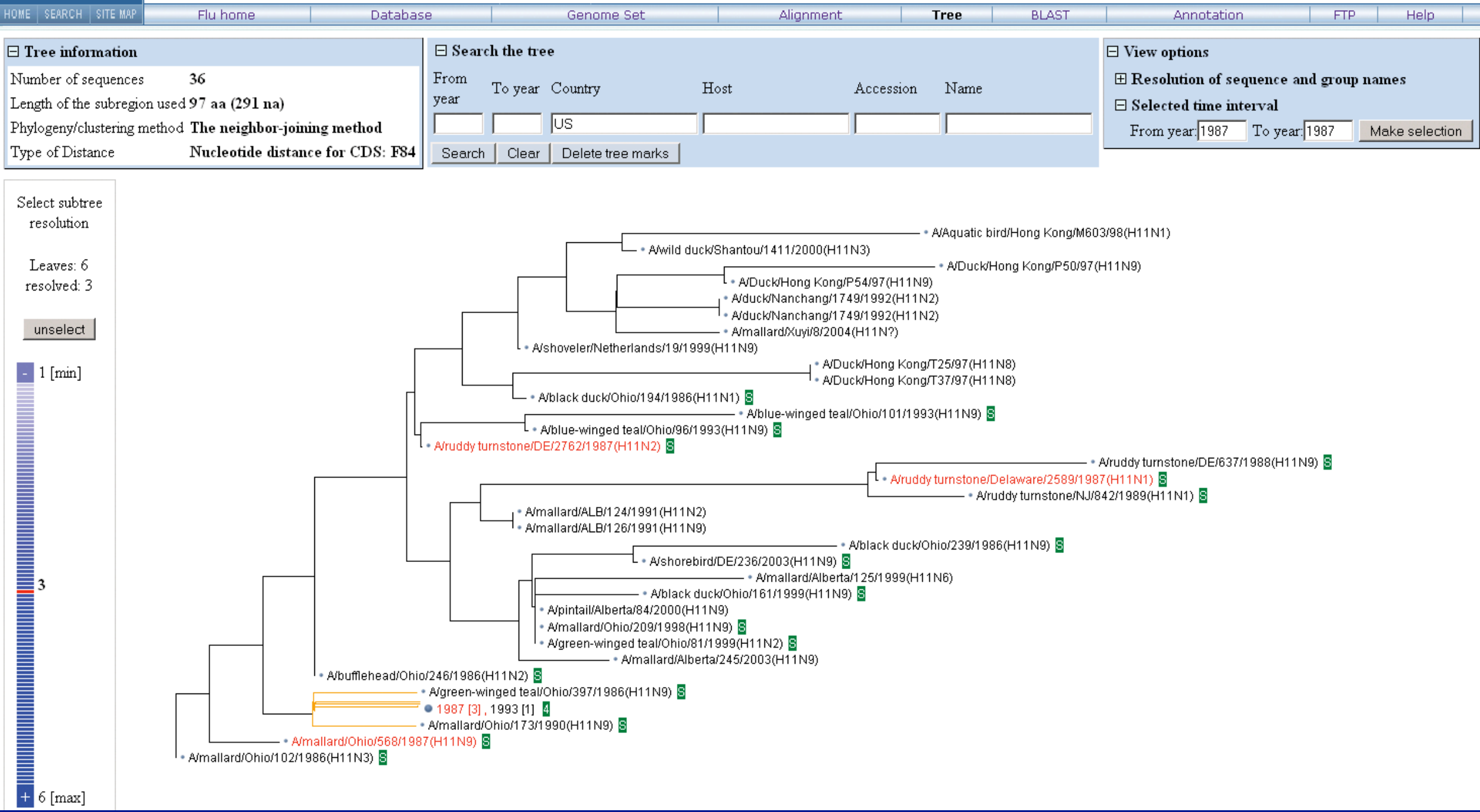




\section{$\mathrm{NCBI}$}

\section{Conserved CDS (CCDS)}

- Identify protein-coding genes that are consistently annotated and of high quality

- Converge toward a standard set of gene annotations

- Scope:

- Human and mouse protein coding regions

- Built by consensus among the collaborating members:

- Ensembl (EBI \& WTSI)

- National Center for Biotechnology Information (NCBI)

- University of California, Santa Cruz (UCSC) 


\section{General Process Flow}

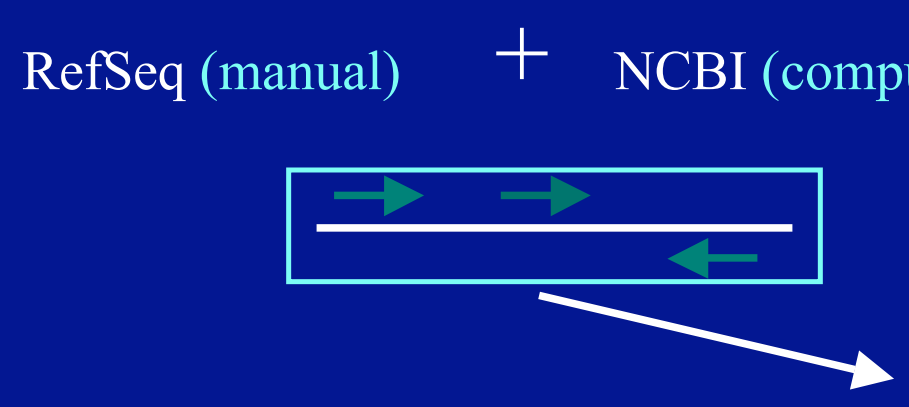

Compare CDS
Havana (manual) $\quad+$ Ensembl (computational)
Identify new matches<smiles>[CH]1C[CH]C1</smiles>
QA Tests $\rightarrow$ CCDS ID<smiles>[AlH][VH]</smiles>

Genome Conservation Pseudogene

Protein homology

Nonsense-mediated decay

Mismatches, Indels, Frameshifts

Consensus splice sites

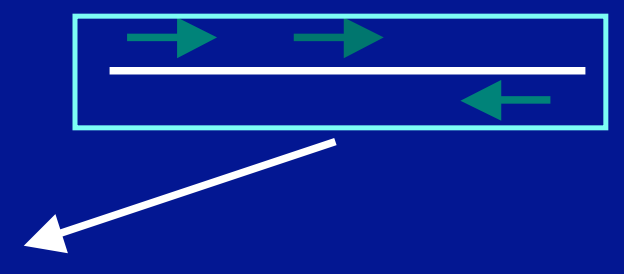

Track existing CCDS IDs

CCDS criteria:

- Identical annotated CDS coordinates -Pass QA tests, or curator review - Updates by agreement -Curated 


\section{CCDS Review}

10101

\begin{tabular}{|c|c|c|c|c|c|c|c|c|}
\hline CCDS & Group & Status & Votes & Species & Chrom. & Gene & $\begin{array}{l}\text { NCBI } \\
\text { Builds }\end{array}$ & Links \\
\hline 5607.1 & 6031.3 & $\begin{array}{l}\text { Under review, } \\
\text { withdrawal }\end{array}$ & $\begin{array}{l}\text { EBI,WTSI:yes; NCBI:open; } \\
\text { UCSC:open }\end{array}$ & $\begin{array}{l}\text { Homo } \\
\text { sapiens }\end{array}$ & 7 & $\mathrm{ABCB} 4$ & $35.1-36.3$ & $\mathrm{GOC}$ \\
\hline 42131.1 & 43404.1 & $\begin{array}{l}\text { Under review, } \\
\text { withdrawal }\end{array}$ & $\begin{array}{l}\text { EBI,WTSI:yes; NCBI:open; } \\
\text { UCSC:open }\end{array}$ & $\begin{array}{l}\text { Homo } \\
\text { sapiens }\end{array}$ & 16 & FLJ41766 & $36.3-36.3$ & $\mathrm{G} O \mathrm{C} \mathrm{G}$ \\
\hline 29038.1 & 30311.2 & Under review, update & $\begin{array}{l}\text { EBI,WTSI:yes; NCBI:open; } \\
\text { UCSC:open }\end{array}$ & $\begin{array}{l}\text { Mus } \\
\text { musculus }\end{array}$ & 18 & Svil & $36.1-37.1$ & $\mathrm{GOC} \mathrm{G}$ \\
\hline
\end{tabular}

- Consensus agreement - public notes of explanation.

- CCDS7915.1 CRY2: ... updated to extend the $\mathrm{N}$-terminus .... The update adds a transmembrane domain to the protein.

- CCDS2674.1 MYD88: ... updated to extend the N-terminus. ... The upstream AUG appears to be conserved only among primates and it has a weak Kozak sequence while the downstream AUG has a strong Kozak sequence. Due to leaky scanning by ribosomes ....

- CCDS11926.2 KIAA1632: ... updated to include additional exons at both the 5' and 3' ends, resulting in an extension of both the $\mathrm{N}$ - and $\mathrm{C}$-termini. ... the update is supported by available overlapping partial transcripts, by conservation data, and by data included in PMID:17549423. 


\section{Human and Mouse CCDS}

Reference Numbers

37,866 CCDS IDs (33,945 Genes)

49,716 RefSeq proteins (NP_) (38,253 Genes)

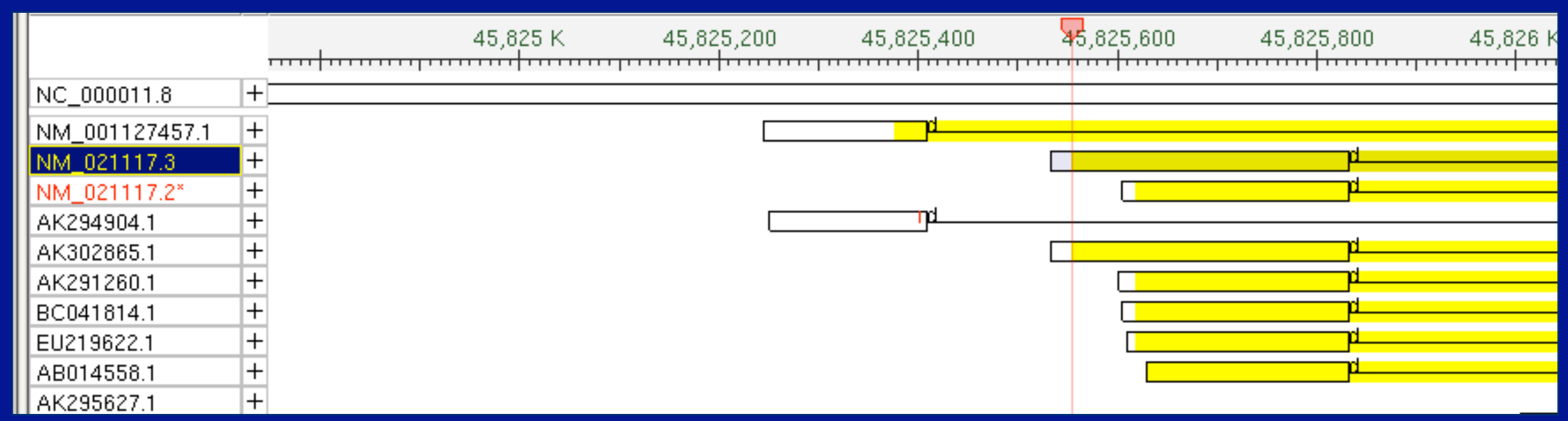




\section{The Genome Reference Consortium}

At the time the human reference was initially described, it was clear that some regions were recalcitrant to closure with existing technology. What was not as clear was the degree to which structural variation affected our ability to produce a truly representative genome sequence at some loci. It is now apparent that some regions of the genome are sufficiently variable that they are best represented by multiple sequences in order to capture all of the sequence potentially available at these loci.

In order to improve the representation of the reference human genome we have formed the Genome Reference Consortium (GRC). The goal of this group is to correct the small number of regions in the reference that are currently misrepresented, to close as many remaining gaps as possible and to produce alternative assemblies of structurally variant loci when necessary. We will provide mechanisms by which the scientific community can report loci in need of further review. In addition, information about loci currently under review and genome assembly production cycles will be made readily available. The human reference assembly is the cornerstone upon which all whole genome studies are based. It is critical to ensure that we have the best possible view of the genome to facilitate continued progress in understanding and improving human health

The Genome Reference Consortium consists of:

8. sanger THE

The Wellcome Trust Sanger Institute

\section{Genome}

C E N T E R

At WASHington University The Genome Center at Washington University

EMBL-EBI

$\overbrace{3} \mathrm{NCBI}$
The European Bioinformatics Institute

The National Center for Biotechnology Information
GRC News and Updates Updated Human Reference (GRCh37) deposited to GenBank 2 Mar 2009

The GRC has released an updated version of the HGP public reference assembly to GenBank.

\section{References}

Whole Genome Papers

The HGP Reference Assembly

The Venter Genome Assembly

The Mouse Genome Assembly

Human Chromosome Papers

Chr1 Chr2 Chr3 Chr4 Chr5 Chr6

Chr7 Chr8 Chr9 Chr10 Chr11

Chr12 Chr13 Chr14 Chr15 Chr16

Chr17 Chr18 Chr19 Chr20 Chr21

Chr22 ChrX ChrY 


\section{Wiv \\ IIIt10101}

\section{Genome Reference Consortium}

\begin{tabular}{|c|c|c|c|c|c|c|}
\hline GRC Home & Human & Mouse & Help & Report an Issue & Contact Us & Curators Only \\
\hline
\end{tabular}

\section{Contact the GRC}

Please feel free to contact us regarding any questions you may have concerning either the human or mouse genome assemblie

\section{Information}

Institution:*

Position:* Please select v

user email:*

Enter your request here:

Attach a figure describing the issue (no bigger than 5Mb): Browse_

Prove you are a human by answering the following question: What is six plus four?

submit issue

\section{\begin{tabular}{c|c|c|c|c|c|c|}
\hline GRC Home & Human & Mouse & Help & Report an Issue & Contact Us & Curators Only \\
\hline
\end{tabular}}

\section{Report a Genome Problem}

If you have found a region of the genome for which there seems to be an error, or a region of variation that needs to be better represented, please let us know. Provid as much detail as possible in the form below and someone in our group will get back to you as soon as possible. For examples of regions under review, see the currentissues for Human or Mouse

\section{Genome Information}

Please provide us with some

Organism* Select one

Genome Build*

\section{Location Information} Please provide information concerning the location of the issue. You can either provide information using the chromosome coordinates or the flanking accessions pulldown menu.

Chromosome None

Specify by Chromosome coordinates

Range Type $\odot$

Chromosome Start

Specify by Flanking accessions

Chromosome End

\section{Submitter Information}

Please provide some information about yourselt:

Submitter Email *

Affliation

Position * select one

Issue Detail

Jimation about the genome issue,

Desription of issue "

Browse_-

Prove you are a human by answering the following question: What is six plus fou

Submit lssue

| NHGRI | The Wellcome Trust | HHS | NH | Accessibility |

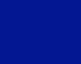


$\mathrm{NCBI}$

\section{Genome Reference Consortium}

\begin{tabular}{|c|l|l|l|l|l|l|}
\hline GRC Home & Human & Mouse & FAQ & Report an Issue & Contact Us & Curators Only \\
\hline
\end{tabular}

Overview Issues Under Review Assembly Data Report a problem

\section{Issues Reported on the Human Genome: Chromosome 2}

Column definitions can be found in the legend at the bottom of the page.

\begin{tabular}{|c|c|c|c|c|c|c|}
\hline ID & Category & ReportType & Status & Description & Location & View Region \\
\hline HG-25 & Unknown & $\begin{array}{c}\text { End Sequence } \\
\text { Profile }\end{array}$ & $\begin{array}{c}\text { In } \\
\text { Progress }\end{array}$ & $\begin{array}{c}\text { ESP analysis suggests the reference chromosome } \\
\text { contains an inversion between AC068279.6 and } \\
\text { AC116050.3 }\end{array}$ & $87,386,368-91,195,640$ & Ensembl NCBI UCSC \\
\hline HG-35 & Gap & Optical Map & Resolved & $\begin{array}{c}\text { Optical map data suggests genomic gap is larger than } \\
\text { reported gap size between AC144527.3 and AC140476.2. }\end{array}$ & $1,232,027-1,273,492$ & Ensembl NCBI UCSC \\
\hline HG-36 & Gap & Optical Map & $\begin{array}{c}\text { In } \\
\text { Progress }\end{array}$ & $\begin{array}{c}\text { Optical map data suggests genomic gap is smaller than } \\
\text { reported gap size between AC112228.3 and AC115619.3. }\end{array}$ & $20,956,755-21,081,128$ & Ensembl NCBI UCSC \\
\hline HG-37 & Gap & Optical Map & Resolved & $\begin{array}{c}\text { Optical map data suggests genomic gap is smaller than } \\
\text { reported gap size between AC092664.2 and AC112229.4. }\end{array}$ & $110,255,103-110,652,930$ & Ensembl NCBI UCSC \\
\hline HG-38 & Gap & Optical Map & $\begin{array}{c}\text { In } \\
\text { Progress }\end{array}$ & $\begin{array}{c}\text { Optical map data suggests genomic gap is smaller than } \\
\text { reported gap size between AC105402.5 and AC144611.2. }\end{array}$ & $149,335,381-149,509,794$ & Ensembl NCBI UCSC \\
\hline
\end{tabular}




\section{NCBPetter access to data and tools}

\section{Alignment for AC116176.4 and AC099799.6}

\section{View in Genome Workbench Download Genome Workbench}

AC116176.4 Homo sapiens BAC clone RP11-299D11 from 2, complete sequence [htgs_phase3] Length: $96,974 \mathrm{bp}$

AC099799.6 Homo sapiens BAC clone RP11-637F15 from 2, complete sequence [htgs_phase3] Length: 85,432 bp

Certified join: Variation, Clones are different haplotypes. AC099799.6 contains a 375bp gap in it's overlap with AC116176.4 Unfortunately, there is no annotation nor any repetitive elements in the region in question on AC116176.4 according to RepeatMasker. 2 pair of BAC end reads support join (CH17-261D24 and Ch17-334J15). (view) Alignment Summary
Alignment last updated: 11/11/2008 11:5

\section{Join Evaluation Legend}

Serious alignment problem, requires review. (details...)

Minor alignment problem. (details...)

Excellent alignment, meets all defined criteria. (details...)

- Certificate submitted, not yet approved.

- Certificate submitted and approved.

Valid, contained clone

Join not evaluated due to one accession not being finished.

\section{Curator Links}

Add/Update certificate

Approve certificate

Join evaluation: (initial certificate; $>0$ gap of $50 \mathrm{bp}$ or more, not simple sequence)

Alignment count: 1

Go to Endhit Table

Alignment 1

Align ID: 57571

Total Length: 57894

Aligned Length: 57432

Percent Identity: 99.7684

Number of Gaps: 31

Number of Mismatches: 133

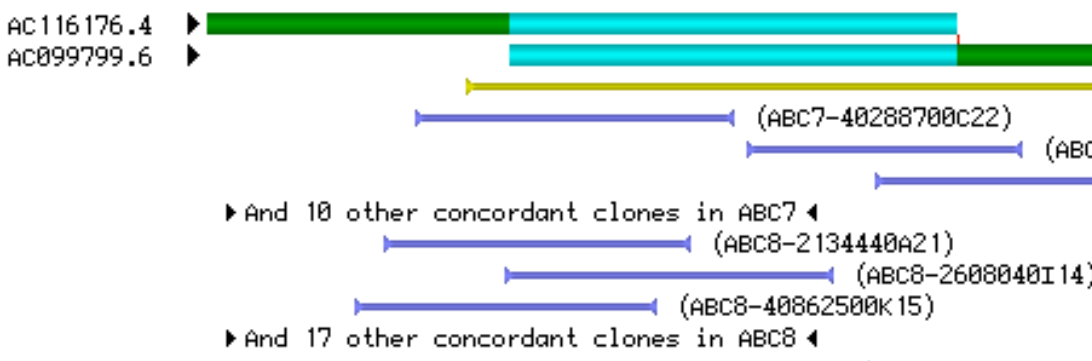

- And 10 other concordant clones in ABC7$$
\Longleftarrow \text { (ABC8-2608040I 14) }
$$

- And 17 other concordant clones in ABC8 4 


\section{$\mathrm{NCB}$ Fetter access to data and tools}

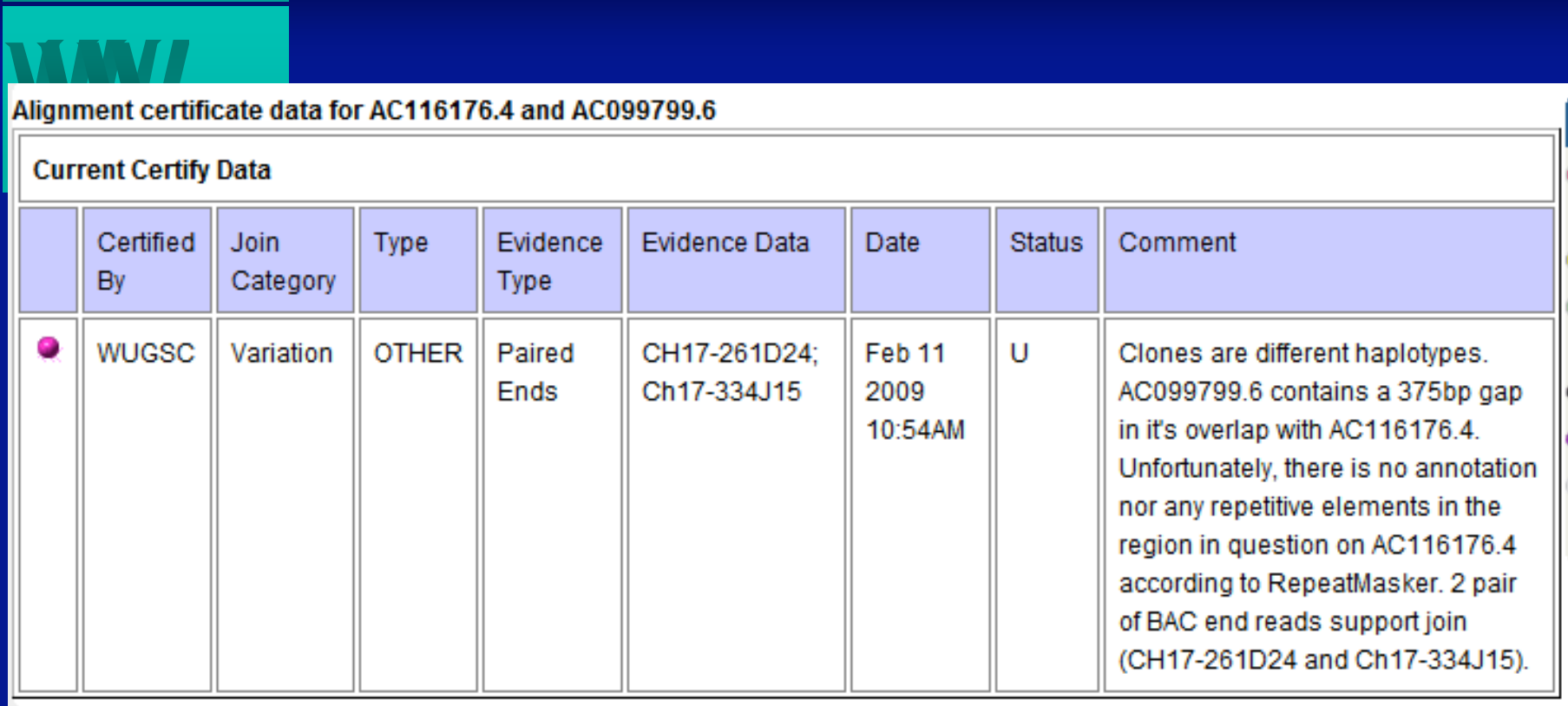

Join Evaluation Legend

Serious alignment problem, requires review. (details...)

Minor alignment problem. (details...)

Excellent alignment, meets all defined criteria. (details...)

- Certificate submitted, not yet approvied.

- Certificate submitted and approved. Join not evaluated due to one accession not being finished. 


\section{NCBGorrecting Sequence Errors in the Genome: GPBAR1}

\section{Wh10101}
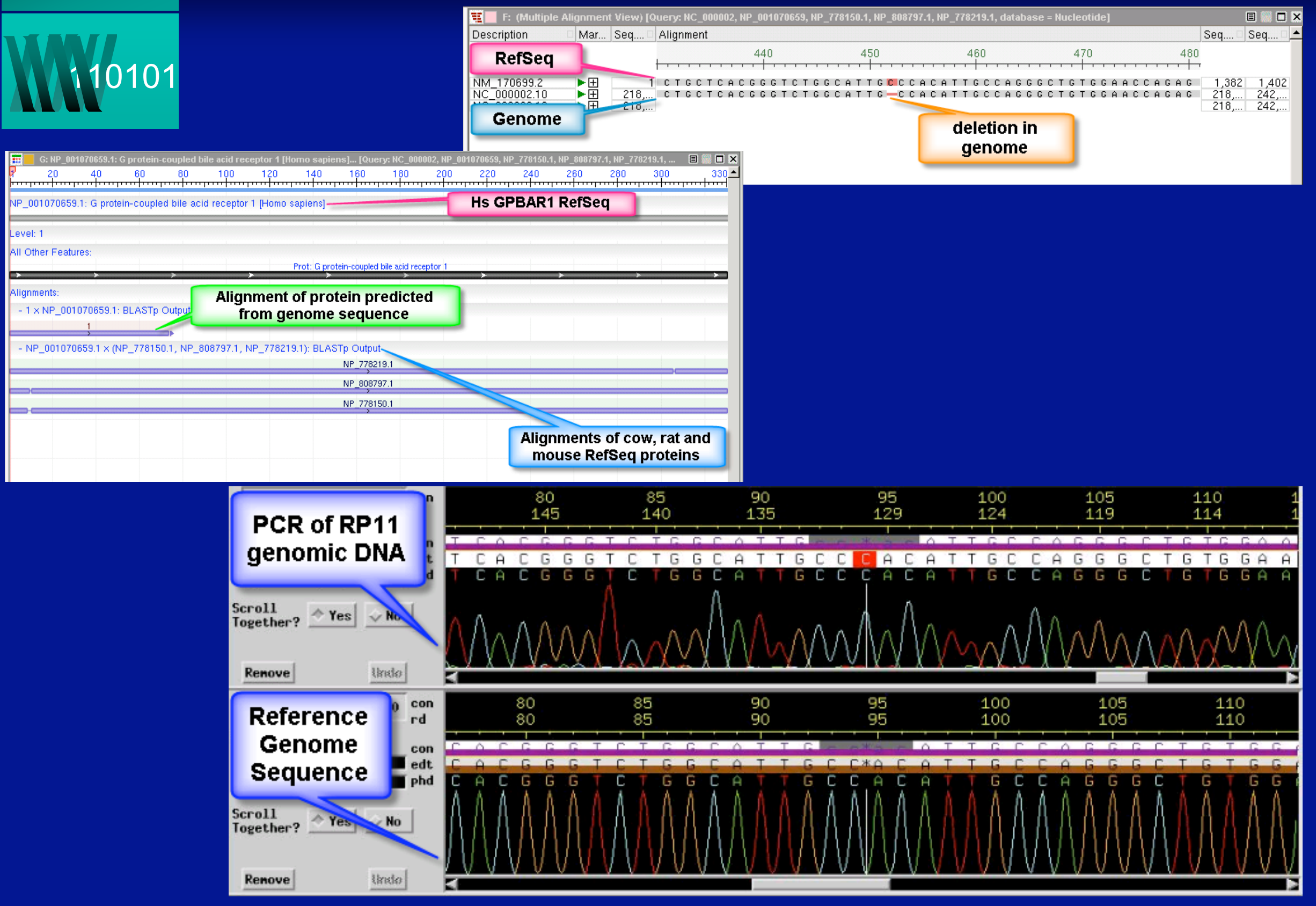


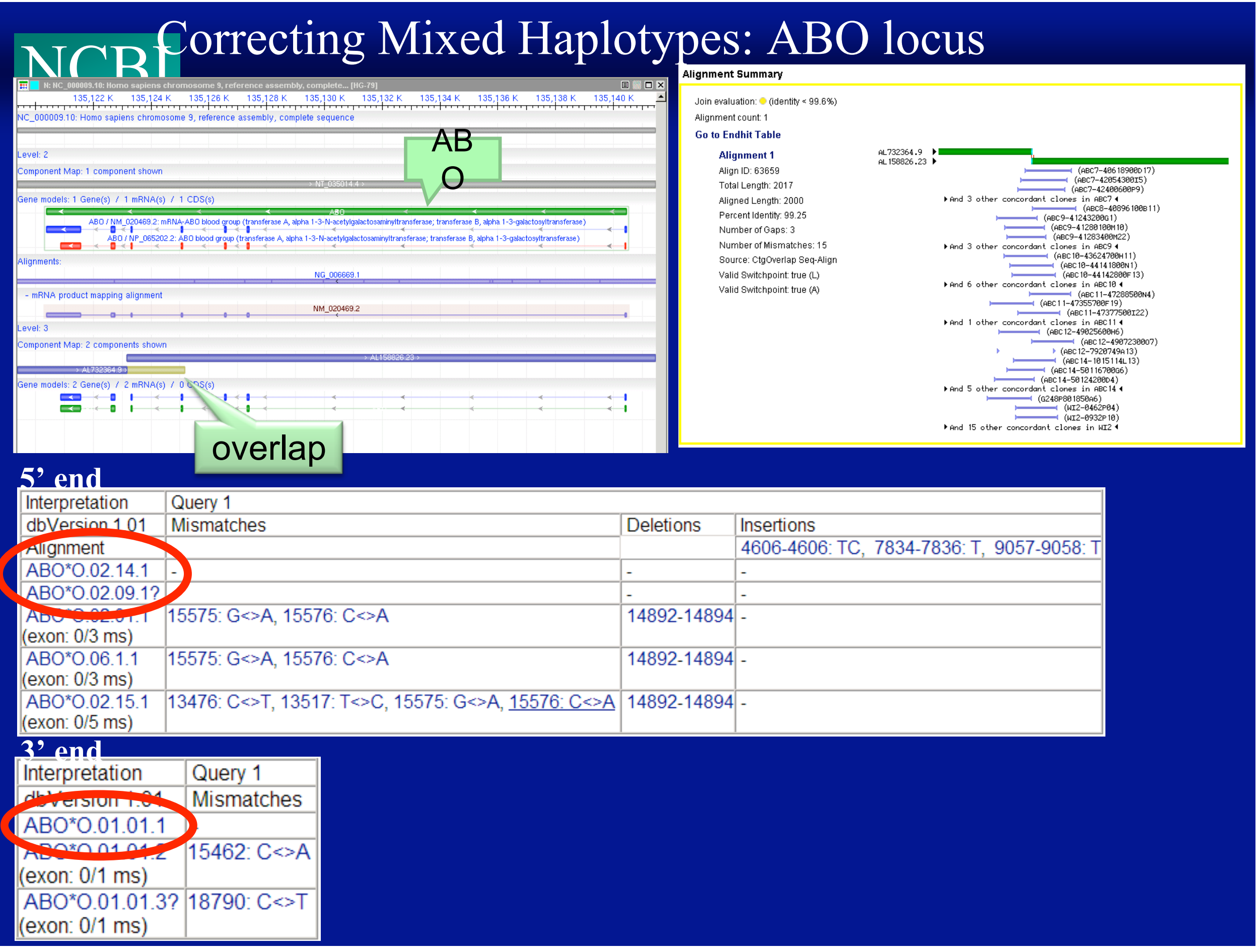




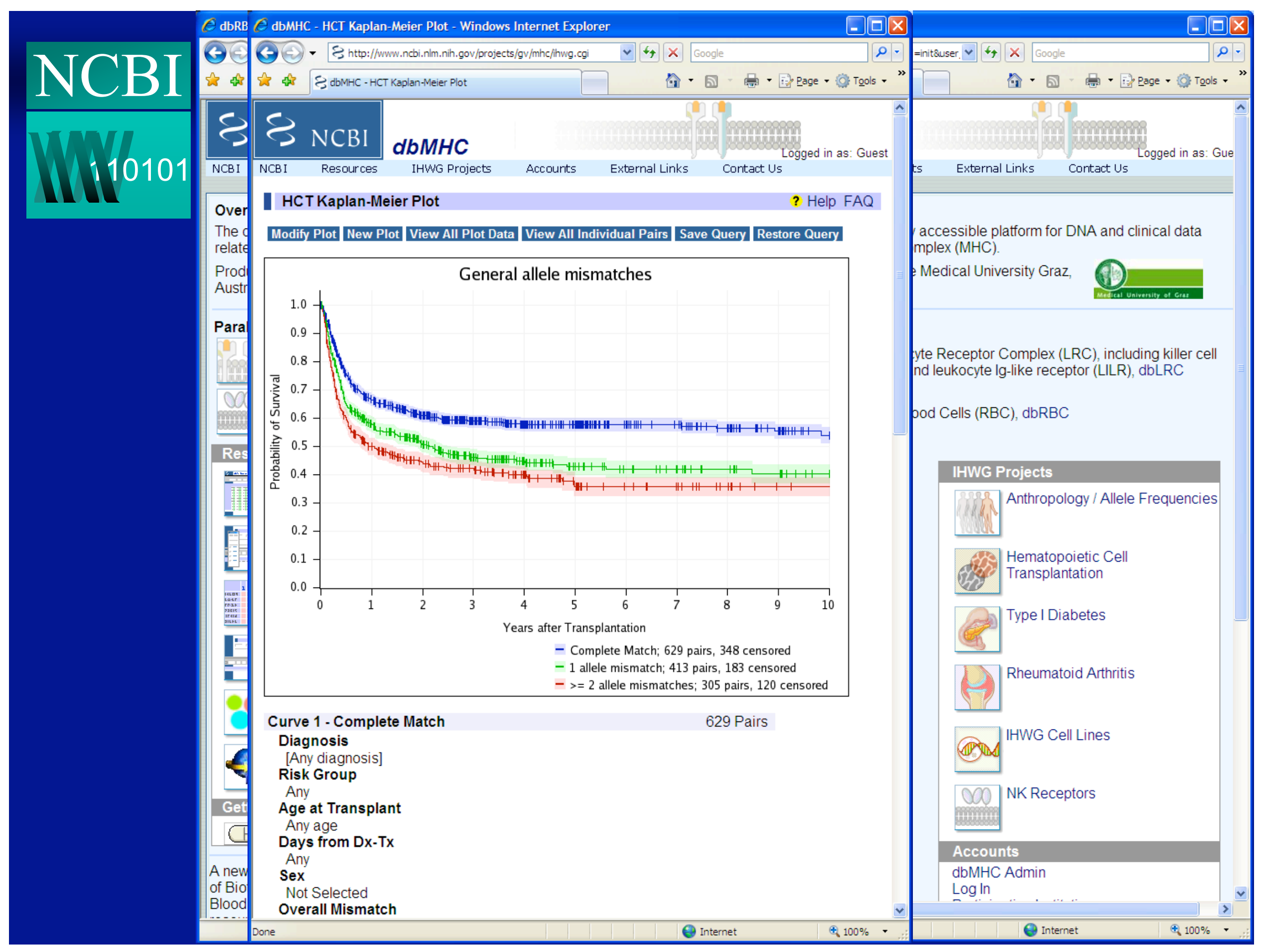




\section{$\mathrm{NCBI}$}

\section{Clinical Studies Have Been Unique}

- Framingham Heart Study (NHLBI)

- Blood pressure resting

- Blood pressure after exercise

- Blood pressure over many years and generations

- Occasional eye exams

- AREDS Macular Degeneration Study (NEI)

- Retinal images

- Staging of Macular degeneration progress

- Cataracts

- Blood pressure as part of physical exam 
NCBI

Writo101

\section{Whole Genome Association Finds}

\section{Genes Involved in Disease}

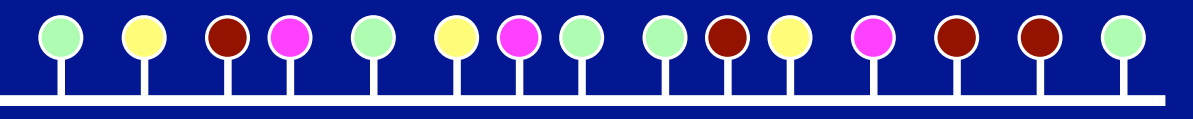

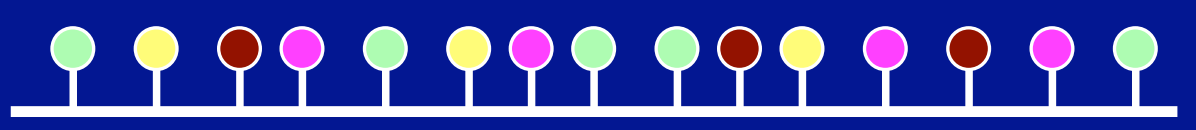

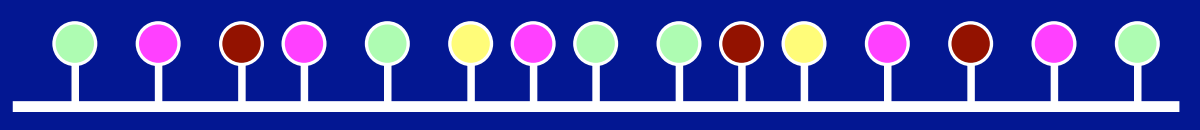

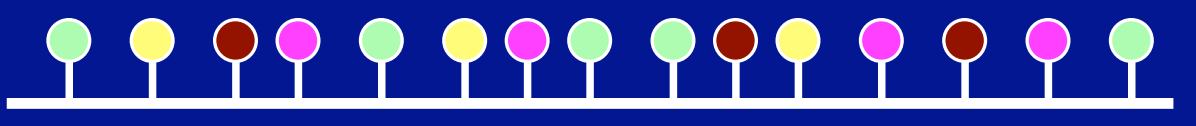

ำ ㅇำำคำำ오

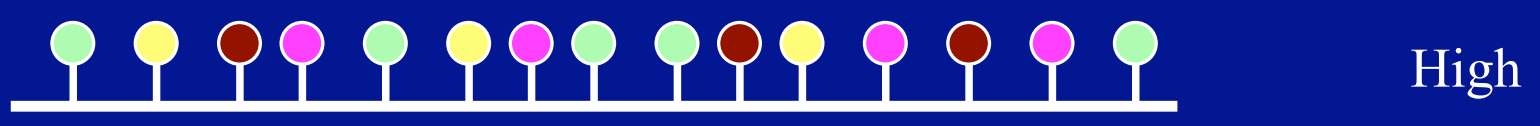

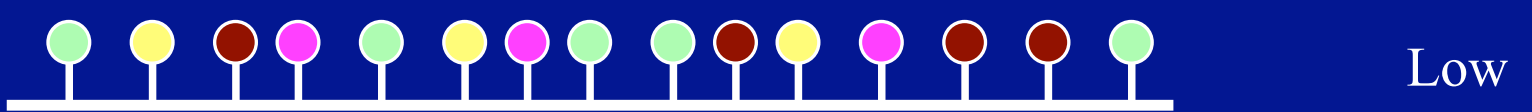

Macular Degeneration

No

No

Yes

No

No

BP Resting 
Study: National Eye Institute (NEI) Age-Related Eye Disease Study (AREDS) - Windows Internet Explorer

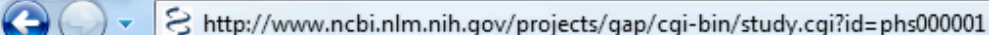

is the ₹ Study: National Eye Institute (NEI) Age-Related Ey...

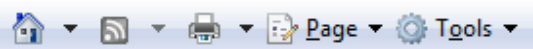
Research Group

Centrum use and progression of age-related cataract in the Age-Related Eye

Disease Study: a propensity score approach. AREDS report No. 21.

Ophthalmology. 2006 Aug;113(8):1264-70

Diseases Related to This Study (MESH terms)

- Macular Degeneration

- Cataract

Attribution

- Directors of Clinical Sites

- Susan B. Bressler, MD. Wilmer Eye Institute, The Johns Hopkins Medical

Institutions, Baltimore, MD

- Suresh R. Chandra, MD. University Station Clinics, University of Wisconsin, Madison, WI

- Emily Y. Chew, MD. The National Eye Institute, National Institutes of Health, Bethesda, MD

- Michael J. Elman, MD. Elman Retina Group, Baltimore, MD

- Thomas R. Friberg, MD. The Eye and Ear Institute, University of Pittsburgh, Pittsburgh, PA

- Justin Gottlieb, MD. University Station Clinics, University of Wisconsin, Madison, WI

- Aaron Kassoff, MD. Albany Eye Associates, The Eye Center at Memorial, Albany, NY

- Michael L. Klein, MD. Devers Eye Institute, Portland, OR

- Daniel F. Martin, MD. Emory Eye Center, Emory University, Atlanta, GA

- David H. Orth, MD. Irwin Retina Center, Ingalls Memorial Hospital, Harvey, IL

- Alan J. Ruby, MD. Associated Retinal Consultants, P.C., Clinical Research Center, Royal Oak, MI

- Johanna M. Seddon, MD. Massachusetts Eye and Ear Infirmary, Boston, MA

- Study Leadership (The National Eye Institute, National Institutes of Health, Bethesda, MD)

- Frederick L. Ferris III, MD, Study Chair.

- Emily Y. Chew, MD, Co-Investigator.

- John Paul SanGiovanni, ScD, Project Officer (2003 to 2007).

- Natalie Kurinij, PhD, Project Officer (1990 to 2003).

- Robert Sperduto, MD, Director, Lens Project.

- Coordinating Center (The EMMES Corporation, Rockville, MD)

- Traci E. Clemons, PhD, Principal Investigator (2003-2007).

- Anne S. Lindblad, PhD, Principal Investigator (1990-2003).

- Roy C. Milton, PhD, Co-Principal Investigator.

- Alice K. Henning, MS, Director of Genetic Ancillary Studies.

- Reading Center (University of Wisconsin - Madison, Madison, WI)

- Matthew D. Davis, MD, Co-Principal Investigator.

- Ronald Klein, MD, Co-Principal Investigator. 


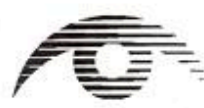

A R E D S

National Eye Institute (NEI) Age-Related Eye Disease Study (AREDS)

\section{Accession: phs000001.v1.p1}

Description

The Age-Related Eye Disease Study (AREDS) was initially designed as a long-term multi-center, prospective study of the clinical course of age-related macular

degeneration (AMD) and age-related cataract. In addition to collecting natural history data, AREDS included a clinical trial of high-dose vitamin and mineral supplements for AMD and a clinical trial of high-dose vitamin supplements for cataract. AREDS

participants were 55 to 80 years of age at enrollment and had to be were free of any illness or condition that would make long-term follow-up or compliance with study medications unlikely or difficult. On the basis of fundus photographs graded by a central reading center, best-corrected visual acuity and ophthalmologic evaluations, over 4,700 participants were enrolled in one of several AMD categories, including persons with no AMD.

The clinical trials for AMD and cataract were conducted concurrently.

AREDS participants were followed on the clinical trial for a median time of 6.5 years. Subsequent to the conclusion of the clinical trial, participants were followed for an additional 5 years and natural history data were collected. The AREDS research design is detailed in AREDS Report 1. AREDS Report 8 contains the mainline results from the AMD trial; AREDS Report 9 contains the results of the cataract trial. Blood samples were also collected for genetic research. Genetic samples from 600 AREDS participants were evaluated with a genome-wide scan for inclusion in the dbGaP.

It is hoped that this resource will better help researchers understand two important diseases that affect an aging population. These data may be applied to examination and inference on genetic and genetic-environmental bases for age-related diseases of public health significance and may also help elucidate the clinical course of both conditions, generate hypotheses, and aid in the design of clinical trials of preventive interventions.

AREDS, The National Eye Institute

AREDS, The EMMES Corporation

- Subjects: 600

\section{Search Within This Study}

Search for:

\section{Associated Analyses}

JNEI Age-Related Eye Disease Study (AREDS)

\section{AMD status}

Associated Variables

$$
\begin{aligned}
& \checkmark \text { Physical Observations } \\
& \checkmark \text { Clinical Examination } \\
& \text { Gorgan Systems } \\
& \text { GEye }
\end{aligned}
$$

- rpscscore

- rPSCbase

- rpsc

Associated Documents

Share 


\section{Chapter 7 EXAMINATION PROCEDURES}

\subsection{INTRODUCTION}

The procedures for carrying out the examinations required in the study are described in this chapter. Required ocular examinations include refraction and visual acuity measurements, intraocular pressure measurement, and ophthalmoscopic examination. General characteristic assessments include measurement of height, weight, and blood pressure and determination of past medical history. Risk factor assessments will require the administration of the food frequency and sunlight exposure questionnaires as well as collection of blood specimens. Procedures for participant identification, masking, distribution and management of the supplementation, adherence assessment, and home visit examination are also described. Procedures for taking photographs of the lens and fundus are described in detail in Chapter 8. The schedule and description of participant visits in Chapter 6 outline the examinations required during each visit.

\subsection{REFRACTION AND VISUAL ACUITY}

A manifest refraction and visual acuity measurement according to the detailed study protocol must be performed during (a) the Qualifying Visit when the visual acuity score using Chart $R$ is 73 letters or less in at least one eye, (b) the Randomization Visit, (c) Annual Visits, and (d) any Nonannual Visit when the visual acuity score using Chart $R$ has dropped by 10 letters or more compared to the Randomization Visit score for the first time. Participants' pupils should not be dilated at the time of visual acuity testing at any study visit; except they may be dilated during the Qualifying Visit. Pinhole acuity will not be tested as part of AREDS. At the Qualifying Visit, visual acuity may be initially assessed utilizing the participant's current distance glasses. At the Nonannual Visits, visual acuity is initially assessed utilizing the previously obtained manifest refraction. Participants will be asked to read the letters on Chart $\mathrm{R}$ only (not Charts 1 or 2), using the equipment described in Section 7.2.1. They will start reading from the top left-most letters--first with the right eye and then with the left eye. A visual acuity score will be calculated as described in Section 7.2.3.3. If at the Qualifying Visit 
systolic blood pressure - dbGaP Results - Windows Internet Explorer

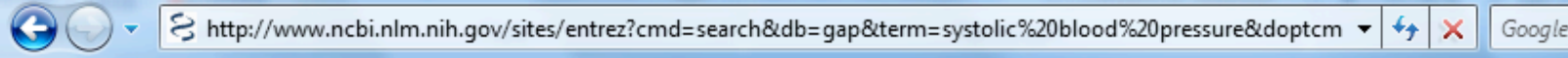




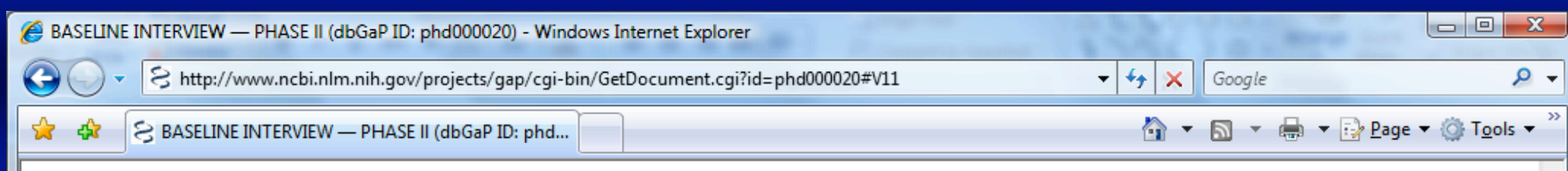

\section{I would like to take your blood pressure now and again later during this interview.}

8. Sitting blood pressure. (Participant must have been seated and quiet for at least 5 minutes prior to the measurement. See Section 7.6 of the Manual of Operations.):
a. Systolic $(\mathrm{mmHg})$
V
a. Diastolic $(\mathrm{mmHg})$ V
b. Certification number of blood pressure examiner:

9. Have you ever smoked cigarettes for a total of 6 months or more?

no

yes

\section{If no, skip to 10}

a. How old were you when you first started smoking?

b. Over your lifetime of smoking, on the average, how many packs per day have you smoked? $\leq 1 / 2$ pack

$>1 / 2, \leq 1$ pack

$>>1, \leq 2$ packs

$\bigcirc>2$ packs

c. Do you smoke cigarettes at present?

no

$\bigcirc$ yes

If no, skip to e

d. If you currently smoke, how many cigarettes a day do you smoke?

Skip to 10

e. If you do not smoke currently, how old were you when you last quit smoking?

10. Have you ever smoked cigars, a pipe, or chewed tobacco for a total of 6 months or more?

no

yes 


\section{$\sum \mathrm{NCBI}$ \\ dbSNP Build 127}

$\underset{\text { GENOTYPE and PHENOTYPE }}{\mathbf{d}} \mathrm{a}$

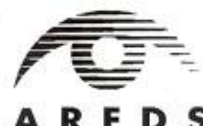

-logl0(uncorrected P-ralue) \begin{tabular}{|c|c|c|c|c|c|c|}
$\mathbf{N} / \mathbf{A}<2$ & $2-$ & $3-$ & $4-$ & $5-$ & $6-$ & $>7$ \\
\hline
\end{tabular}

STUDY: NEI Age-Related Eye Disease Study (AREDS)

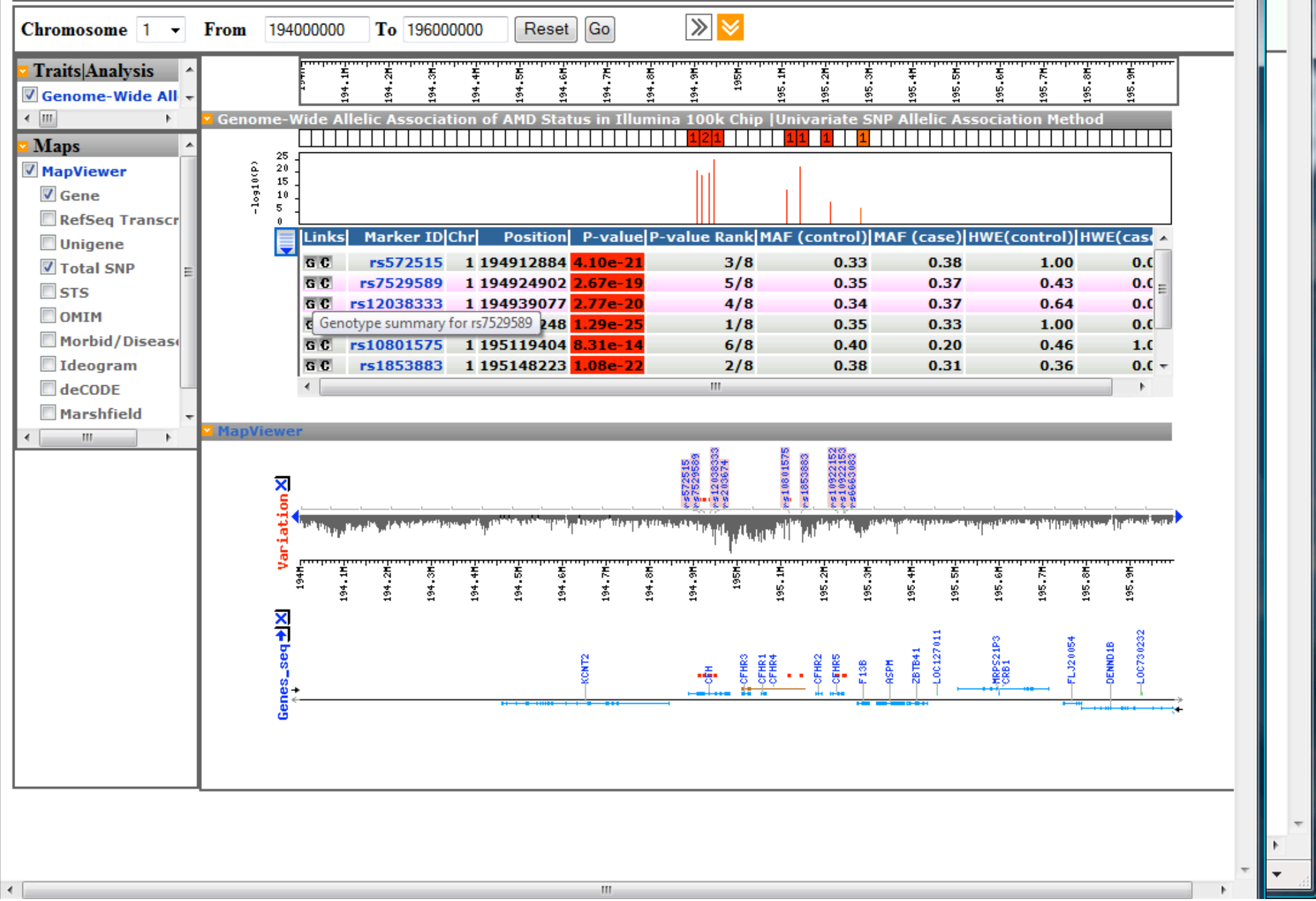

$\circ$ o.

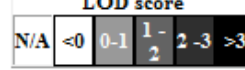




\section{$\mathrm{NCBI}$}

\section{Associations to the Basepair}

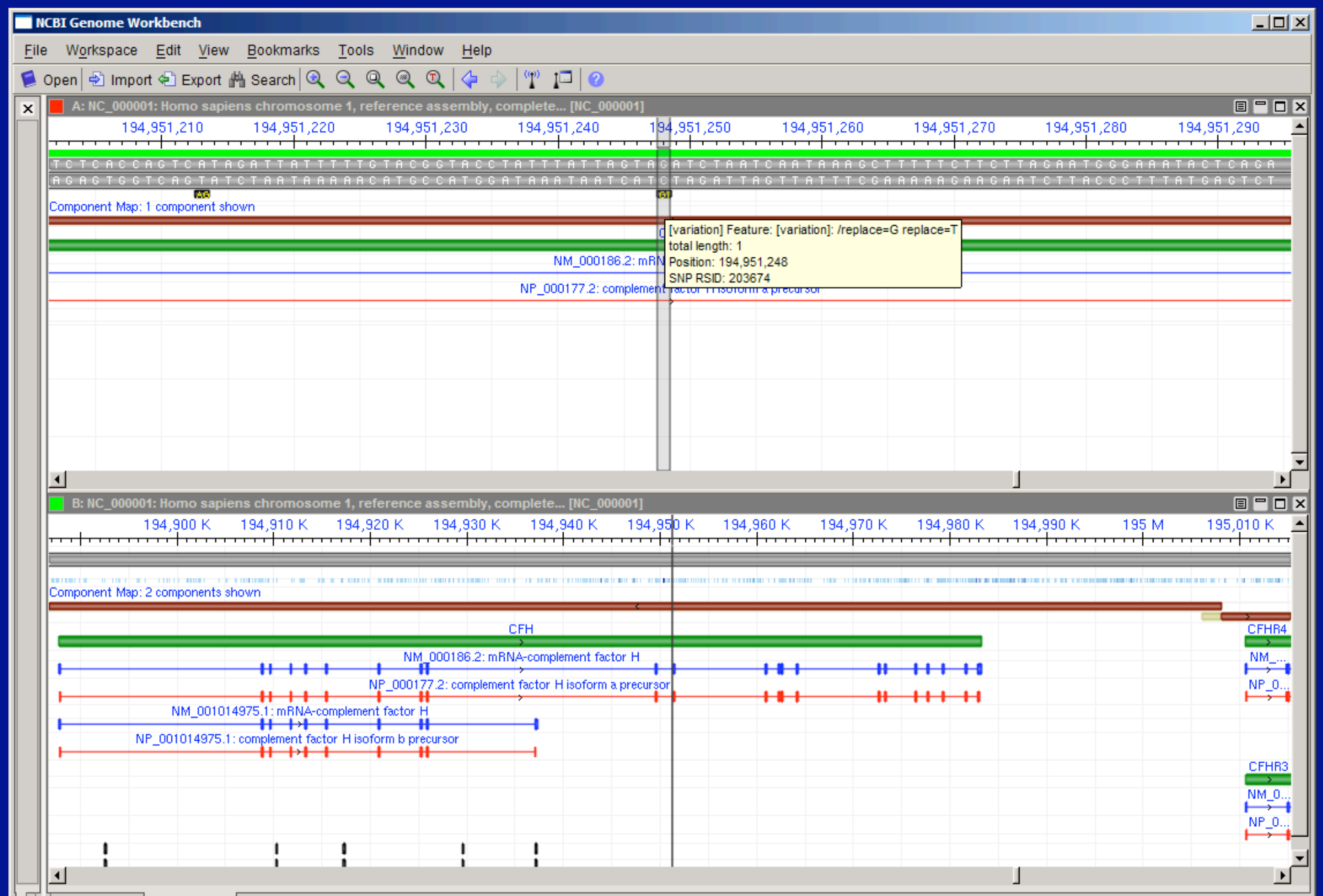

Home Page Splitter $x$ 


\section{NCBI}

The Medical Sequencing Project Finding the Causitive Mutations

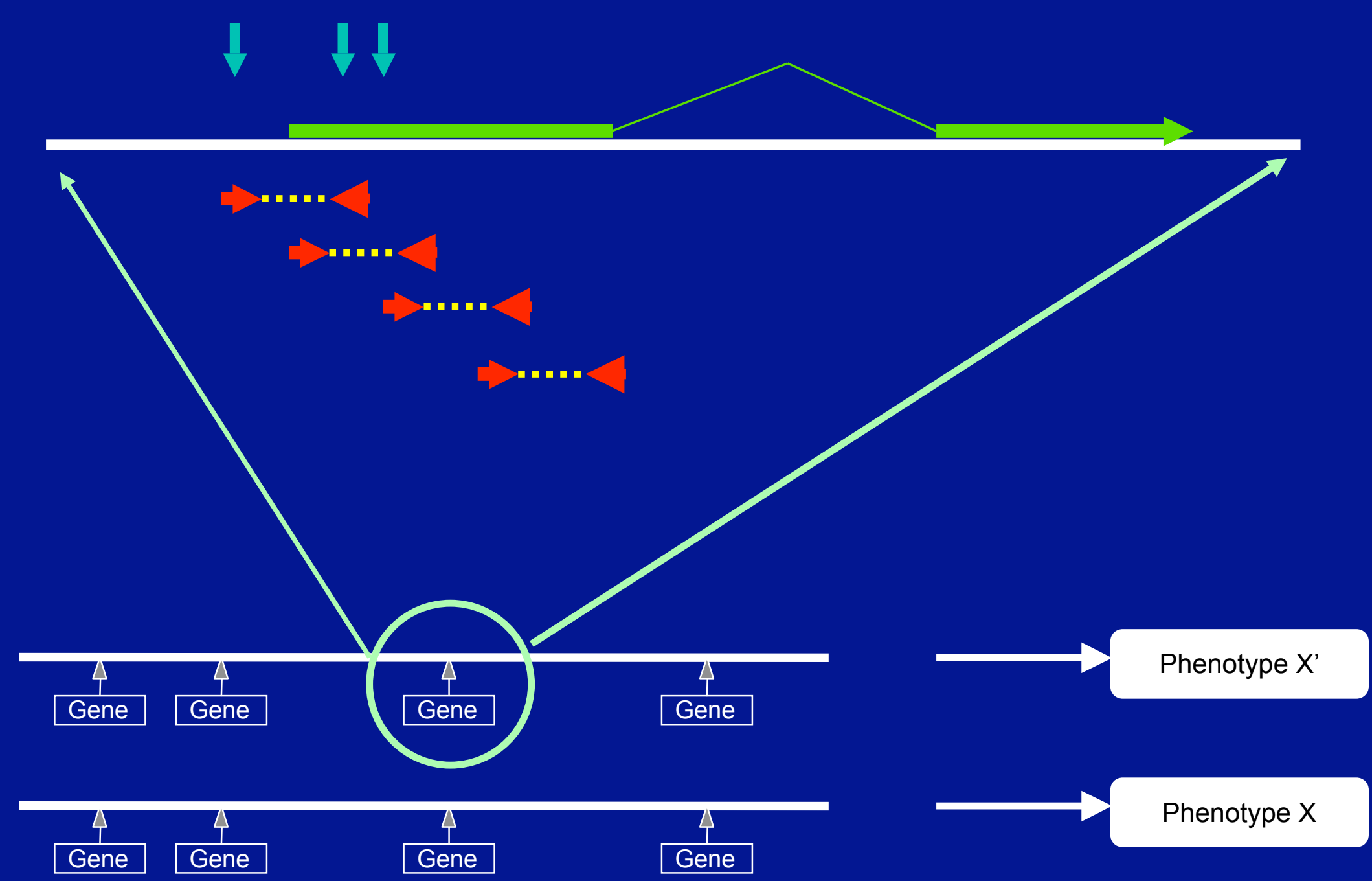



to Clinical Tests

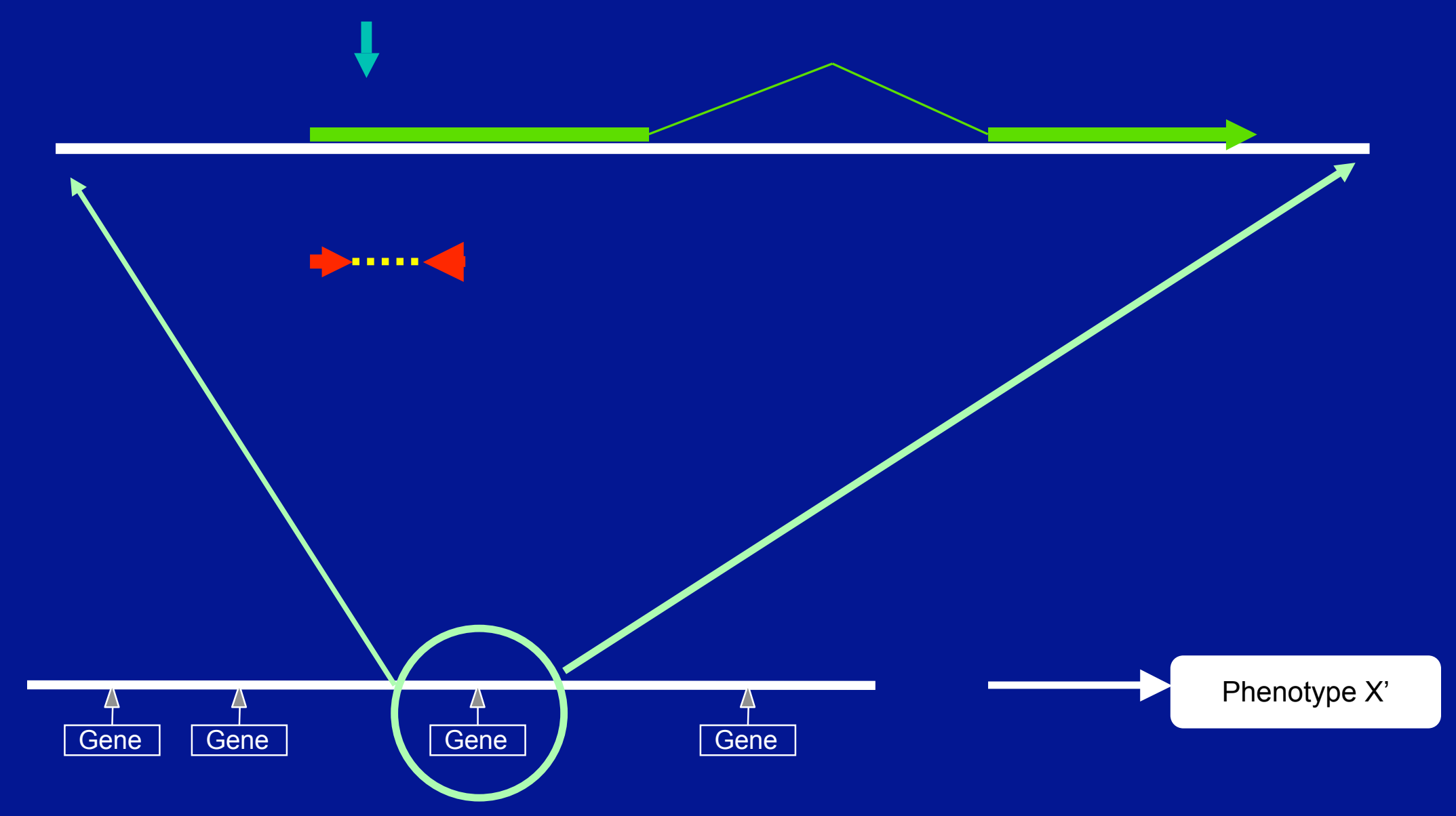




\section{CETT Tests to date}

\begin{tabular}{|c|c|c|c|c|}
\hline Disease Name & $\begin{array}{l}\text { Gene } \\
\text { Symbol }\end{array}$ & $\begin{array}{l}\text { OMIM } \\
\text { (Gene) }\end{array}$ & $\begin{array}{l}\text { Clinical } \\
\text { Laboratory }\end{array}$ & \begin{tabular}{|l} 
Yr. 1\# \\
Samples \\
Expected
\end{tabular} \\
\hline Infantile Neuroaxonal Dystrophy (INAD) & PLA2G6 & 603604 & OHSU & $>100$ \\
\hline Kallmann Syndrome (KS) & \begin{tabular}{|l|} 
KAL1 \\
FGFR1 \\
\end{tabular} & \begin{tabular}{|l|}
308700 \\
136350
\end{tabular} & GeneDx & $>100$ \\
\hline Russell Silver Syndrome (RS) & H19 & 103280 & Emory & $<50$ \\
\hline $\begin{array}{l}\text { Progressive Familial Intrahepatic } \\
\text { Cholestasis (PFIC) }\end{array}$ & \begin{tabular}{|l|} 
ATP8B1 \\
ABCB11 \\
ABCB4 \\
\end{tabular} & \begin{tabular}{|l|}
602397 \\
603201 \\
171060 \\
\end{tabular} & Baylor & $50-100$ \\
\hline $\begin{array}{l}\text { Periventricular Nodular Heterotopia } \\
\text { (PVNH) }\end{array}$ & FLNA & 300017 & Harvard (Wu) & $<50$ \\
\hline Xeroderma Pigmentosum (XP) & \begin{tabular}{|l|}
$X P A$ \\
$E R C C 3$ \\
$X P C$ \\
$E R C C 2$ \\
$D D B 2$ \\
$E R C C 4$ \\
ERCC5 \\
GTF2H5 \\
\end{tabular} & \begin{tabular}{|l|}
278700 \\
133510 \\
278720 \\
278730 \\
278740 \\
278760 \\
122530 \\
608780 \\
\end{tabular} & $\begin{array}{l}\text { UMDNJ/ } \\
\text { Harvard (Wu) }\end{array}$ & $<50$ \\
\hline Cornelia de Lange Syndrome (CdLS) & $\begin{array}{l}\text { NIPBL } \\
\text { SMC1L1 }\end{array}$ & $\begin{array}{l}608667 \\
300590\end{array}$ & U of & \begin{tabular}{|l|}
$60-120$ \\
$30-60$
\end{tabular} \\
\hline $\begin{array}{l}\text { Autosomal Recessive } \\
\text { Agammaglobulinemia (AR-Agamma) }\end{array}$ & \begin{tabular}{|l|} 
IGHM \\
IGLL1 \\
CD79A \\
$B L N K$ \\
\end{tabular} & \begin{tabular}{|l|}
147020 \\
146770 \\
112205 \\
604515 \\
\end{tabular} & Correlagen & 25 \\
\hline Arginase Deficiency (Arg Def) & ARG1 & 608313 & UCLA & $20-100$ \\
\hline $\begin{array}{l}\text { MCT8-specific Thyroid Hormone Cell } \\
\text { Transporter (THCT) Deficiency (MCT8) }\end{array}$ & \begin{tabular}{|l} 
MCT8 \\
(SLC16A \\
2) \\
\end{tabular} & 300095 & U of & $<12$ \\
\hline $\begin{array}{l}\text { Galactose Epimerase Deficiency (GALE } \\
\text { Def) }\end{array}$ & GALE & 606953 & Emory & 10 \\
\hline $\begin{array}{l}\text { Multiple Acyl-CoA Dehydrogenase } \\
\text { Deficiency (Glutaric Acidemia, Type 2) } \\
\text { (MADD) }\end{array}$ & \begin{tabular}{|l|} 
ETFA \\
EFTB \\
EFTDH \\
\end{tabular} & \begin{tabular}{|l|}
608053 \\
130410 \\
231675 \\
\end{tabular} & $\mathrm{U}$ of & $\sim 25-50$ \\
\hline Deletion 9q34 ( 9q34) & EHMT1 & 607001 & Emory & 20 \\
\hline Mucopolysaccharidosis VI (MPSVI) & $A R S B]$ & 253200 & Emory & $\sim 10$ \\
\hline $\begin{array}{l}\text { Neimann-Pick Disease A and B (NPD } \\
\text { A/B) }\end{array}$ & SMPD1 & $\underline{607608}$ & Emory & $\sim 10$ \\
\hline Pseudoxanthoma Elasticum (PXE) & $A B C C 6$ & 603234 & GeneDx & 300 \\
\hline
\end{tabular}

\begin{tabular}{|c|c|c|c|c|}
\hline \multirow[t]{3}{*}{ Focal Glomerulosclerosis (Focal GS) } & NPHS2 & 604766 & \multirow{3}{*}{$\begin{array}{l}\text { Hosp for Sick } \\
\text { Children }\end{array}$} & \multirow[t]{3}{*}{38} \\
\hline & 4 & 604638 & & \\
\hline & TRPC6 & 603652 & & \\
\hline $\begin{array}{l}\text { X-linked Autosomal Recessive } \\
\text { Chondrodysplasia Punctata (XLRCD) }\end{array}$ & ARSE & 300180 & GeneDx & 50 \\
\hline \multirow{3}{*}{$\begin{array}{l}\text { Arrhythmogenic Right Ventricular } \\
\text { Cardiomyopathy (ARVC) }\end{array}$} & DSG2 & 125671 & \multirow{3}{*}{$\begin{array}{l}\text { Hosp for Sick } \\
\text { Children }\end{array}$} & \multirow[t]{3}{*}{$80-380$} \\
\hline & $D S P$ & 125647 & & \\
\hline & PKP2 & 602861 & & \\
\hline $\begin{array}{l}\text { bilateral frontoparietal polymicrogyria } \\
\text { (BFPP) (GPR56 PMG) }\end{array}$ & GPR56 & 604110 & $\mathrm{U}$ of & $15-30$ \\
\hline $\begin{array}{l}\text { Conradi-Hünermann-Happle syndrome, X- } \\
\text { linked dominant chondrodysplasia } \\
\text { punctata (CDPX2) }\end{array}$ & $E B P$ & 302960 & $\mathrm{U}$ of & $5-10$ \\
\hline Cherubism (CRBM) & SH3BP2 & 118400 & $\begin{array}{l}\text { Hosp for Sick } \\
\text { Children }\end{array}$ & $10-16$ \\
\hline Joubert Syndrome (JBTS) & $\begin{array}{l}\text { EN1 } \\
\text { EN2 } \\
\text { FGF8 }\end{array}$ & $\begin{array}{l}131290 \\
131310 \\
600483 \\
\end{array}$ & $\begin{array}{l}\text { Prevention } \\
\text { Genetics }\end{array}$ & $<100$ \\
\hline Total :23 & 46 & & 12 & \\
\hline
\end{tabular}


RefSeqGene - Standardizing Clinical Reporting

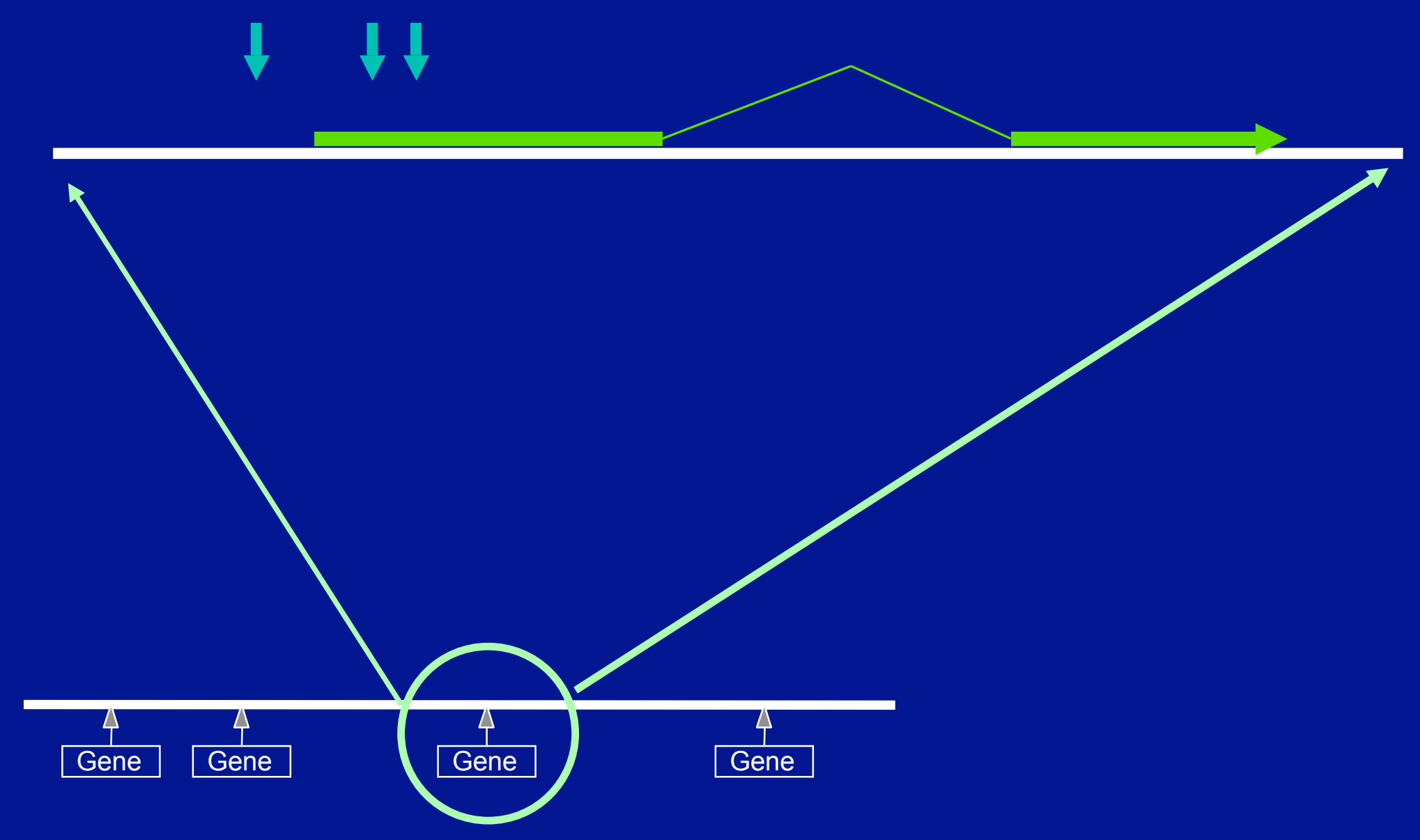




\section{TSC2 RefSeqGene}

\section{WNCBI Genome Workbench}

File Workspace Édit View Iools Window Help

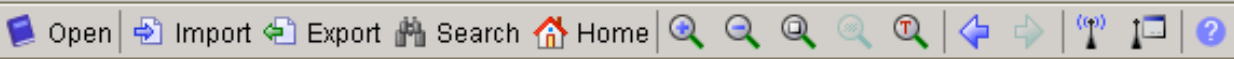

$\times$ A: NG_005895.1: Homo sapiens tuberous sclerosis 2 (TSC2); and partial nth... [TSC2]

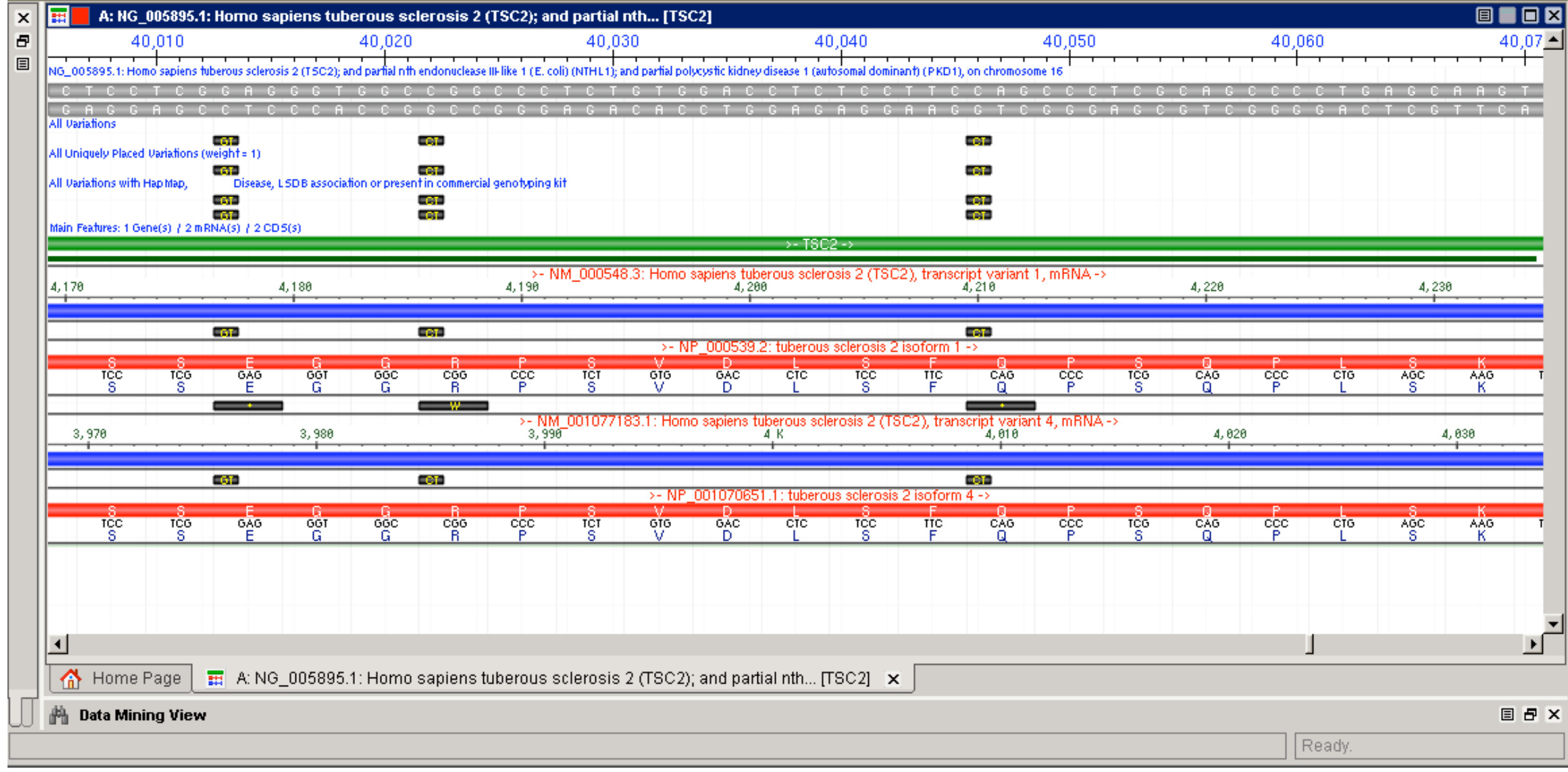




\title{
TSC2 Variation Report
}

\author{
e. TSC2@ chromium.liacs.nl/lovd/ - Windows Internet Explorer

\section{(a)}

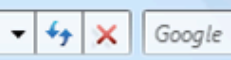 \\ 밀 \\ (3) $\mathrm{e}$ http://chromium.liacs.n//lovd/search.php?select_db=TSC2\&srch=TSC2_00559

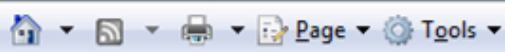

[ Select Gene I ISC2 Home I Submit new variant I Current LOVD status ] [ Register I Edit vour data I List of submitters ]

When using or discussing LOVD please refer to:

Fokkema IFAC, Den Dunnen JT and Taschner PEM (2005). LOVD: easy creation of a locus-specific sequence variation database using an "LSDB-in-a-Box" approach.
Hum Mutat. 2005 Augi-26(2):63-8.

\section{TSC2 @ chromium.liacs.nl/lovd/}

Back

Sequence variant tables - Search sequence variants

Total results: 1

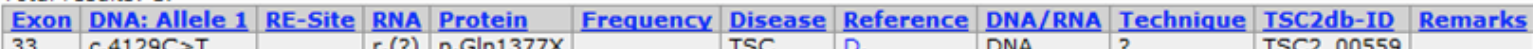

Total results: 1 . Showing result 1

Under construction, from the database of Dr David Kwiatkowski, from the published literature and The Cardiff-Rotterdam Tuberous Sclerosis mutation database. The curation of this database is supported by the TSAlliance and it is kindly hosted by the Leiden University Medical Center. The curators are employees of University College London.

Liability - We have used all reasonable efforts to ensure that the information displayed on these pages and contained in the databases is of high quality. We make no warranty, express or implied, as to its accuracy or that the information is fit for a particular purpose, and will not be held responsible for any consequences arising out of any inaccuracies or omissions. Individuals, organisations and companies which use this database do so on the understanding that no liability whatsoever either direct or indirect shall rest upon the TS Alliance, University College London, Leiden University Medical Centre or any of their employees or agents for the effects of any product, process or method that may be produced or adopted by any part, notwithstanding that the formulation of such product, process or method may be based upon information here provided.

Legend: [ full legend ]

Sequence variations are described basically as recommended by the Ad-Hoc Committe for Mutation Nomenclature (AHCMN), with the recently suggested additions (den Dunnen JT and Antonarakis SE [2000], Hum.Mut. 15:7-12); for a summary see Nomenclature. coding DNA Reference Sequence, with the first base of the Met-codon counted as position 1 .

Exon: exon numbering. DNA allele 1: variation at DNA-level (allele 1). If present, "Full Details" will show you the the full-length entry. "Show all records" will show you similar entries. RE-site: variation creates (+) or destroys ( $(-)$ restriction enzyme recognition sequence. RNA: variation at RNA-level (allele 1), (?) unknown but probably modified by the curator (if so, see Remarks column). Reference: publication describing the variation, "Submitted:" indicating that the mutation was submitted directly to this database. DNA/RNA: variation detected in RNA or DNA. Technique: technique used to detect the variation. For a full list of techniques, see the full legend. TSC2dbID: ISC2 database IDentifier; if present, links to OMIM ID's are provided. Remarks: Listings in bold italics indicate compound heterozygous patients with both mutated alleles known. Consequently, the case is mentioned twice in this table.

[ Select Gene I ISC2 Home I Submit new variant I Current LOVD status ] [ Register I Edit your data I List of submitters ] 
TSC2 Variation Report - Windows Internet Explorer

$(9)$ - 3 http://www.ncbi.nlm.nih.gov/sites/variation?gene=7249

- $\star_{4} \times$ Google

- 2. Whito

Ceference SNP(refSNP) Cluster Report: rs9209 - Windows Internet Explorer

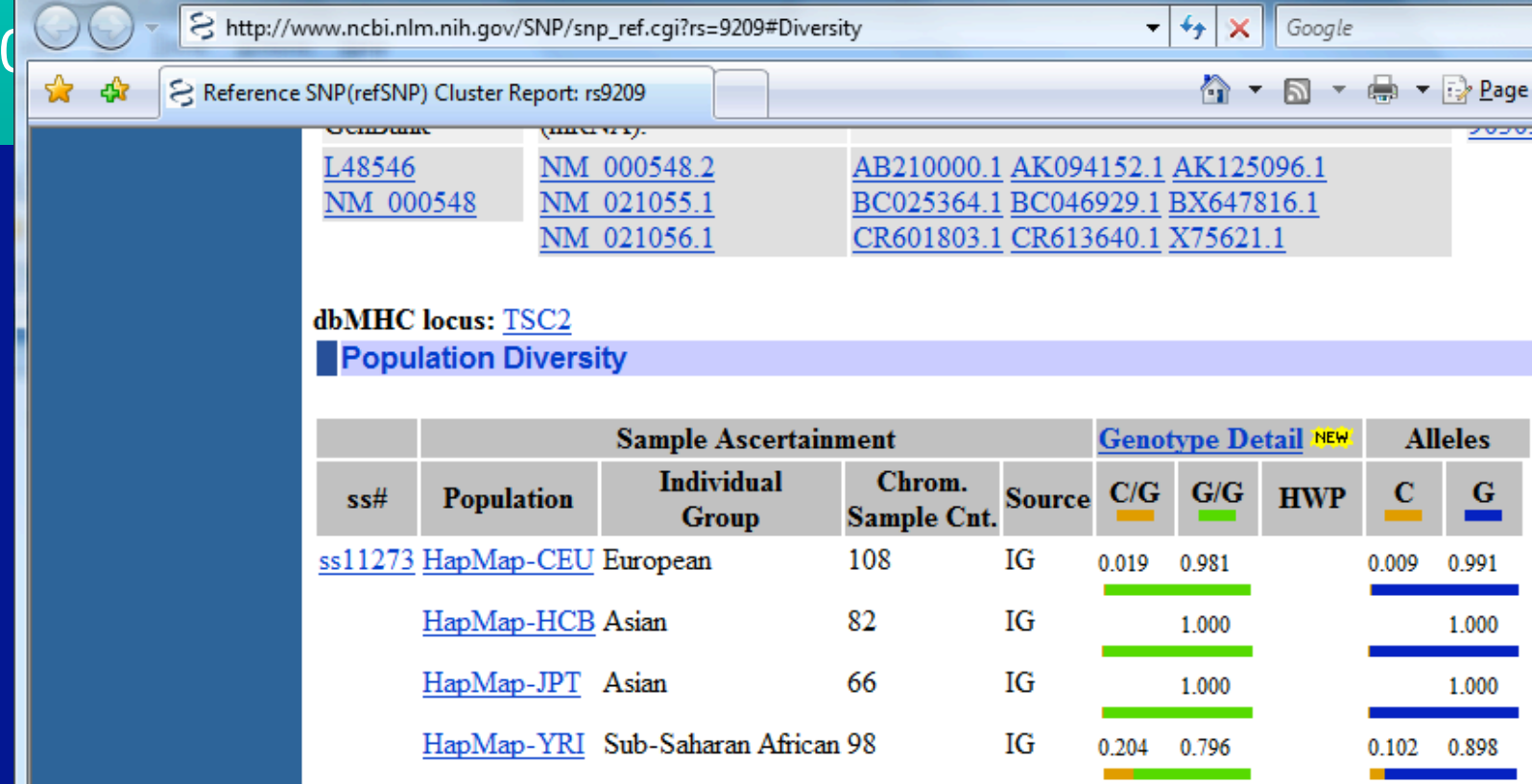

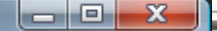

- Foge Pagels -

Average Individual Founders Individual Genotype

Summary Het.+/- std err: Count Count Overlap Conflict

$\begin{array}{lllll}-1.000+1-0 & 270 & 210 & 0 & 0\end{array}$

Validation Summary:

\begin{tabular}{|l|l|l|l|l|} 
& Marker displays & PCR results confirmed Homozygotes detected
\end{tabular}

Internet | Protected Mode: On $\rho-$
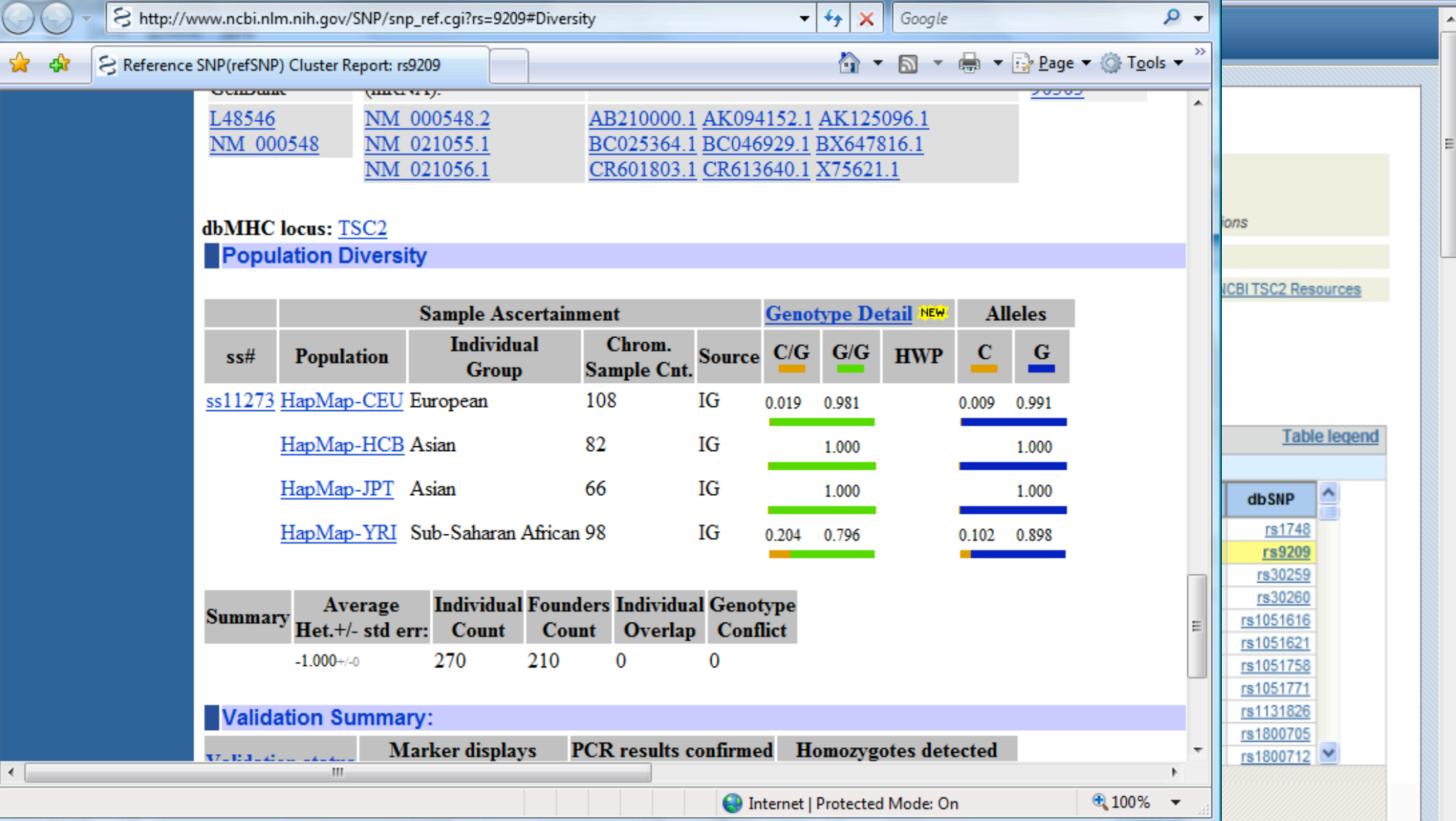

Submitted Observations of this Variation

Showing 2 submissions

Method

Computation $\mathrm{NCl}$ ct (CGAP)

[more] 53388

Link

more] TSC2 00891 
E A New Gene That Shapes Mouse Pigmentation Patterning - Microsoft Internet Explorer _ - $[$ 口 $\mid \underline{x}$

File Édit Yiew Fạvorites Iools Help

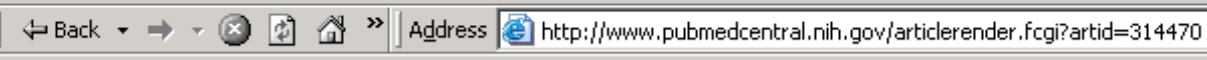

N $\begin{aligned} & \text { PubMed } \\ & \text { Central }\end{aligned}$

Central

Search

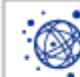

\section{PLOS BIOLOGY}

S BIOLOGY Submit Manuscript Issue Alert

- Utilities

\section{View This Article Submit Manuscript Issue Alert}

(cis: issues are available online now.

PubMed

Central

Copyriaht: (- 2004 Public Library of Science. This is an open-access article distributed under the terms of the Creative Commons Attribution License, which permits unrestricted

- Full Text

- FiguresiTables

use distribution, and reproductio

Droduction in any medium, provided the original work is properly

-PDF

cited

Contents

- Archive

Dol: 10.1371 journal pbio.0020016

\section{A New Gene That Shapes Mouse Pigmentation}

\section{Patterning}

PubMed 믈 Published January 20, 2004

of See accompanying research article "Dorsoventral Patterning of the Mouse Coat by Tbx15"

Related articles 号.

Show

- Top

Scientists have long known that variation in animal color patterns carry far more than cosmetic significance. Darwin first connected pigmentation with adaptive advantage, noting that male finches with bright red plumage enjoyed greater reproductive success than their drab competitors. Explaining why coloration confers such advantages, however, has proved somewhat easier than showing how it arises. Biologists studying how neighboring regions of the vertebrate body plan develop differences in appearance and form have identified a small number signaling pathways common to all animals. How and whether these pathways als control the developmental expression and variation of surface attributes like hair

o. color, hair density, and hair length are unclear. By studying an old mouse mutant called droopy ear, Gregory Barsh and colleagues show that a member of the well-known family of T-box genes is required for a key pigmentation pattem in mice.

-... 2 pmc.ppt

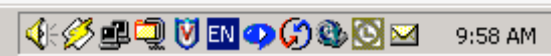

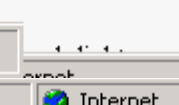

I next | latest | archive

\section{, January 2004}

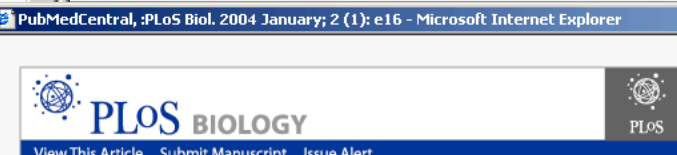

View This Arricle Submit Manuscript Issue Alert
Volume 2 Number 1, January 2004

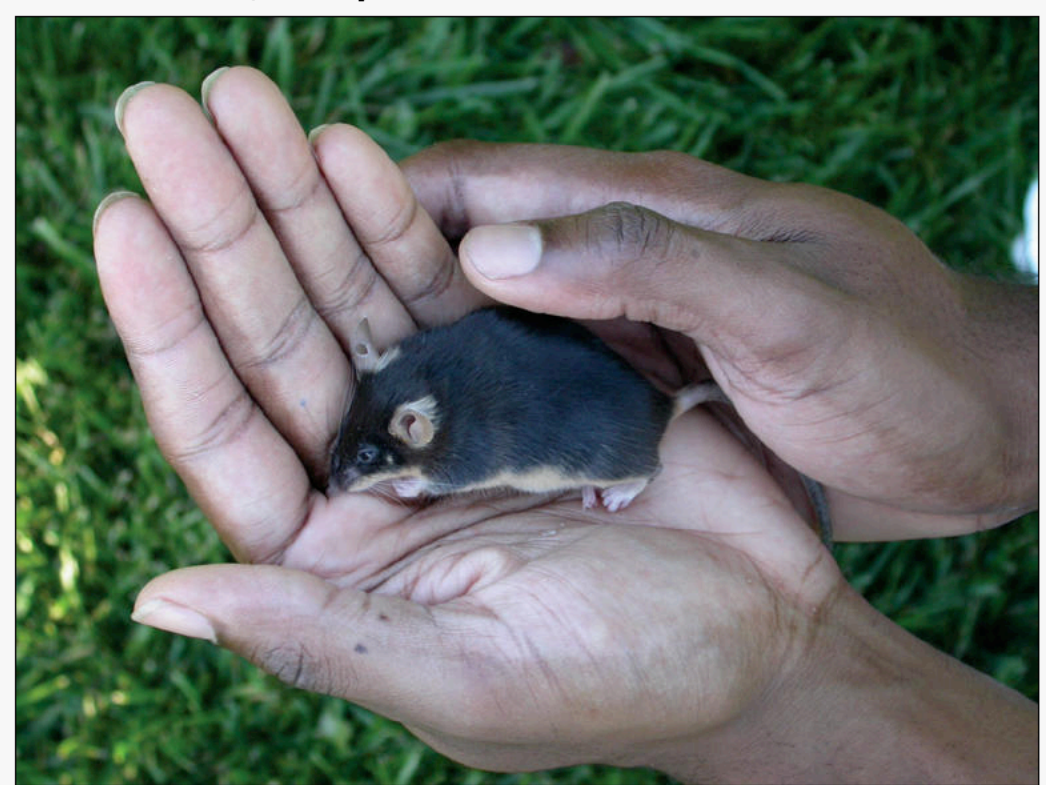

Dorsoventral pigment boundaries in mouse and human 
NCBI BookShelf

110101

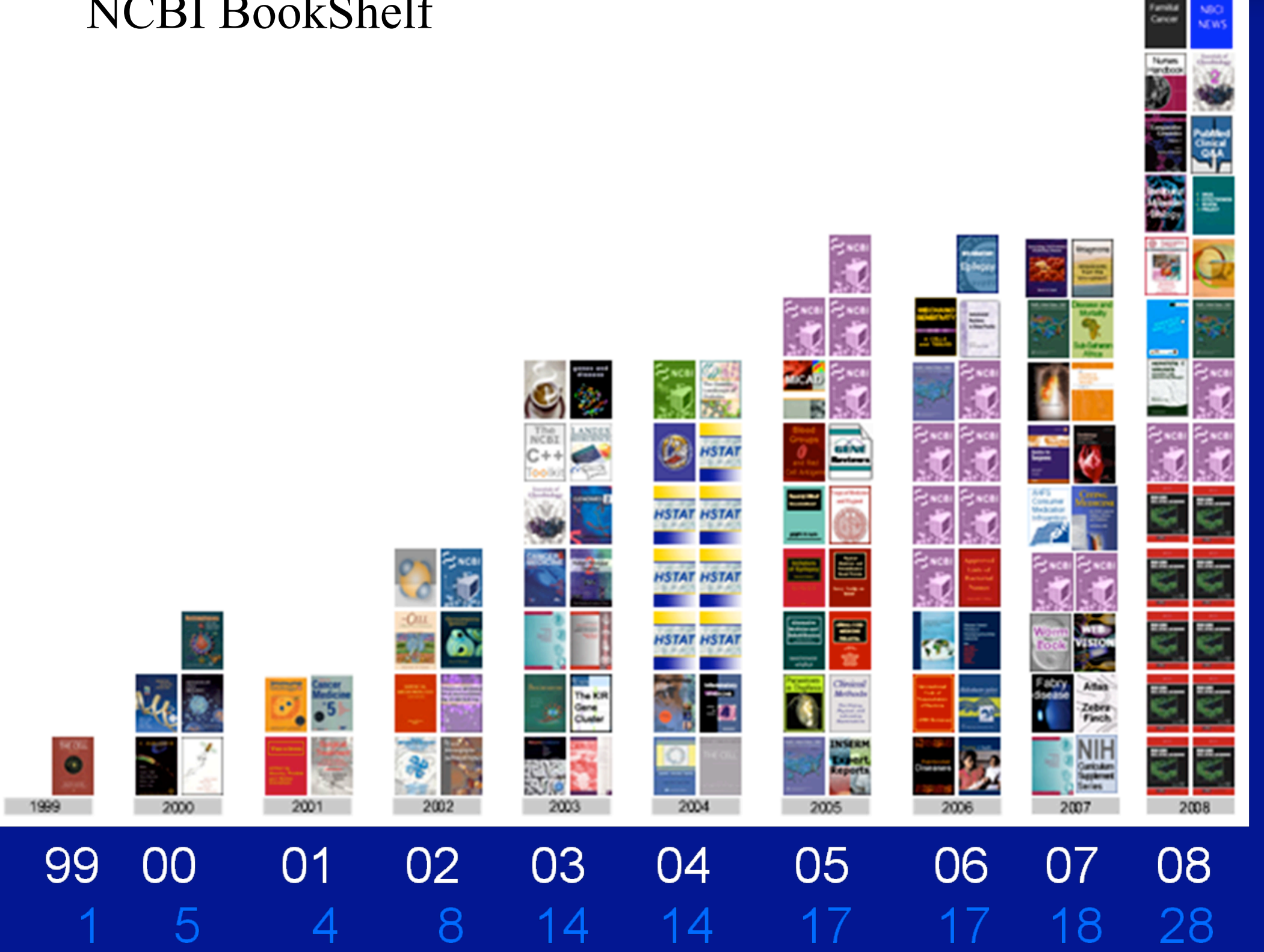




\section{NCBI}

\section{BookShelf Dynamic Content}

- Obesity in the US demo

- Marfan's Syndrome demo

Excel table in PMC demo 


\section{NCBI}

\section{Curation by Publication}

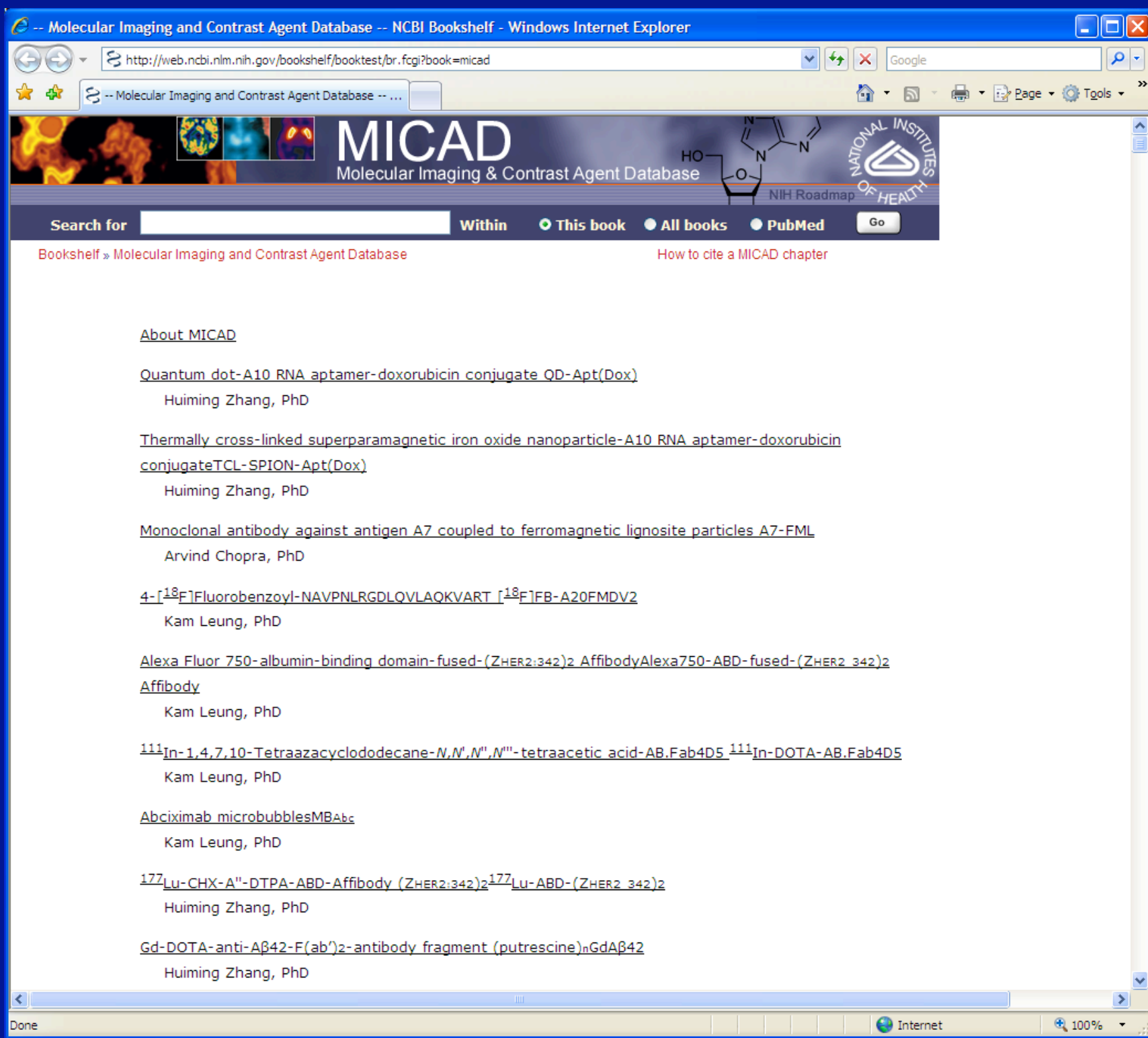


(3) - ¿ http://web.ncbi,nlm,nih.gov/bookshelf/booktest/br.ffgi?book=micad\&part=Tm-DOTA-G|

$\checkmark 4_{4} \times$ Google

is the 80 . Home-Bookshelf Presentations 2 Tm-1,4,7,10-Tetraazacyc... $x$

औิ В

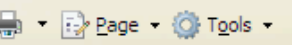

Tm-1,4,7,10-Tetraazacyclododecane- $N, N^{\prime}, N^{\prime \prime}, N^{\prime \prime}$ acetamidoacetic acid

Tm-DOTA-Gly

\section{Mark Pagel, Ph.D.}

University of Arizona, Email: mpagel@u.arizona.edu

\section{Kam Leung, $\mathrm{PhD}$}

National Center for Biotechnology Information, NLM, NIH, Bethesda, MD, Email: micad@ncbi.nlm.nih.gov

Created February 19, 2009.

Last update March 10, 2009

Chemical name: $\mathrm{Tm}-1,4,7,10-$

Tetraazacyclododecane$\mathrm{N}, \mathrm{N}^{\prime}, \mathrm{N}^{\prime \prime}, \mathrm{N}^{\prime \prime \prime}$ - acetamidoacetic acid Abbreviated Tm-DOTA-Gly, Tm-DOTAM-Gly name:

Synonym:

Agent category: Compound

Target: Non-targeted

Target category: Non-targeted

Method of PARACEST magnetic resonance

detection: imaging (MRI)

Source of $\mathrm{Tm}^{3+}$

signal\contrast:

Activation: No

Studies:

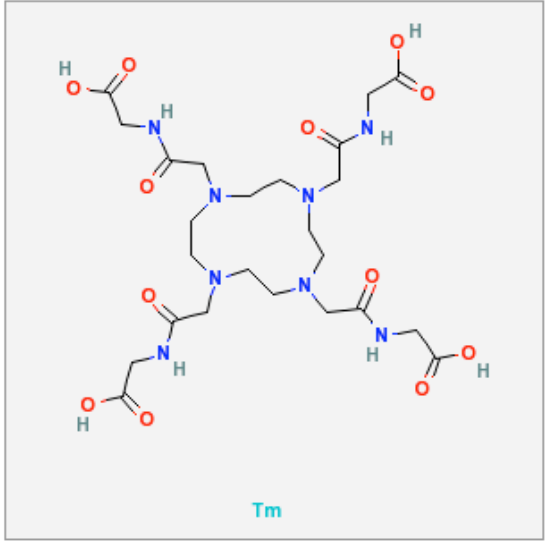

Click on the above structure for additional information in PubChem.
Browse All Entries

Homepage

ESU MICAD Summary

Background

Synthesis

In Vitro Studies: Testing in Cells and Tissues

Animal Studies

Human Studies

NIH Support

References 
Chemical name: Tm-1,4,7,10-

Tetraazacyclododecane$\mathrm{N}, \mathrm{N}^{\prime}, \mathrm{N}^{\prime \prime}, \mathrm{N}^{\mathrm{m}}$ - acetamidoacetic acid

Abbreviated Tm-DOTA-Gly, Tm-DOTAM-Gly name:

Synonym:

Agent category: Compound

Target: Non-targeted

Target category: Non-targeted

Method of PARACEST magnetic resonance

detection: imaging (MRI)

Source of $\mathrm{Tm}^{3+}$

signal\contrast:

Activation: No

Studies:

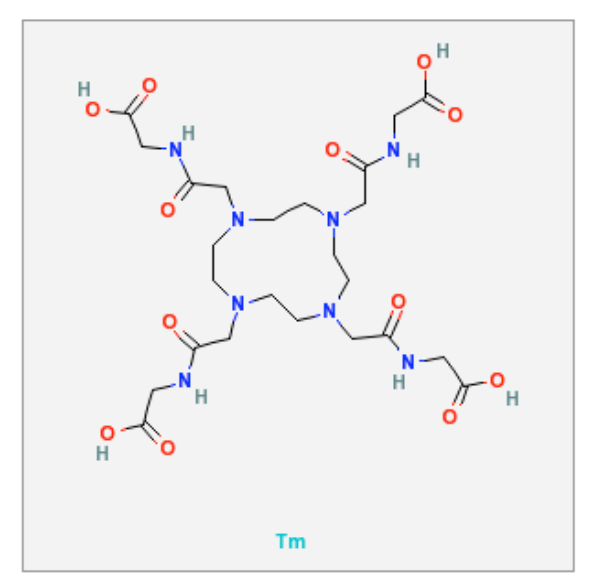

Animal Studies

Human Studies

NIH Support

References

\section{Background}

[PubMed]

Chemical Exchange Saturation Transfer (CEST) is a novel magnetic resonance imaging (MRI) contrast mechanism (1) that is an attractive alternative to $T_{1}$ and $T_{2}$ contrast mechanisms, particularly at high magnetic fields (2). CEST agents possess a hydrogen proton with a moderate to slow exchange rate with water. Selective saturation of the MR frequency of this proton, followed by exchange with solvent water, reduces the MR signal of the water. PARACEST (PARAmagnetic CEST) agents include a paramagnetic lanthanide ion that shifts the MR frequencies of the exchangeable proton to unique values to facilitate selective detection $(\underline{3}, \underline{4})$. Endogenous MR contrast may be continually monitored in the presence of PARACEST agents by neglecting to saturate the MR frequency of the exchangeable proton (and assuming that the $T_{1}$ relaxation of the PARACEST agent is negligible).

The selective saturation is typically applied for two or more seconds to generate a steady-state of saturation $(\underline{5})$, which greatly lengthens the time required for in vivo detection of PARACEST MRI contrast agents. However, computer simulations and studies with chemical solutions have shown that more rapid MRI acquisition schemes can be prepended with a selective saturation pulse to accelerate the detection of PARACEST MRI contrast agents $(\underline{6})$. The choice of the MRI acquisition scheme is dependent on the $\mathrm{T}_{1}$ Molecular Imaging and Contrast Agent Data 


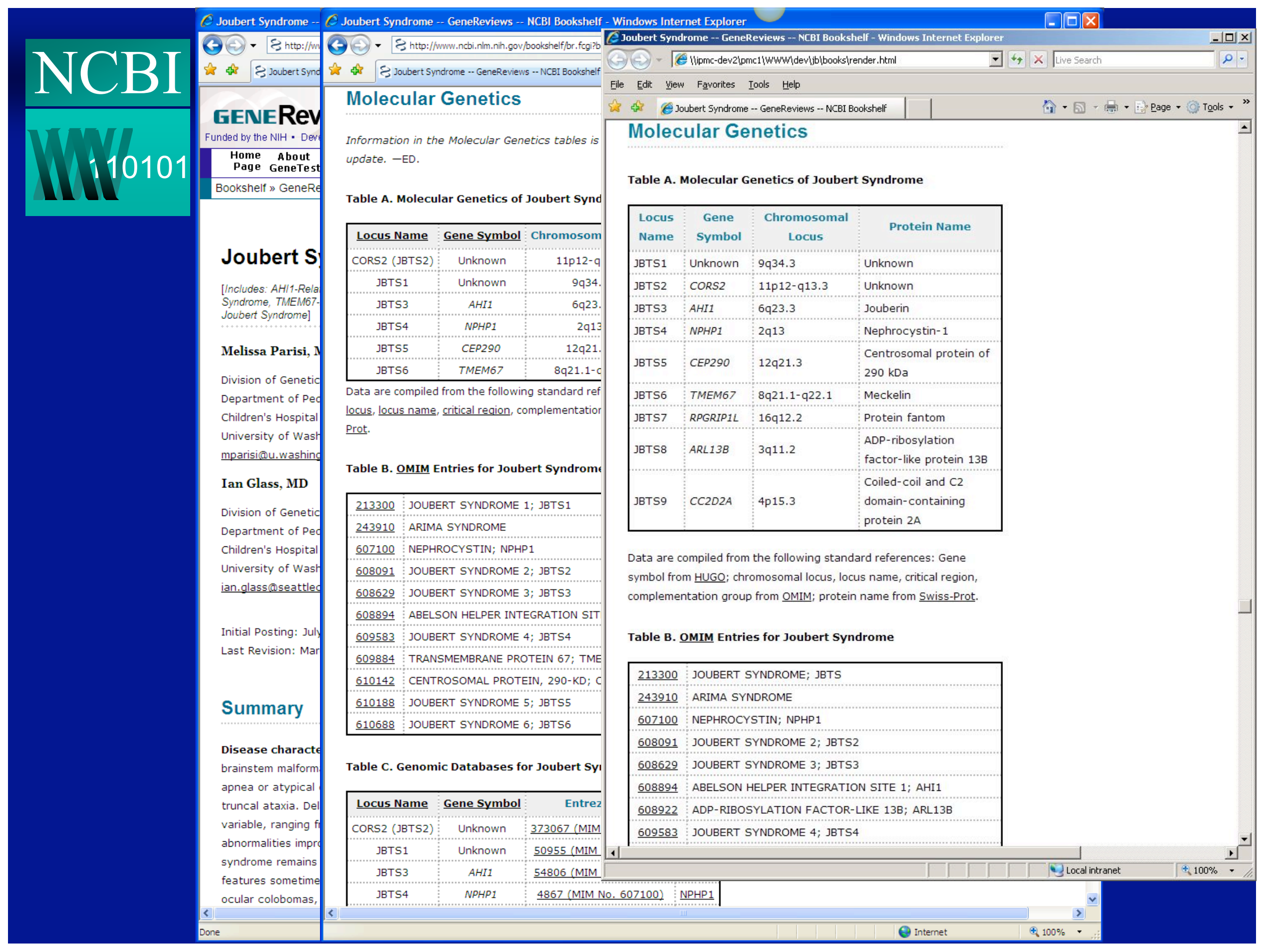




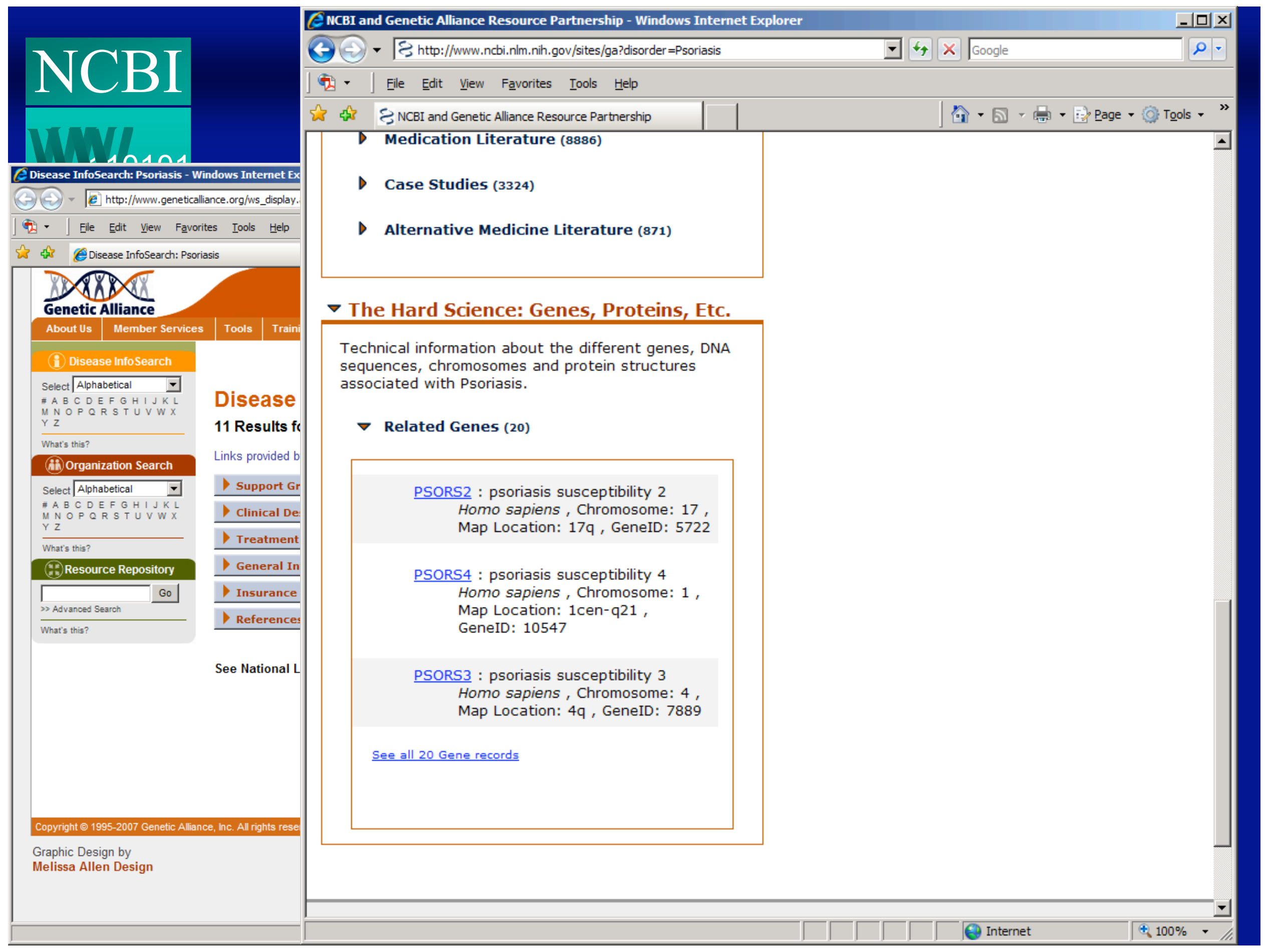




\section{NCBI}

\section{Closing the Loop}

\section{IIti10101}

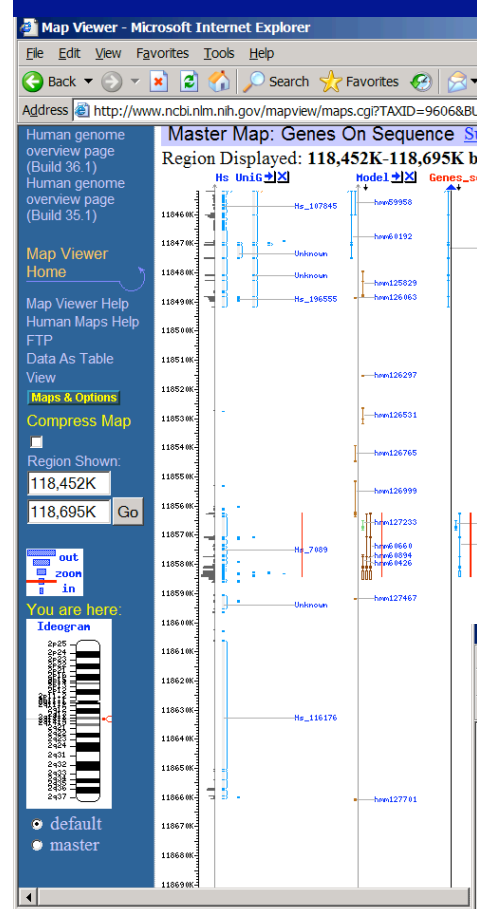

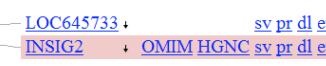

Ii Entrez GEO - Cene Exprescion Ommibus - Microsoft Int Ele Edit Vew Femprossion Omnibs-

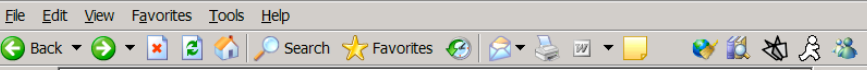

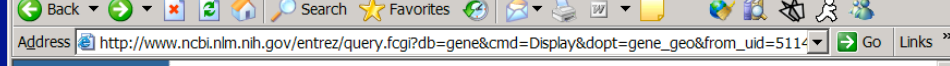

\& NCBI Enter GES profiles NO

My NCBI a

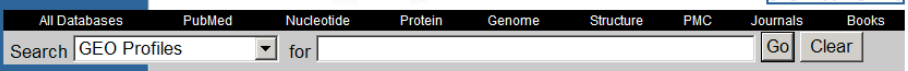

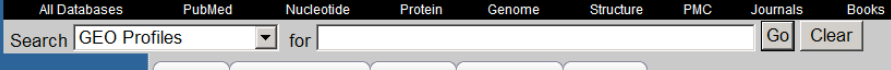

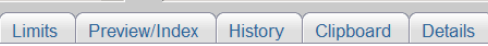

Display Summary $\quad \nabla$ Show $20 \quad$ Subgroup effect $v$ Send to $>$

All: $221 ;$

S Entrez PubMed - Microsoft Internet Explore

The oce ste

Items 1 - 20 of 221

File Edit View Fagorites Iools Help

ᄃ 1: GDS501 record | GPL371 27849 [Homo

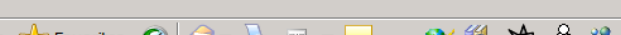
Reporter: AL080184

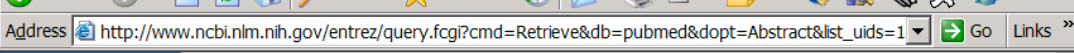

Experiment: Inflammatory cytokine effect on

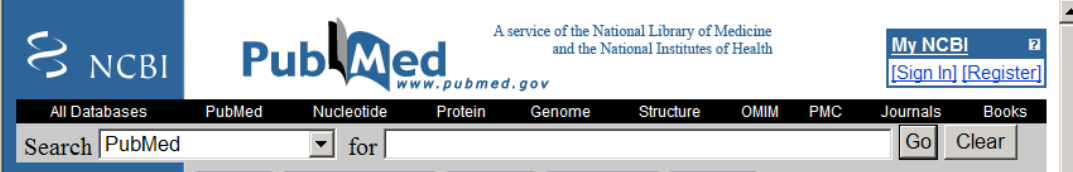

2: GDS1048 record | GPL564 1001267 sapies
Annotation: INSIG2: insulin induced gene 2 (

INSIG2: insul
MGC26273)
AL 080184

Experiment: Lymphoblastoid cell lines from

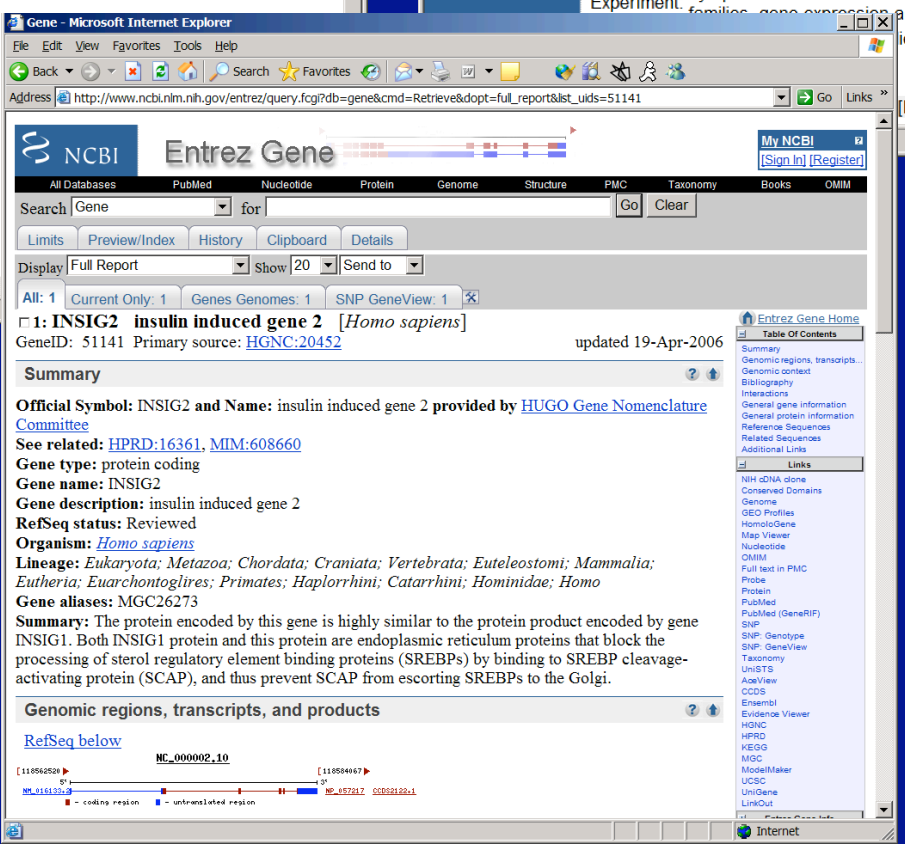

About Entrez
NCBI Toolbar

NCBI Toolbar

Text Version

Overview
Help | FAQ

Help |FAQ
Tutorials

Tutorials
NewiNoteworthy
E-Utilities

Limits Preview/Index 4 History Clipboard Details

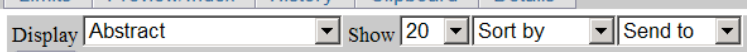

All: 1 Review: 0 ;

ᄃ1: Science. 2006 Apr 14;312(5771):279-83 Science ans

A common genetic variant is associated with adult and childhood obesity.

Herbert A, Gerry NP, McQueen MB, Heid IM, Pfeufer A, Illig T, Wichmann HE, Meitinger T, Hunter D, Hu FB, Colditz G, Hinney A, Hebebrand J, Koberwitz K, Zhu X, Cooper R, Ardlie K, Lyon H, Hirschhorn JN, Laird NM, Lenburg ME, Lange C, Christman MF.

Department of Genetics and Genomics, Boston University Medical School, E613, 715 Albany Street, Boston, MA 02118, USA. aherbert@bu.edu

Obesity is a heritable trait and a risk factor for many common diseases such as type 2 diabetes, heart disease, and hypertension. We used a dense wholegenome scan of DNA samples from the Framingham Heart Study participants to identify a common genetic variant near the INSIG2 gene associated with obesity. We have replicated the finding in four separate samples composed of individuals of Western European ancestry, African Americans, and children. The obesity-predisposing genotype is present in $10 \%$ of individuals. Our study suggests that common genetic polymorphisms are important determinants of obesity. 